\title{
Use of Circulating Tumor DNA for the Clinical Management of Metastatic Castration-Resistant Prostate Cancer: A Multicenter, Real-World Study
}

Baijun Dong, PhD; Liancheng Fan, MD; Bin Yang, MD, PhD²; Wei Chen, MD³; Yonghong Li, MD; Kaijie Wu, MD, PhD; Fengbo Zhang, MD; Haiying Dong, MD, PhD7; Huihua Cheng, MBBS ${ }^{8}$; Jiahua Pan, MD'; Yinjie Zhu, MD';

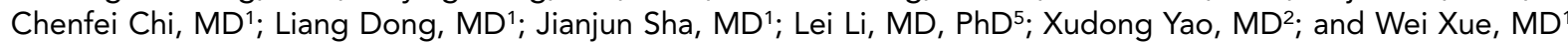

\section{ABSTRACT}

Background: This study aimed to describe the aberrations of DNA damage repair genes and other important driving genes in Chinese patients with metastatic castration-resistant prostate cancer (mCRPC) using circulating tumor (ctDNA) sequencing and to evaluate the associations between the clinical outcomes of multiple therapies and key genomic alterations in $\mathrm{mCRPC}$, especially DNA damage repair genes. Patients and Methods: A total of 292 Chinese patients with $\mathrm{mCRPC}$ enrolled from 8 centers. Multigene targeted sequencing was performed on 306 ctDNA samples and 23 matched tumor biopsies. The frequency of genomic alterations were compared with the Stand Up to Cancer-Prostate Cancer Foundation (SU2C-PCF) cohort. The Kaplan-Meier method was used to evaluate progression-free survival (PFS) following standard systemic treatments for mCRPC. Cox regression analyses were performed to determine prognostic factors associated with PFS resulting from treatments for mCRPC. Results: In total, 33 of $36(91.7 \%)$ mutations were found consistently between ctDNA and paired biopsy samples. The most common recurrent genomic alterations were found in AR (34.6\%), TP53 (19.5\%), CDK12 (15.4\%), BRCA2 (13\%), and RB1 (5.8\%). The frequency of CDK12 alterations $(15.4 \%)$ in our cohort was significantly higher than that in Western populations (5\%-7\%). AR amplification and TP53 and/or RB1 alterations were associated with resistance to abiraterone or docetaxel. Patients with a CDK12 defect showed rapid disease progression after abiraterone treatment. However, the clinical outcome after docetaxel treatment was similar between patients with and without CDK12 defects. In multivariate Cox regression analysis, a CDK12 defect was significantly associated with inferior PFS after abiraterone treatment. Patients with a BRCA2 defect showed marked response to both PARP inhibitors and platinum-based chemotherapy. Conclusions: Our study explored the genomic landscape of Chinese patients with $\mathrm{mCRPC}$ at different treatment stages using minimally invasive methods and evaluated the clinical implications of the driver genomic alterations on patients' response to the most widely used therapies for mCRPC. We observed a significantly higher alteration frequency of CDK12 in our cohort compared with the SU2C-PCF cohort.

J Natl Compr Canc Netw 2021;19(8):905-914 doi: $10.6004 /$ jnccn.2020.7663

See JNCCN.org for supplemental online content.

\section{Background}

Metastatic castration-resistant prostate cancer (mCRPC) remains incurable, despite incremental improvements provided by multiple agents, including new-generation hormone therapies, taxane chemotherapy, and PARP inhibitors. ${ }^{1-6}$ Genomic profiling of metastatic biopsies of mCRPC has revealed multiple molecular alterations, including alterations of DNA damage repair (DDR) genes, the androgen receptor (AR) gene, and the tumor suppressor genes TP53 and $R B 1 .{ }^{7}$ Previous studies preliminarily showed the prognostic relevance of these genes with multiple treatments in patients with mCRPC. ${ }^{8-11}$ Despite this important advance in patient management, the understanding of mCRPC genetic epidemiology is mainly based on data from Western populations, with limited data available from other ethnicities. The large differences between Chinese and Western patients, especially in terms of their genomics, should not be ignored..$^{12,13}$ Whether these genetic alterations, especially those involving DDR genes, can predict the clinical outcomes of Chinese patients with mCRPC following specific treatments remains to be fully elucidated.

Routine sampling of bone and other metastatic tissues in patients with mCRPC is impractical. Therefore, the use of circulating tumor DNA (ctDNA) as a sample source for genomic analysis has gained momentum. ctDNA analysis is compatible with multiple sampling at different time points and can accurately capture tumor heterogeneity in a minimally invasive manner. Previous studies have

${ }^{1}$ Department of Urology, Renji Hospital, School of Medicine, Shanghai Jiao Tong University, Shanghai; ${ }^{2}$ Department of Urology, Shanghai Tenth People's Hospital, Tongji University School of Medicine, Shanghai; ${ }^{3}$ Department of Urology, The First Affiliated Hospital of Wenzhou Medical University, Wenzhou ${ }^{4}$ Department of Urology, Sun Yat-Sen University Cancer Center, Guangzhou; ${ }^{5}$ Department of Urology, The First Affiliated Hospital of Xi'an Jiao Tong University, Xi'an; ${ }^{6}$ Department of Urology, Beijing Friendship Hospital, Capital Medical University, Beijing; ${ }^{7}$ Department of Urology, Zhejiang Provincial People's Hospital, Hangzhou; ${ }^{8} 900$ th Hospital of Joint Logistic Support Force, Fuzhou.

*These authors contributed equally as senior authors. 
shown substantial interpatient and intrapatient genomic heterogeneity in mCRPC. ${ }^{7,14}$ In addition, the genomic profile of mCRPC is dynamic and evolves with systemic treatments, explaining its diverse molecular signatures at different treatment stages. ${ }^{15,16}$

Consequently, we hypothesized that ctDNA analysis could detect genomic alterations of mCRPC at different treatment stages and that these results might support its clinical utility in the standard-of-care setting. In the present study, we enrolled 292 patients with mCRPC from 8 centers in a real-world study and applied deep targeted ctDNA sequencing for an exploratory analysis of clinical implications.

\section{Patients and Methods}

\section{Patients}

This study was approved by the Committee for Ethics of Renji Hospital (approval number: [2016]115K), and informed consent was obtained from each of the $292 \mathrm{en-}$ rolled patients with mCRPC treated at Renji Hospital of Shanghai Jiaotong University School of Medicine, Shanghai Tenth People's Hospital, The First Affiliated Hospital of Wenzhou Medical University, Sun Yat-sen University Cancer Center, The First Affiliated Hospital of Xi'an Jiaotong University, Beijing Friendship Hospital, Fuzhou Central Hospital of Nanjing Military Command, and Zhejiang Provincial People's Hospital between December 2017 and December 2019. The study included 306 ctDNA samples and 23 matched biopsied tumor tissue samples ( 20 from the prostate, 2 from the liver, 1 from bone) collected at the same time. Among the 292 patients with mCRPC, 14 had 2 serial monitoring ctDNA samples and 23 had concurrent biopsied tumor tissue samples and ctDNA samples (supplemental eTable 1, available with this article at JNCCN.org). Clinical data were collected by the lead investigators at each site. Progression-free survival (PFS) was defined as the time from the date of treatment initiation to confirmed prostate-specific antigen (PSA) increase, clinical or radiographic progression, or death.

\section{Target Capture and Sequencing}

The targeted next-generation sequencing test of all samples was performed at GloriousMed Clinical Laboratory Co., Ltd. For blood samples, plasma was isolated by centrifugation at $1,600 \times g$ for 10 minutes and then at $16,000 \times g$ for 10 minutes. Cell-free DNA was extracted from 3 to $5 \mathrm{~mL}$ of plasma using a QIAamp Circulating Nucleic Acid Kit (Qiagen) according to the manufacturer's instructions. Tumor formalin-fixed paraffin-embedded (FFPE) DNA was extracted from 5 to 10 sections $(5 \mathrm{~mm}$ thick) using a QIAamp DNA FFPE Tissue Kit (Qiagen), and genomic DNA was extracted from white blood cells using a Blood Genomic DNA Mini Kit (Cwbiotech). Two separate custom-designed DNA enrichment panels were used: The NimbleGen SeqCap EZ choice probe pool (Roche) was used to capture the coding regions of 620 or 642 genes, and the xGen Lockdown Probe Pool (Integrated DNA Technologies, Inc.) was used to capture the coding regions of 50 or 66 genes. To confirm concordance between the different gene panels used in the present study, 12 ctDNA samples were duplicated and sequenced from the 66-gene panel and the 620/642-gene panel. For analysis, we focused on the common 50 genes shown in supplemental eTable 2. For each sample, 20 to $100 \mathrm{ng}$ of cell-free DNA, 200 to 500 ng of FFPE DNA, or 500 ng of genomic DNA were then used for library preparation and quantification, guided by KAPA Hyper Prep protocols (Kapa Biosystems, Inc.). Pools of 4 to 6 libraries were used to hybridize to the capture panel for 16 hours at $47^{\circ} \mathrm{C}$ for NimbleGen panel and at $65^{\circ} \mathrm{C}$ for $\mathrm{xGen}$ panel. Washing, recovery, and amplification were performed sequentially according the standard procedures of the NimbleGen SeqCap EZ and $x G e n$ panels. The libraries were then purified using AMPure XP (Beckman) and quantified using a Qubit dsDNA HS Assay Kit (ThermoFisher). The final libraries were sequenced on the Illumina Nextseq500 (75 bp pairedend reads) or the Novoseq6000 (150 bp paired-end reads) instruments (Illumina).

\section{Quality Control and Variant Calling}

Sequencing adapters were trimmed from the raw data using Trimmomatic. ${ }^{17}$ The reads after adapter trimming were then aligned with the human reference genome using Burrows-Wheeler Alignment tool. ${ }^{18}$ Duplicated reads were removed using Picard (http://broadinstitute. github.io/picard/). Mapped reads were also realigned to the genome using the Genome Analysis Toolkit (GATK). ${ }^{19}$ Somatic and germline mutations were called using Mutect2 and the GATK Haplotype Caller ${ }^{19}$ with a paired workflow, respectively. Variants were then annotated using ANNOVAR ${ }^{20}$ and an in-house developed code. An in-house script was used to verify the human identity concordance of paired samples. Somatic copy number alterations were also detected using the GATK. ${ }^{19}$

\section{Germline Variant Filtering}

Germline variants called by the GATK on WBC samples were first filtered using a threshold of minimum coverage of $50 \times$ and an allele frequency of $>30 \%$. Variants not on coding regions and synonymous mutations annotated with ANNOVAR $^{20}$ were filtered out. Furthermore, variants with $>0.1 \%$ population minor allele frequency annotated in the ExAC database (http://exac.broadinstitute.org/) were considered less functional and were ignored in the downstream analysis. Germline mutations considered deleterious (nonsense/stop-gains, frameshift insertions and deletions, and $\pm 1,2$ splice-site variants, or those reported as pathogenic or likely pathogenic in the ClinVar database; 
https://www.ncbi.nlm.nih.gov/clinvar/) were included for analysis.

\section{Somatic Variant Filtering}

Somatic mutations from ctDNA samples were filtered using the following rules: (1) 10 allele reads support, (2) $1 \%$ allele frequency, (3) supporting reads should be $<4$ in the WBC control, (4) mutation frequency should be 5 times higher than in the WBC control, (5) mutations should not occur more than twice in the panel of normals, and (6) no significant strand bias (GATK parameter FisherStrand annotation $>60$ for single-nucleotide polymorphisms and GATK parameter FisherStrand annotation $>200$ for insertions/deletions). Similar filtering rules were applied for somatic mutations from FFPE samples except for the allele frequency, which was required to be $>5 \%$, and the mutation frequency, which was required to be 8 times higher than that in the WBC control. Functional filtering removed variants located in noncoding regions, and synonymous mutations were removed for downstream analysis. A log2 ratio of $>0.6$ was considered a copy gain event for $A R$. A log2 ratio of $<-0.7$ was considered a copy loss.

\section{Biallelic Inactivation Definition}

Biallelic inactivation was defined as either homozygous deletion, $\geq 2$ deleterious somatic mutations, 1 deleterious germline mutation with concurrent heterozygous loss of the wild-type allele, or 1 somatic mutation with loss of heterozygosity as computed using the FACETS algorithm. ${ }^{21}$ Only samples with a ctDNA fraction $\geq 0.2$ were used to infer biallelic inactivation. ${ }^{22}$

\section{ctDNA Fraction Estimation}

The mutant allele fraction (MAF) was first calculated using the somatic mutation profile from the sequencing results, followed by a correction model. ${ }^{8}$ The ctDNA\% was defined as $2 /(1 / \mathrm{MAF}+1)$ in diploid chromosomes as $\mathrm{MAF}$, and $\mathrm{ctDNA} \%$ was related as MAF $=(\mathrm{ctDNA} \times 1) /$ $[(1-\operatorname{ctDNA}) \times 2+\operatorname{ctDNA} \times 1]$.

\section{Statistical Analysis}

All statistical analysis was conducted using R version 3.7 (R Foundation for Statistical Computing). The Fisher exact test was used to test the significance of differences for the somatic alterations between different groups. The Kaplan-Meier method was used to estimate the PFS of different treatments for patients, and differences between groups were analyzed using the log-rank test in the survival package (version 2.44-1.1). Univariate and multivariate Cox regression analyses were used to calculate their respective hazard ratios (HRs) and 95\% confidence intervals. Only factors significant in univariate analyses were included in the subsequent multivariate analyses. A test result was considered as statistically significant for $P<.05$.

\section{Results}

\section{Patient Characteristics}

From the 8 institutions, 292 patients were recruited for analysis between December 2017 and December 2019 (supplemental eTable 3). Their baseline characteristics are summarized in Table 1. Median age before ctDNA sequencing was 69 years (interquartile range,

\section{Table 1. Summary of Clinical Characteristics of 292 Patients With mCRPC (306 Samples)}

\begin{tabular}{|c|c|}
\hline Characteristic & Result \\
\hline Median age at baseline (IQR), y & $69(65-76)$ \\
\hline \multicolumn{2}{|l|}{ Gleason score } \\
\hline 6 & 7 \\
\hline 7 & 54 \\
\hline 8 & 77 \\
\hline 9 & 82 \\
\hline 10 & 28 \\
\hline Unknown & 44 \\
\hline Median time from ADT initiation to $\mathrm{mCRPC}$ (IQR), mo & $19(11-30)$ \\
\hline \multicolumn{2}{|l|}{ Unknown $(n=39)$} \\
\hline \multicolumn{2}{|l|}{ PSA at time of ctDNA collected, $n(\%)$} \\
\hline$>0-10 \mathrm{ng} / \mathrm{mL}$ & $66(21.6)$ \\
\hline$>10-20 \mathrm{ng} / \mathrm{mL}$ & $42(13.7)$ \\
\hline$>20-100 \mathrm{ng} / \mathrm{mL}$ & $89(29.1)$ \\
\hline$>100 \mathrm{ng} / \mathrm{mL}$ & $96(31.4)$ \\
\hline Unknown & $13(4.2)$ \\
\hline \multicolumn{2}{|l|}{ Site of metastatic cancer, n (\%) } \\
\hline Lymph node & $273(89.2)$ \\
\hline Bone & $280(91.5)$ \\
\hline Visceral & $29(9.5)$ \\
\hline \multicolumn{2}{|c|}{ Received prior regimens for $\mathrm{mCRPC}$ at time of ctDNA collected, $\mathrm{n}(\%)$} \\
\hline Treatment-naïve & $93(30.4)$ \\
\hline First-line treatment of abiraterone & $92(30.1)$ \\
\hline First-line treatment of docetaxel & $40(13.1)$ \\
\hline Second-line or later-line treatment & $81(26.5)$ \\
\hline \multicolumn{2}{|l|}{ Treatment of mCRPC after ctDNA collected, $\mathrm{n}(\%)$} \\
\hline Abiraterone & $58(19.0)$ \\
\hline Docetaxel & $66(21.6)$ \\
\hline Platinum-based chemotherapy (post docetaxel) & $19(6.2)$ \\
\hline Olaparib & $27(8.8)$ \\
\hline Other & $136(44.4)$ \\
\hline Median follow-up time (IQR), d & $406(285-550$ \\
\hline
\end{tabular}

Abbreviations: ADT, androgen deprivation therapy; ctDNA, circulating tumor DNA; IQR, interquartile range; $M C R P C$, metastatic castration-resistant prostate cancer; PSA, prostate-specific antigen. 


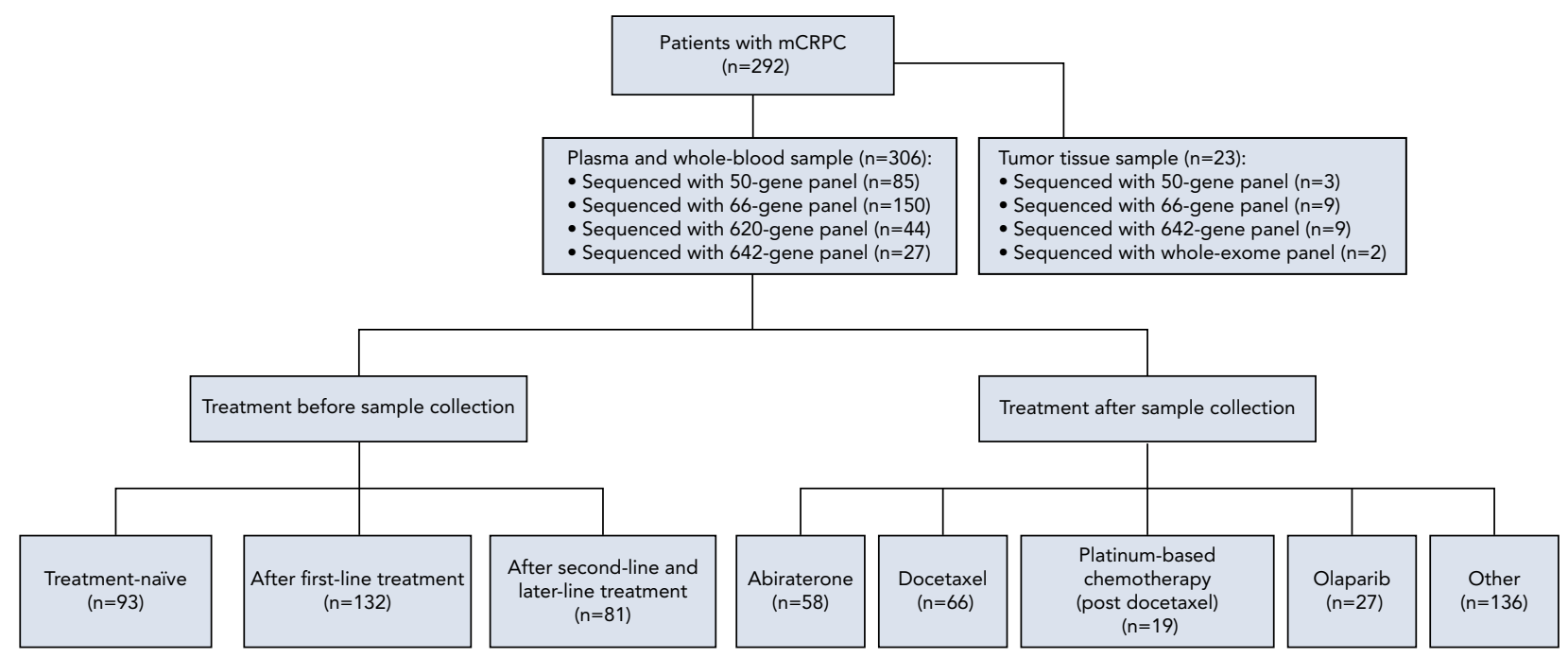

Figure 1. Flow diagram depicting the patients included in this cohort and patient groups according to treatments received before and after blood collection.

Abbreviation: $\mathrm{mCRPC}$, metastatic castration-resistant prostate cancer.

65-76 years). The patients were categorized according to treatments received before blood collection. Among the 306 ctDNA samples, the patient numbers (proportion) of group A (treatment-naïve), group B (post first-line treatment of mCRPC), and group $\mathrm{C}$ (post second-line or later-line treatment of mCRPC) were $93(30.4 \%), 132(43.1 \%)$, and $81(26.5 \%)$, respectively. Patients were also categorized according to treatment after blood collection. Baseline sample numbers from those receiving treatment (after baseline ctDNA collection) were as follows: abiraterone $(n=58)$, docetaxel $(n=66)$, platinumbased chemotherapy post docetaxel $(n=19)$, olaparib $(n=27)$, and other treatments $(n=136)$ (Figure 1).

\section{Mutational Concordance Between Tumor Tissue and ctDNA}

Twenty-three patients with ctDNA samples also had paired tumor biopsy tissues available (20 from the prostate, 2 from the liver, 1 from the bone, collected at the same time). Among these 23 patients, 5 had no detectable somatic mutations in either the ctDNA or the tissue sample. For the remaining 18 patients, 54 and 36 somatic mutations were identified in ctDNA samples and the corresponding tumor tissue samples, respectively. In total, 33 of $36(91.7 \%)$ mutations were found consistently between ctDNA and tissue samples (Figure 2A, supplemental eTable 4). All CDK12 mutations identified in tissue samples were found in ctDNA. Among the 24 mutations detected in 1 sample type but not in the other (ie, discordant mutations), 3 were present in tumor tissues but absent in ctDNA (FOXA1 S436fs, RB1 P29fs, PALB2 L708X) and 21 were unique to ctDNA, including mutations in AR, BRCA2, ATM, PTEN, and TP53 (Figure 2B).
As the sequencing platform evolved, different targeted gene sequencing panels were used in the present study. To confirm the concordance between different gene panels, 12 ctDNA samples were duplicated and subjected to tests with the 66-gene and 620/642-gene panels. All somatic mutations detected using the 620/642-gene panel were confirmed using the 66-gene panel, with remarkably consistent allele fractions (supplemental eFigure 1A). Copy number calls in 4 driver genes $(A R, B R C A 2, C D K 12$, and TP53) of mCRPC were also concordant between the 2 DNA capture panels (supplemental eFigure 1B).

\section{Genomic Landscape of Chinese Patients With mCRPC}

Somatic and deleterious germline alterations were identified in 201 of 292 patients (for the 14 patients with serial samples, data from the first sample were used) (supplemental eFigure 2A, B and eTable 5). In total, $43.2 \%$ of patients carried alterations of homologous recombination repair (HRR) genes and 6.85\% harbored alterations in mismatch repair genes. Among the top 3 altered HRR genes, CDK12 (15.4\%) alterations were exclusively somatic events, and alterations in BRCA2 (13\%) and $A T M(7.5 \%)$ were either in the germline or somatic (supplemental eFigure 2B, C, D). Among the patients with a ctDNA fraction $>20 \%$, biallelic inactivation occurred in $62.5 \%$ (10/16), $73.9 \%$ (17/23), and $44.4 \%$ (4/9) of BRCA2, $C D K 12$, and $A T M$, respectively. Compared with other DDR genes (including BRCA1, BRCA2, ATM, MLH1, and MSH2), the proportion of $C D K 12$ mutations (15.4\%) was significantly higher than reported previously in the Stand Up to Cancer-Prostate Cancer Foundation (SU2C-PCF) cohort (supplemental eFigure 3). 
A

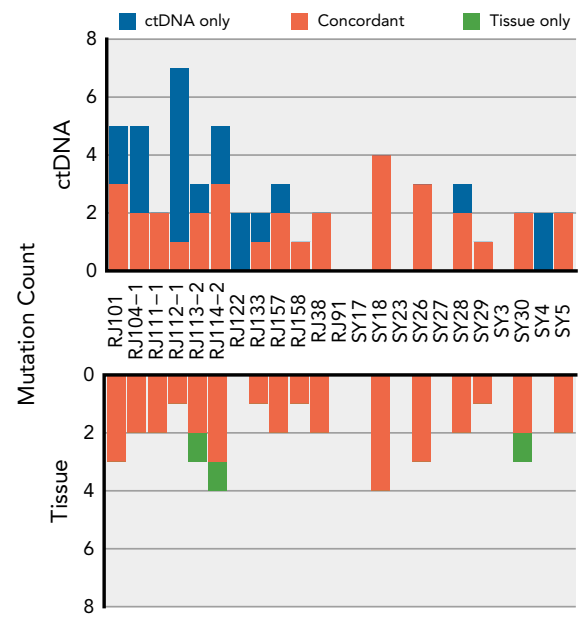

B

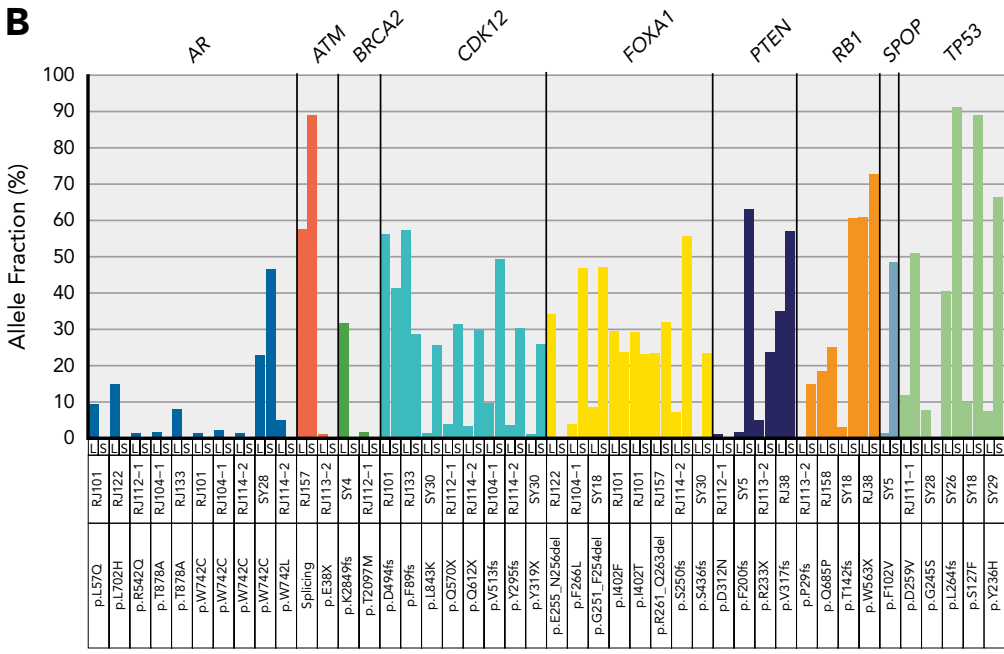

Figure 2. Concordance of mutation calls between ctDNA samples and paired tumor tissues in 23 patients. (A) Somatic mutation count of ctDNA and tumor tissues. (B) Variant allele frequencies for selected driven mutations between matched liquid cell tumor DNA and solid tumor tissue. Abbreviations: ctDNA, circulating tumor DNA; L, liquid cell tumor DNA; $S$, solid tumor tissue.

According to the number of prior therapies before sampling, the 306 samples from the 292 patients were divided into 3 groups: treatment-naïve (group $A ; n=93$ ), post first-line treatment (group $\mathrm{B} ; \mathrm{n}=132$ ), and post second-line or later-line treatment (group $C ; n=81$ ). The somatic alteration patterns in these subgroups are shown in Figure 3A. Alterations in $A R$ increased progressively from group A $(21.5 \%)$ to group B (37.1\%) to group C $(46.9 \%)(P<.001)$. Likewise, the frequency of TP53 alterations increased significantly in group $C(24.7 \%)$ compared with group A (12.9\%) $(P=.035)$ (Figure 3B). The somatic profile of 14 patients with 2 serial ctDNA samples is shown in supplemental eFigure 4 .

\section{Somatic Alterations of CDK12, TP53, and/or RB1 Associated With Outcomes of Abiraterone}

Among patients with ctDNA collected before abiraterone treatment $(\mathrm{n}=58)$, the PSA response $(>50 \%$ decline) in 12 weeks was observed in 27 patients $(46.55 \%)$ (Figure $4 \mathrm{~A}$, supplemental eTable 6). Only $1(14.29 \%)$ of 7 patients with $C D K 12$ defects achieved a PSA response. None of the patients with TP53 or $R B 1$ defects $(\mathrm{n}=8)$ achieved a PSA response. No significant difference in PFS was observed between patients with and without BRCA2 or ATM defects in the abiraterone-treated group (supplemental eFigure 5A, B). CDK12 defects were associated with shorter PFS after abiraterone treatment (1.6 vs 10.4 months; $P=.001$ ) (Figure 4B). Patients with TP53 or RB1 defects had a significantly shorter PFS than those without these defects after abiraterone treatment (2.0 vs 11.0 months; $P<.001$ ) (supplemental eFigure 5C). Median PFS for patients receiving abiraterone treatment was 3.0 months for those with $A R$ gain $(n=5)$ compared with 10.4 months in those without
$A R$ gain ( $P=.007$ ) (supplemental eFigure 5D). No significant difference in median PFS was observed between patients with and without $A R$ mutations (supplemental eFigure 5E).

In univariate analysis, 6 variables were significantly associated with PFS after abiraterone treatment (Table 2). In multivariable analysis, after adjusting for clinical factors, mutation classification, and therapeutic information (Table 2), CDK12 defects (HR, 19.587; 95\% CI, 3.788-101.278; $P<.001$ ), TP53 or $R B 1$ defects (HR, 4.727; 95\% CI, 1.554-14.383; $P=.006$ ), and visceral metastasis (HR, 10.827; 95\% CI, 2.386-49.119; $P=.002$ ) remained significant.

\section{Somatic Alterations of TP53 and/or RB1 Associated With Outcomes of Docetaxel}

Among patients with ctDNA collected before docetaxelonly treatment $(n=66)$, a PSA response in 12 weeks was observed in 29 patients (43.94\%) (Figure 4C, supplemental eTable 7). A total of $4(40 \%)$ of 10 patients with CDK12 defects achieved a PSA response, and $2(20 \%)$ of 10 patients with TP53 or RB1 defects achieved a PSA response. No significant difference in median PFS was observed between patients with and without CDK12, $B R C A 2$, or $A T M$ defects (Figure 4D, supplemental eFigure 6A, B). Patients with TP53 or RB1 defects had a significantly shorter PFS than those without TP53 or $R B 1$ defects after docetaxel treatment (4.8 vs 8.0 months; $P=.019$; supplemental eFigure 6C). Median PFS for patients receiving docetaxel treatment was 5.0 months for those with $A R$ gain compared with 8.0 months in those without $A R$ gain $(P=.012)$ (supplemental eFigure $6 \mathrm{D}$ ).

In univariate analysis, 4 variables were significantly associated with PFS after docetaxel treatment (Table 2). 
A
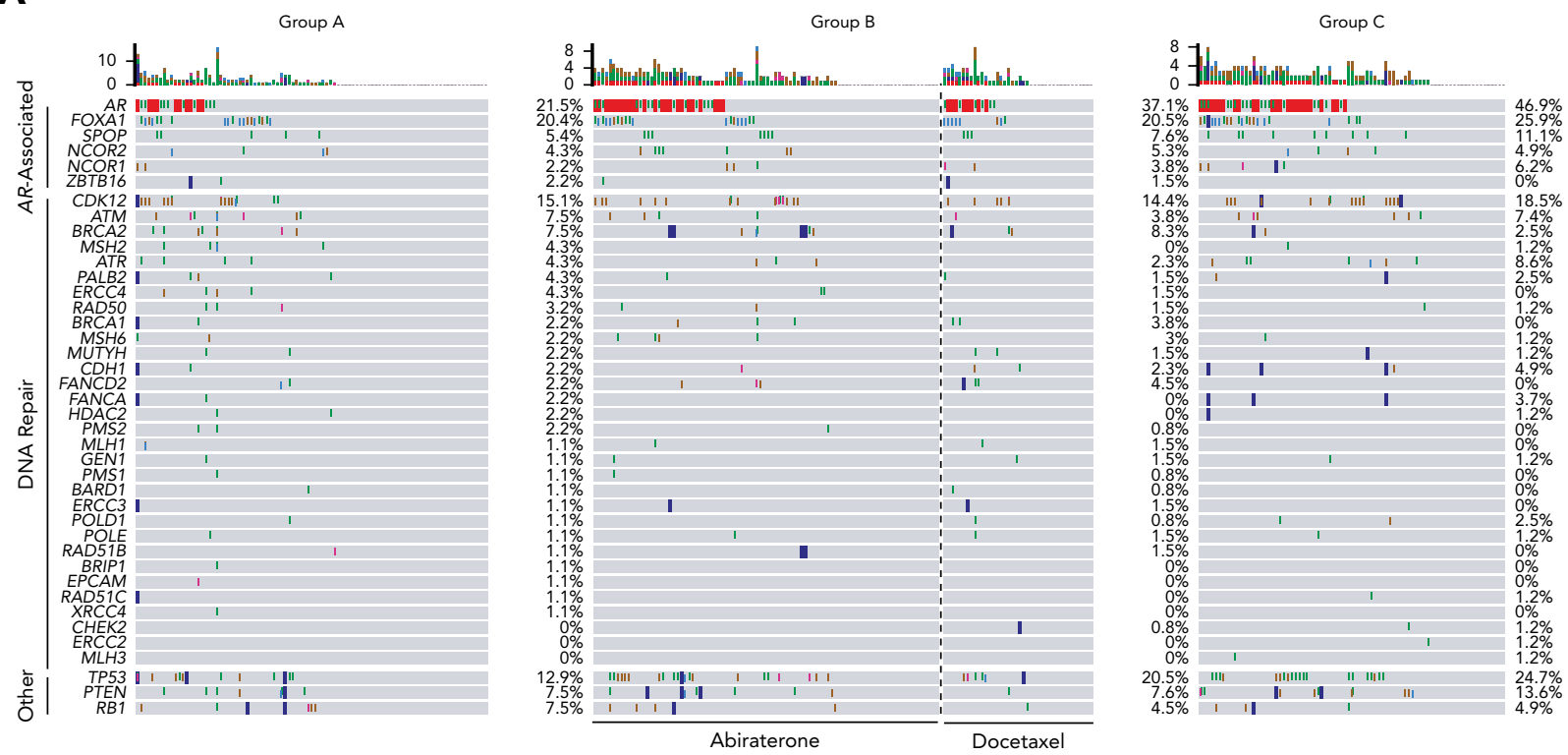

Missense $\square$ Truncating $\square$ Splicing $\square$ In-frame indel $\square$ Gain (log ratio >0.6) $\square$ Deletion (log ratio $<-0.7)$

B

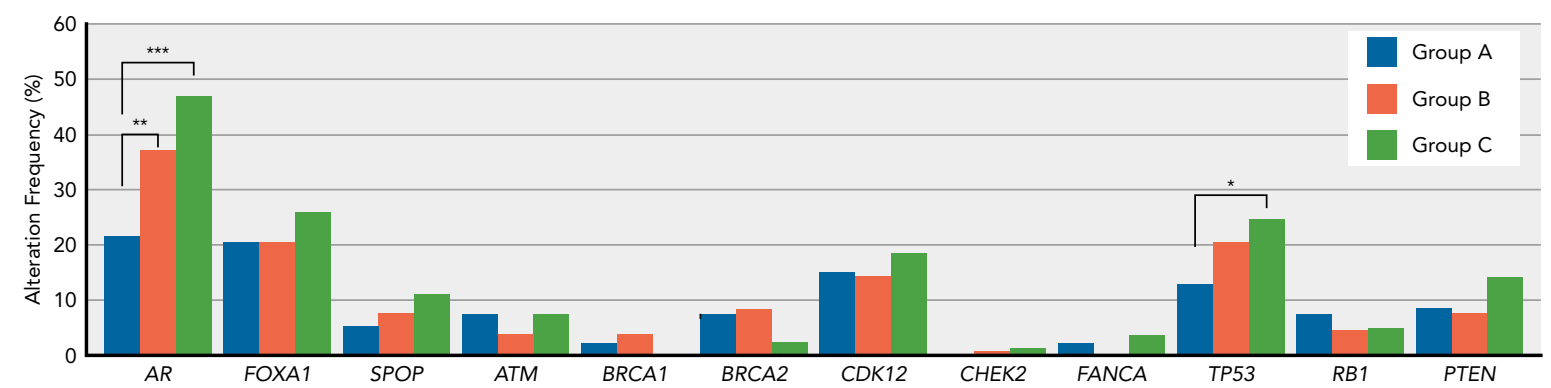

Figure 3. Somatic genomic alterations across different treatment stage groups for mCRPC. (A) Somatic alterations in patients stratified into 3 groups based on prior number of $\mathrm{mCRPC}$ systemic treatments: group $\mathrm{A}$ (treatment-naïv; $n=93$ ), group $B$ (post first-line treatment with abiraterone or docetaxel; $n=132$ ), and group $C$ (post second-line or later-line treatment; $n=81$ ). (B) Comparison of frequency of somatic alteration in selected genes from the 3 groups based on prior number of treatments.

Abbreviations: indel, insertions/deletions; $\mathrm{mCRPC}$, metastatic castration-resistant prostate cancer.

${ }^{\star} P<.05 ;{ }^{\star \star} P<.01 ;{ }^{\star \star *} P<.001$.

In multivariable analysis, after adjusting for clinical factors, mutation classification, and therapeutic information (Table 2), TP53 or RB1 defects (HR, 2.805; 95\% CI, $1.130-6.965 ; P=.026$ ), PSA level ( $>100$ vs $\leq 100 \mathrm{ng} / \mathrm{mL}$; HR, 2.731; 95\% CI, 1.418-5.262; $P=.003$ ), and visceral metastasis (HR, 11.517; 95\% CI, 2.348-56.503; $P=.003$ ) showed statistical significance.

\section{DDR Genes May Help Predict Efficacy of Platinum-}

\section{Based Chemotherapy and PARP Inhibitors}

Nineteen patients were sequenced before platinumbased chemotherapy, and 3 of these discontinued treatment after 1 cycle of cisplatin or carboplatin because of serious adverse effects. Of these 16 patients, 8 showed deleterious alterations in DDR genes (supplemental
eTable 8). PSA changes at 12 weeks for each patient during platinum-based chemotherapy are displayed in supplemental eFigure 7A. Of the 8 patients with a DDR defect, $7(87.5 \%)$ had a PSA decline (including 1 patient with a CDK12 defect) and $6(75 \%)$ had a PSA decline $>50 \%$. Conversely, in the 8 patients who had no PSA decline, only 1 harbored an ERCC3 alteration and the remaining 7 had no detectable alteration of DDR genes.

Median PFS after platinum-based chemotherapy in patients with a DDR gene defect was significantly longer than for those without a DDR gene defect (12.0 vs 2.0 months; $P=.002$; supplemental eFigure $8 \mathrm{~A})$. Patients with BRCA2 defects had a median PFS of 12 months $(95 \% \mathrm{CI}$, 11.0-not available), compared with 13 months in patients 
A

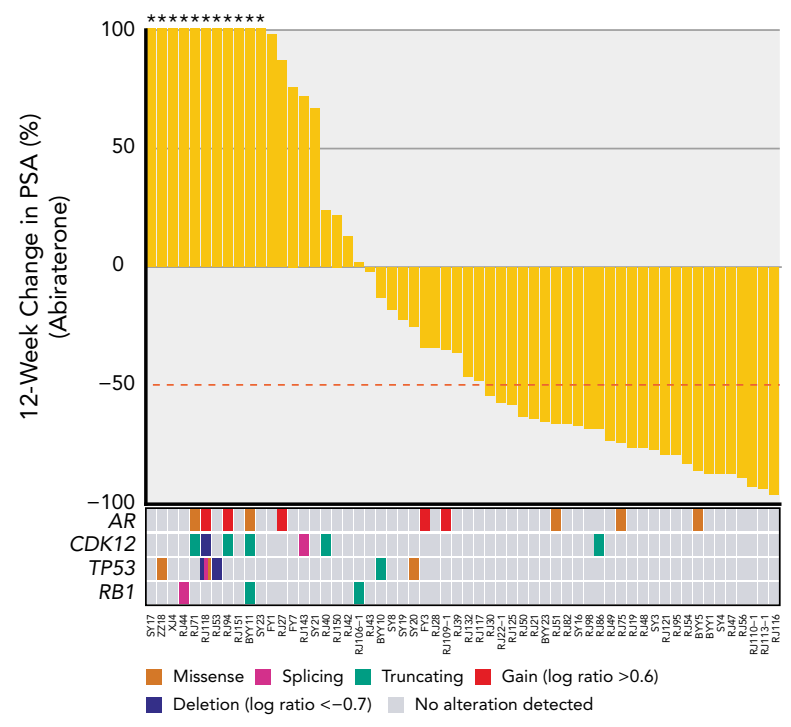

B

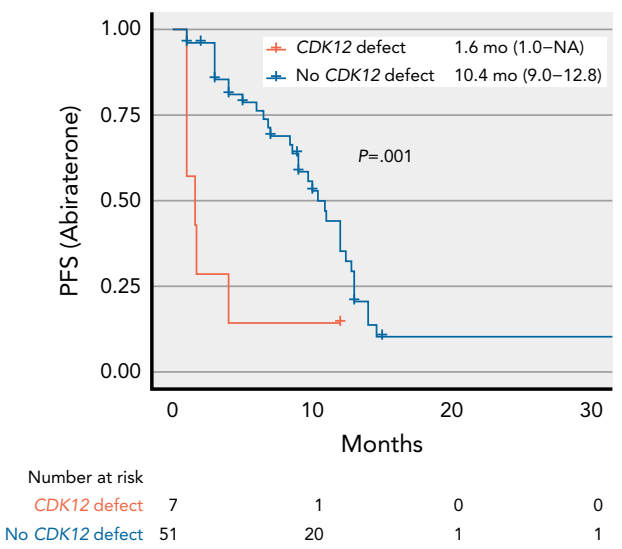

C

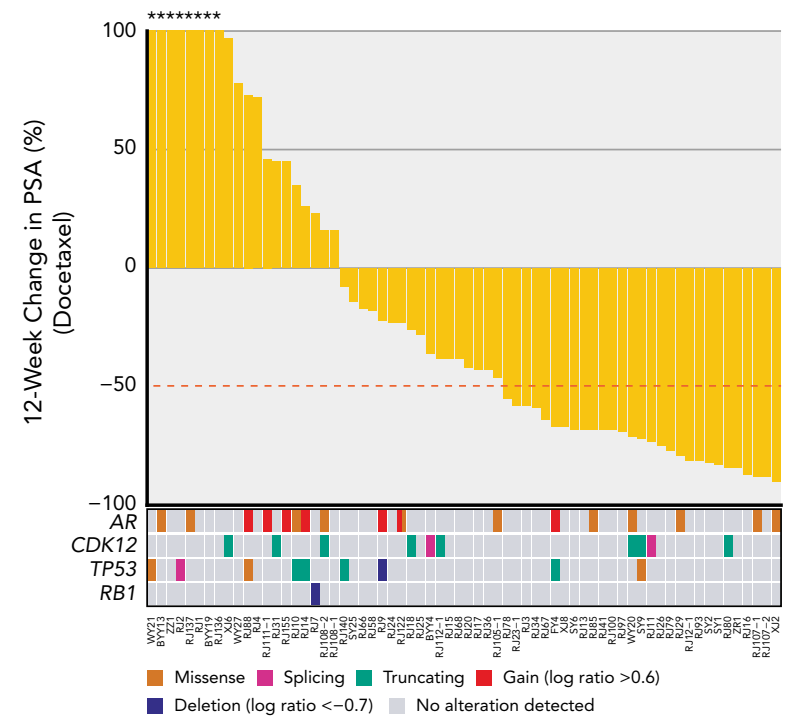

D

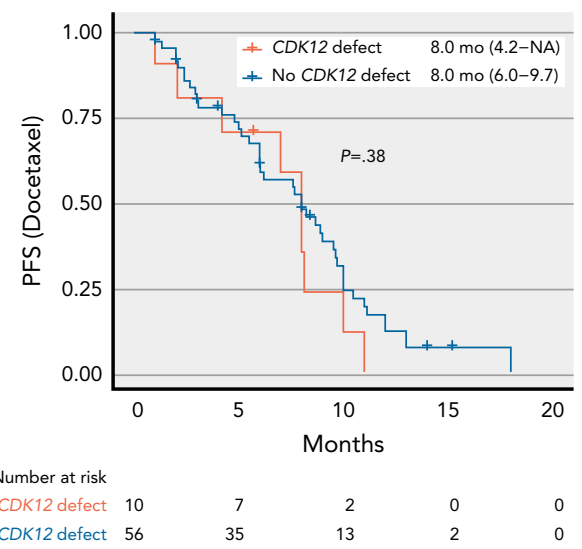

Figure 4. Association between genomic alterations and clinical outcomes of abiraterone or docetaxel. (A) Waterfall plot for percent PSA change in response to abiraterone in 12 weeks. (B) Kaplan-Meier curves for PFS in patients with and without a CDK12 defect in the abiraterone treatment group. (C) Waterfall plot for percent PSA change in response to docetaxel in 12 weeks. (D) Kaplan-Meier curves for PFS in patients with and without a CDK12 defect in the docetaxel treatment group. The asterisk (*) above each bar indicates that it was truncated.

Abbreviations: NA, not available; PSA, prostate-specific antigen; PFS, progression-free survival.

with other DDR defects and 2.0 months in those with no DDR defect $(P=.008$; supplemental eFigure 8B).

A total of 27 patients in the entire cohort received olaparib, including 5 who were lost to follow-up; 10 revealed no defect in DDR genes, whereas 12 of 22 patients had DDR gene defects (supplemental eTable 9), and PSA responses were observed in 5 (41.7\%) of these 12 patients. All 4 patients with BRCA2 defects had a PSA level decline, 3 (75\%) of whom achieved a PSA response, and 1 (25\%) of the 4 patients with CDK12 defects achieved a PSA response (supplemental eFigure 7B). There was no significant difference in median PFS between patients with and without DDR gene defects (4.0 vs 1.8 months; $P=.19$; supplemental eFigure $8 \mathrm{C}$ ). The median PFS of patients receiving olaparib was 10.7 months for those with BRCA2 defects $(\mathrm{n}=4)$ compared with 2.9 months for those with other DDR gene defects (including ATM and CDK12 defects; $\mathrm{n}=8$ ) and 1.8 months for those without detectable DDR gene defects ( $\mathrm{n}=10 ; P=.1$; supplemental eFigure $8 \mathrm{D})$.

\section{Discussion}

This was a real-world multi-institutional study that explored the genomic landscape of Chinese patients with mCRPC at different treatment stages and evaluated the relevance of ctDNA targeted sequencing with treatments for mCRPC. First, we found that CDK12 alterations (15.4\%) in our Chinese CRPC cohort were significantly more frequent than in Caucasian patients. In addition, 


\begin{tabular}{|c|c|c|c|c|c|c|c|c|}
\hline & \multicolumn{4}{|c|}{ Abiraterone-Treated Group $(n=58)$} & \multicolumn{4}{|c|}{ Docetaxel-Treated Group $(n=68)$} \\
\hline & \multicolumn{2}{|c|}{ Univariate Analyses } & \multicolumn{2}{|c|}{ Multivariate Analyses } & \multicolumn{2}{|c|}{ Univariate Analyses } & \multicolumn{2}{|c|}{ Multivariate Analyses } \\
\hline & HR $(95 \% \mathrm{Cl})$ & $\begin{array}{c}P \\
\text { Value }\end{array}$ & HR $(95 \% \mathrm{Cl})$ & $\begin{array}{c}P \\
\text { Value }\end{array}$ & HR $(95 \% \mathrm{Cl})$ & $\begin{array}{c}P \\
\text { Value }\end{array}$ & HR $(95 \% \mathrm{Cl})$ & $\begin{array}{c}P \\
\text { Value }\end{array}$ \\
\hline $\begin{array}{l}\text { PSA level } \\
(>100 \text { vs } \leq 100 \mathrm{ng} / \mathrm{mL})\end{array}$ & $6.472(2.172-19.282)$ & .001 & $5.938(0.778-45.296)$ & .086 & $2.172(1.168-4.041)$ & .014 & $2.731(1.418-5.262)$ & .003 \\
\hline Gleason score ( $\leq 7$ vs $>7$ ) & $1.086(0.555-2.126)$ & .81 & - & - & $0.858(0.454-1.621)$ & .637 & - & - \\
\hline $\begin{array}{l}\text { Treatment-naïve vs } \\
\text { posttreatment }\end{array}$ & $1.199(0.598-2.404)$ & .61 & - & - & $1.001(0.572-1.751)$ & .997 & - & - \\
\hline $\begin{array}{l}\text { Visceral metastasis vs } \\
\text { no visceral metastasis }\end{array}$ & $5.582(1.745-17.860)$ & .004 & $10.827(2.386-49.119)$ & .002 & $7.185(1.581-32.657)$ & .011 & $11.517(2.348-56.503)$ & .003 \\
\hline $\begin{array}{l}\text { Time from ADT initiation } \\
\text { to } \mathrm{mCRPC}(\leq 12 \text { vs }>12 \mathrm{mo})\end{array}$ & $2.436(1.100-5.392)$ & .028 & $1.522(0.591-3.922)$ & .385 & $0.952(0.523-1.732)$ & .867 & - & - \\
\hline $\begin{array}{l}\text { CDK12 defect vs } \\
\text { no CDK12 defect }\end{array}$ & $3.877(1.568-9.585)$ & .003 & 19.587 (3.788-101.278) & $<.001$ & $1.377(0.664-2.854)$ & .39 & - & - \\
\hline $\begin{array}{l}\text { AR amplification vs } \\
\text { no } A R \text { amplification }\end{array}$ & $3.910(1.294-11.281)$ & .016 & $1.484(0.184-11.976)$ & .711 & $2.968(1.210-7.277)$ & .017 & $1.375(0.459-4.117)$ & .569 \\
\hline $\begin{array}{l}A R \text { pathogenic mutation vs } \\
\text { no } A R \text { pathogenic mutation }\end{array}$ & $1.523(0.592-3.915)$ & .383 & - & - & $0.687(0.308-1.533)$ & .359 & - & - \\
\hline $\begin{array}{l}\text { TP53 or RB1 defect vs } \\
\text { no TP53 or RB1 defect }\end{array}$ & $7.401(2.935-18.665)$ & $<.001$ & $4.727(1.554-14.383)$ & .006 & $2.328(1.112-4.875)$ & .025 & $2.805(1.130-6.965)$ & .026 \\
\hline $\begin{array}{l}\text { BRCA2 defect vs } \\
\text { no } B R C A 2 \text { defect }\end{array}$ & $0.719(0.220-2.346)$ & .584 & - & - & $1.327(0.615-2.866)$ & .471 & - & - \\
\hline $\begin{array}{l}\text { ATM defect vs } \\
\text { no ATM defect }\end{array}$ & $1.613(0.382-6.811)$ & .515 & - & - & $1.305(0.314-5.426)$ & .715 & - & - \\
\hline
\end{tabular}

Abbreviations: ADT, androgen deprivation therapy; HR, hazard ratio; mCRPC, metastatic castration-resistant prostate cancer; PSA, prostate-specific antigen; PFS, progression-free survival.

we found that $C D K 12$ defect had a predictive role in mCRPC's response to multiple treatments, including abiraterone and docetaxel chemotherapy, which may help guide treatment selection in mCRPC. Third, we found that DDR genes, especially $B R C A 2$, detected by ctDNA targeted sequencing may help predict the efficacy of platinum-based chemotherapy and PARP inhibitors.

Recently, a novel molecular subtype of advanced prostate cancer harboring CDK12 mutations was reported in patients with mCRPC. ${ }^{7,23-27}$ In a whole-exome sequencing study of 150 metastatic biopsies, the SU2CPCF International Consortium identified DDR gene inactivation in $23 \%$ of patients, with $B R C A 2$ defects being the most common (12\%). ${ }^{7}$ Previous studies in Western populations reported that the frequency of CDK12 mutations was $5 \%$ to $7 \%{ }^{7,8,14}$ In our cohort of Chinese men with mCRPC, the most frequently altered gene among the DDR genes was CDK12 (15.4\%), which was almost double that observed in Western populations with mCRPC. ${ }^{7,8,14} \mathrm{By}$ contrast, the alteration frequencies of BRCA1, BRCA2, and $A T M$ were more in line with the SU2C-PCF International Consortium data. ${ }^{7}$ CDK12 functions in DNA transcription and RNA splicing, regulates DDR genes involved in HRR, and has been suggested to increase susceptibility to PARP inhibitors. ${ }^{28-31}$ More recently, studies have shown that $C D K 12$-mutated prostate cancer had different molecular characteristics ${ }^{23}$ with aggressive clinical behaviors..$^{25,32,33}$ Biallelic inactivation of $C D K 12$ in prostate cancer is associated with elevated neoantigen burden and increased tumor T-cell infiltration/clonal expansion, resulting in sensitivity to immune checkpoint inhibitors. ${ }^{24}$ However, the clinical outcomes of CDK12mutated prostate cancer using standard systemic therapies remain controversial. ${ }^{25,32,33}$ Our data support that CDK12 had a predictive role in mCRPC's response to multiple treatments, including abiraterone and docetaxel chemotherapy. $C D K 12$ defects were associated with worse efficacy after abiraterone treatment, whereas the clinical outcome after docetaxel treatment was similar between patients with and without CDK12 defects. Further stu dies will assess how CDK12 defects are involved in the resistance or sensitivity to multiple therapies in mCRPC.

Emerging evidence suggests that DDR-associated prostate cancer has an impressive response to platinumbased chemotherapy. ${ }^{34-36}$ In this study, we observed that 7 patients experienced a PSA response, and 6 of them $(85.7 \%)$ had deleterious alterations in DDR genes (3 with 
somatic BRCA2 defects). Conversely, of the 8 patients who had no PSA decline, 7 had no detectable alteration of DDR genes. We also found that the median PFS after platinum-based chemotherapy in patients with DDR defects was significantly longer than in those without a DDR defect.

Recently, the FDA approved PARP inhibitors to treat HRR gene-mutated mCRPC. Our results suggest that not all DDR gene defects are equally predictive of a PARP inhibitor response. Patients with BRCA2 defects experienced superior outcomes compared with those with other DDR defects, which is consistent with previous reports. ${ }^{37,38}$ This finding suggests that when considering PARP inhibitor treatment in patients with MCRPC, it is necessary to carefully examine the established functional association of changes in DDR genes, especially in genes other than BRCA2.

$A R$ amplification was reported to indicate worse efficacy of the $A R$ signaling pathway inhibition (ARPI) in previous studies. ${ }^{8,9}$ Our results are consistent with the conclusions made in those studies. Previous analyses have also suggested that mutational loss of TP53 and RB1 may predict poor survival in patients with mCRPC treated using ARPI. ${ }^{8,9}$ Loss of TP53 and $R B 1$ is frequently observed in lethal prostate cancer and has been correlated with lineage plasticity and the formation of neuroendocrine differentiation in prostate cancer, ${ }^{39,40}$ which explains primary resistance to ARPI. However, the association between $T P 53$ or $R B 1$ defects and the efficacy of docetaxel had not been examined previously. Our results showed that patients with MCRPC with TP53 and/or RB1 defects were associated with rapid resistance to both abiraterone and docetaxel.

Our study has several limitations. Although the high concordance between tumor tissue and ctDNA has been shown and liquid biopsies may capture tumor heterogeneity, they may fail to detect ctDNA in patients with a low disease burden and may have included low-frequency mutations from clonal hematopoiesis. In addition, the panels used in the study only capture exon regions, and therefore some meaningful intron mutations could be missing. Moreover, because of the small sample size in each treatment subgroup, clinical outcomes of the biallelic versus monoallelic mutations of key genes in patients with prostate cancer were not compared. Thus, the correlation between mutational status and treatment response should be interpreted with caution. The predictive value of specific genes and clinical benefit of the ctDNA test must be confirmed by additional prospective studies.

\section{Conclusions}

Our study explored the genomic landscape of Chinese patients with mCRPC at different treatment stages using minimally invasive methods and evaluated the clinical implications of the driver genomic alterations on the patients' response to the most widely used therapies for mCRPC. We observed a significantly higher alteration frequency of $C D K 12$ in our cohort compared with the SU2C-PCF cohort. ${ }^{7}$

\section{Acknowledgments}

We thank Tingting Zhao, Xuan Zou, Yining Yang, and Fangqin Wang, who gave strong support to the present study.

Submitted May 12, 2020; final revision received September 13, 2020; accepted for publication September 28, 2020. Published online May 14, 2021.

Disclosures: The authors have disclosed that they have not received any financial consideration from any person or organization to support the preparation, analysis, results, or discussion of this article.

Funding: This study was supported by funds to the Department of Urology, Ren Ji Hospital, from National Natural Science Foundation of China $(81772742$ 81672850), Youth Program of National Natural Science Foundation of China (82002710), Shanghai Municipal Education Commission-Gaofeng Clinical Medicine Grant Support (20191906), and Shanghai Sailing Program (20YF1425300).

Correspondence: Wei Xue, MD, Department of Urology, Renji Hospital, School of Medicine, Shanghai Jiao Tong University, Shanghai, China. Email: xuewei@renji.com; and

Xudong Yao, MD, Department of Urology, Shanghai Tenth People's Hospital, Tongji University School of Medicine, Shanghai, China. Email: yaoxudong1967@163.com

\section{References}

1. de Bono JS, Logothetis CJ, Molina A, et al. Abiraterone and increased survival in metastatic prostate cancer. N Engl J Med 2011;364:1995-2005.

2. Tannock IF, de Wit R, Berry WR, et al. Docetaxel plus prednisone or mitoxantrone plus prednisone for advanced prostate cancer. N Engl J Med 2004;351:1502-1512.

3. Scher HI, Fizazi K, Saad F, et al. Increased survival with enzalutamide in prostate cancer after chemotherapy. N Engl J Med 2012;367:1187-1197.

4. de Bono JS, Oudard S, Ozguroglu M, et al. Prednisone plus cabazitaxel or mitoxantrone for metastatic castration-resistant prostate cancer progressing after docetaxel treatment: a randomised open-label trial. Lancet 2010;376:1147-1154.

5. de Bono J, Mateo J, Fizazi K, et al. Olaparib for metastatic castrationresistant prostate cancer. N Engl J Med 2020;382:2091-2102.

6. Abida W, Campbell D, Patnaik A, et al. Genomic characteristics associated with clinical activity of rucaparib in patients (pts) with BRCA1 or BRCA2 (BRCA)-mutated metastatic castration-resistant prostate cancer (mCRPC) [abstract]. J Clin Oncol 2020;38(Suppl):Abstract 178.
7. Robinson D, Van Allen EM, Wu YM, et al. Integrative clinical genomics of advanced prostate cancer. Cell 2015;161:1215-1228.

8. Annala M, Vandekerkhove G, Khalaf D, et al. Circulating tumor DNA genomics correlate with resistance to abiraterone and enzalutamide in prostate cancer. Cancer Discov 2018;8:444-457.

9. Chen WS, Aggarwal R, Zhang L, et al. Genomic drivers of poor prognosis and enzalutamide resistance in metastatic castration-resistant prostate cancer. Eur Urol 2019;76:562-571.

10. Annala M, Struss WJ, Warner EW, et al. Treatment outcomes and tumor loss of heterozygosity in germline DNA repair-deficient prostate cancer. Eur Urol 2017;72:34-42.

11. Castro E, Romero-Laorden N, Del Pozo A, et al. PROREPAIR-B: a prospective cohort study of the impact of germline DNA repair mutations on the outcomes of patients with metastatic castration-resistant prostate cancer. J Clin Oncol 2019;37:490-503.

12. Wei Y, Wu J, Gu W, et al. Germline DNA repair gene mutation landscape in Chinese prostate cancer patients. Eur Urol 2019;76:280-283. 
13. Li J, Xu C, Lee HJ, et al. A genomic and epigenomic atlas of prostate cancer in Asian populations. Nature 2020;580:93-99.

14. Sowalsky AG, Ye $H$, Bhasin $M$, et al. Neoadjuvant-intensive androgen deprivation therapy selects for prostate tumor foci with diverse subclonal oncogenic alterations. Cancer Res 2018;78:4716-4730.

15. Aggarwal R, Huang J, Alumkal JJ, et al. Clinical and genomic characterization of treatment-emergent small-cell neuroendocrine prostate cancer: a multi-institutional prospective study. J Clin Oncol 2018;36:2492-2503.

16. Arora K, Barbieri CE. Molecular subtypes of prostate cancer. Curr Oncol Rep 2018;20:58.

17. Bolger AM, Lohse M, Usadel B. Trimmomatic: a flexible trimmer for Illumina sequence data. Bioinformatics 2014;30:2114-2120.

18. Li H, Durbin R. Fast and accurate short read alignment with BurrowsWheeler transform. Bioinformatics 2009;25:1754-1760.

19. McKenna A, Hanna M, Banks E, et al. The Genome Analysis Toolkit: a MapReduce framework for analyzing next-generation DNA sequencing data. Genome Res 2010;20:1297-1303.

20. Wang K, Li M, Hakonarson H. ANNOVAR: functional annotation of genetic variants from high-throughput sequencing data. Nucleic Acids Res 2010; 38:e164.

21. Shen R, Seshan VE. FACETS: allele-specific copy number and clonal heterogeneity analysis tool for high-throughput DNA sequencing. Nucleic Acids Res 2016;44:e131.

22. Mayrhofer M, De Laere B, Whitington $T$, et al. Cell-free DNA profiling of metastatic prostate cancer reveals microsatellite instability, structural rearrangements and clonal hematopoiesis. Genome Med 2018;10:85.

23. Quigley DA, Dang HX, Zhao SG, et al. Genomic hallmarks and structural variation in metastatic prostate cancer. Cell 2018;174:758-769;

24. Wu YM, Cieślik M, Lonigro RJ, et al. Inactivation of CDK12 delineates a distinct immunogenic class of advanced prostate cancer. Cell 2018;173: 1770-1782.e14.

25. Reimers MA, Yip SM, Zhang L, et al. Clinical outcomes in cyclindependent kinase 12 mutant advanced prostate cancer. Eur Urol 2020;77: 333-341.

26. Chou J, Quigley DA, Robinson TM, et al. Transcription-associated cyclindependent kinases as targets and biomarkers for cancer therapy. Cancer Discov 2020;10:351-370.

27. van Dessel LF, van Riet J, Smits M, et al. The genomic landscape of metastatic castration-resistant prostate cancers reveals multiple distinct genotypes with potential clinical impact. Nat Commun 2019;10:5251.
28. Chilà R, Guffanti F, Damia G. Role and therapeutic potential of CDK12 in human cancers. Cancer Treat Rev 2016;50:83-88.

29. Dubbury SJ, Boutz PL, Sharp PA. CDK12 regulates DNA repair genes by suppressing intronic polyadenylation. Nature 2018;564:141-145.

30. Blazek D, Kohoutek J, Bartholomeeusen K, et al. The cyclin K/Cdk12 complex maintains genomic stability via regulation of expression of DNA damage response genes. Genes Dev 2011;25:2158-2172.

31. Bajrami I, Frankum JR, Konde A, et al. Genome-wide profiling of genetic synthetic lethality identifies CDK12 as a novel determinant of PARP1/2 inhibitor sensitivity. Cancer Res 2014;74:287-297.

32. Nguyen B, Mota JM, Nandakumar S, et al. Pan-cancer analysis of CDK12 alterations identifies a subset of prostate cancers with distinct genomic and clinical characteristics. Eur Urol 2020;78:671-679.

33. Antonarakis ES, Isaacsson Velho P, Fu W, et al. CDK12-altered prostate cancer: clinical features and therapeutic outcomes to standard systemic therapies, poly (ADP-Ribose) polymerase inhibitors, and PD-1 inhibitors. JCO Precis Oncol 2020;4:370-381.

34. Cheng $\mathrm{HH}$, Pritchard CC, Boyd T, et al. Biallelic inactivation of BRCA2 in platinum-sensitive metastatic castration-resistant prostate cancer. Eur Uro 2016;69:992-995.

35. Pomerantz MM, Spisák S, Jia L, et al. The association between germline BRCA2 variants and sensitivity to platinum-based chemotherapy among men with metastatic prostate cancer. Cancer 2017;123: 3532-3539.

36. Zafeiriou Z, Bianchini D, Chandler R, et al. Genomic analysis of three metastatic prostate cancer patients with exceptional responses to carboplatin indicating different types of DNA repair deficiency. Eur Urol 2019;75:184-192.

37. Marshall $\mathrm{CH}$, Sokolova $\mathrm{AO}, \mathrm{McNatty} \mathrm{AL}$, et al. Differential response to olaparib treatment among men with metastatic castration-resistant prostate cancer harboring BRCA1 or BRCA2 versus ATM mutations. Eur Urol 2019;76:452-458

38. Lu E, Thomas GV, Chen Y, et al. DNA repair gene alterations and PARP inhibitor response in patients with metastatic castration-resistant prostate cancer. J Natl Compr Canc Netw 2018;16:933-937.

39. Beltran H, Prandi D, Mosquera JM, et al. Divergent clonal evolution of castration-resistant neuroendocrine prostate cancer. Nat Med 2016;22: 298-305.

40. Ku SY, Rosario S, Wang Y, et al. Rb1 and Trp53 cooperate to suppress prostate cancer lineage plasticity, metastasis, and antiandrogen resistance. Science 2017;355:78-83. 
Supplemental online content for:

\section{Use of Circulating Tumor DNA for the Clinical Management of Metastatic Castration-Resistant Prostate Cancer: A Multicenter, Real-World Study}

Baijun Dong, PhD; Liancheng Fan, MD; Bin Yang, MD, PhD; Wei Chen, MD; Yonghong Li, MD; Kaijie Wu, MD, PhD; Fengbo Zhang, MD; Haiying Dong, MD, PhD; Huihua Cheng, MBBS; Jiahua Pan, MD; Yinjie Zhu, MD; Chenfei Chi, MD; Liang Dong, MD; Jianjun Sha, MD; Lei Li, MD, PhD; Xudong Yao, MD; and Wei Xue, MD

\section{J Natl Compr Canc Netw 2021;19(8):905-914}

eFigure 1: Concordance Between Genomic Alterations Detected Using the 620/642-Gene and 66-Gene Panels eFigure 2: Genomic Alterations of 292 Patients With mCRPC Assessed Using Targeted ctDNA Sequencing eFigure 3: Comparison of the Alteration Frequency of the Selected DDR Genes Between SU2C-PCF and the Present Cohort

eFigure 4: Somatic Profile of 14 Patients With mCRPC From 2 Serial ctDNA Samples eFigure 5: Association Between Genomic Alterations and Clinical Outcomes of Abiraterone eFigure 6: Association Between Genomic Alterations and Clinical Outcomes of Docetaxel eFigure 7: Association Between DDR Gene Defects and Clinical Outcomes of Platinum-Based Chemotherapy and Olaparib (12-Week Change in PSA)

eFigure 8: Association Between DDR Gene Defects and Clinical Outcomes of Platinum-Based Chemotherapy and Olaparib (PFS)

eTable 1: Treatment State Before Collection of 306 ctDNA Samples and 23 Tumor Tissues

eTable 2: List of Common 50 Genes in 50-Gene, 66-Gene, 620-Gene, and 642-Gene Capture Panels

eTable 3: Clinical Characteristics of 306 ctDNA Samples From 292 Patients

eTable 4: Somatic Mutations Detected in ctDNA and Matched Tumor Tissue of 23 Patients

eTable 5: All Filtered Somatic Mutations and Deleterious Germline Mutations Detected

eTable 6: Genomic Alteration Status, PFS, and PSA Change Over 12 Weeks in 58 Patients With ctDNA Samples Collected Before Abiraterone Treatment

eTable 7: Genomic Alteration Status, PFS, and PSA Change Over 12 Weeks in 66 Patients With ctDNA Samples Collected Before Docetaxel Treatment

eTable 8: Genomic Alteration Status, PFS, and PSA Change Over 12 Weeks in 16 Patients With cfDNA Samples Collected Before Platinum-Based Chemotherapy

eTable 9: Genomic Alteration Status, PFS, and PSA Change Over 12 Weeks in 16 Patients With cfDNA Samples Collected Before Olaparib Treatment 
A

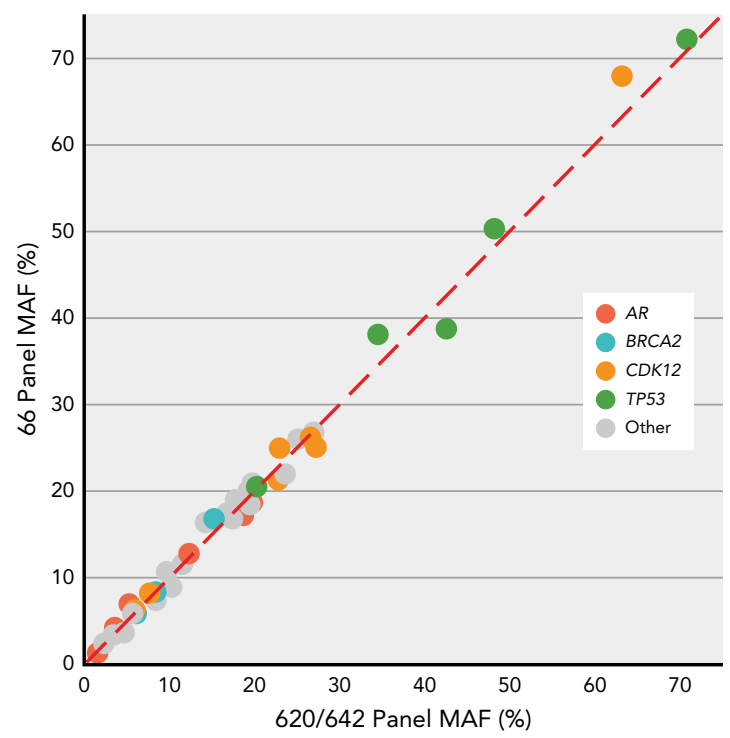

B
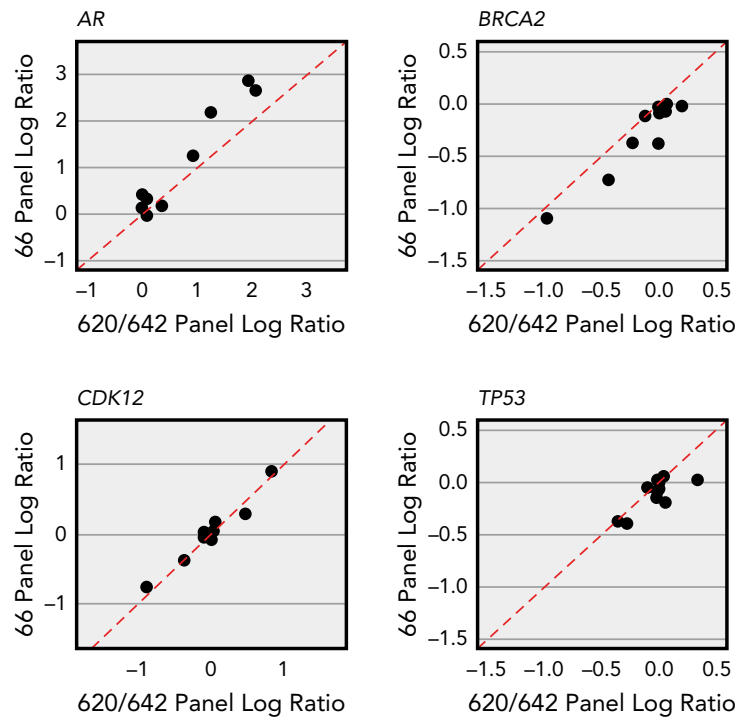

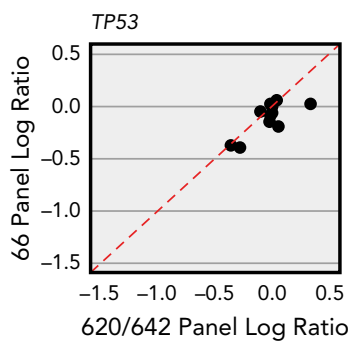

eFigure 1. Concordance between genomic alterations detected using the 620/642-gene and the 66-gene panels. (A) Scatterplot showing MAF measured using the 2 panels. All mutations detected using the 66-gene panel are shown. (B) Scatterplots showing coverage log ratios measured using the 2 panels for 4 driver genes of $\mathrm{mCRPC}$. Each dot represents a ctDNA sample whose sequence was present in both panels. Abbreviations: ctDNA, circulating tumor DNA; MAF, mutant allele fraction; mCRPC, metastatic castration-resistant prostate cancer. 
A

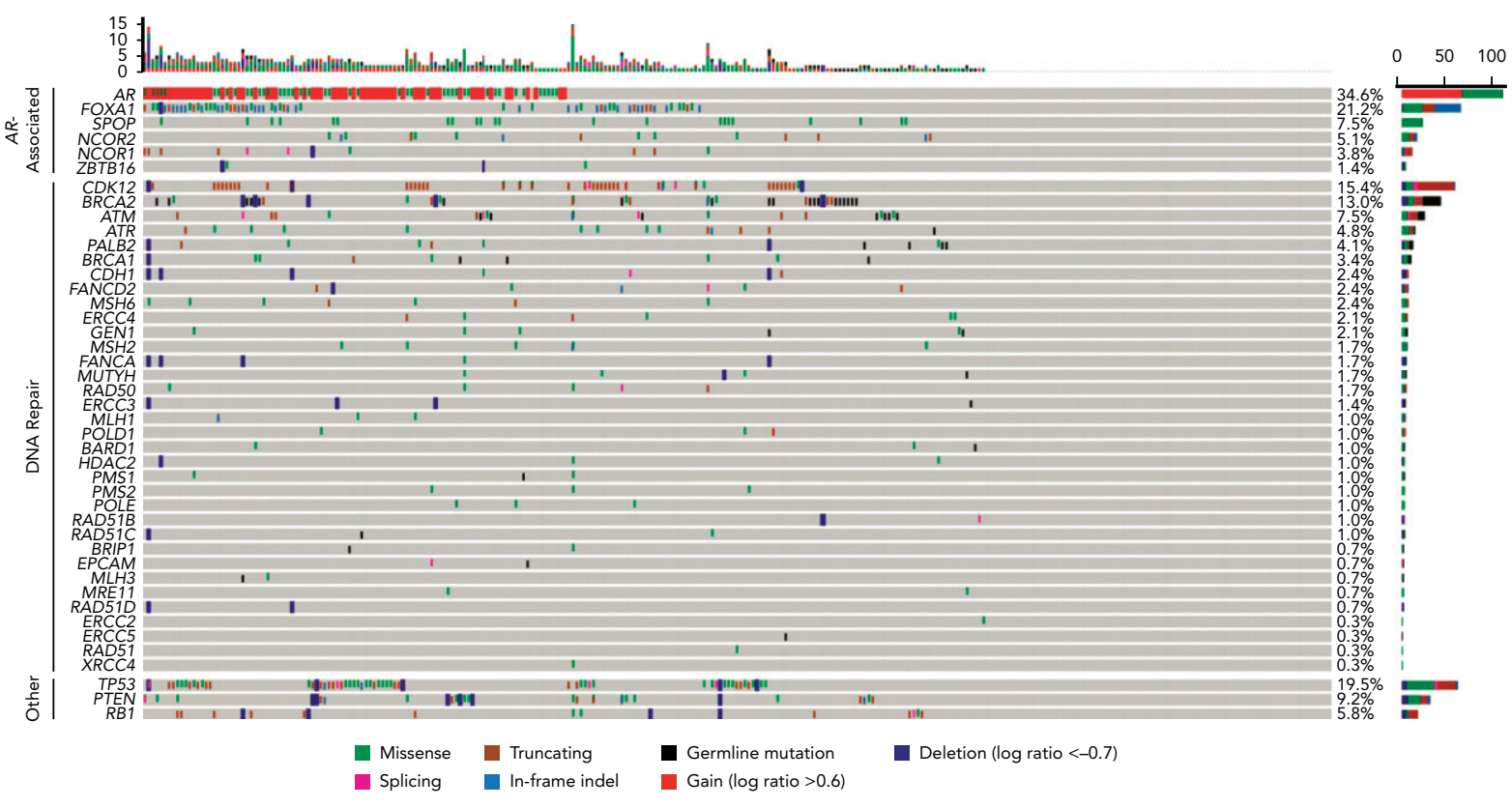

B

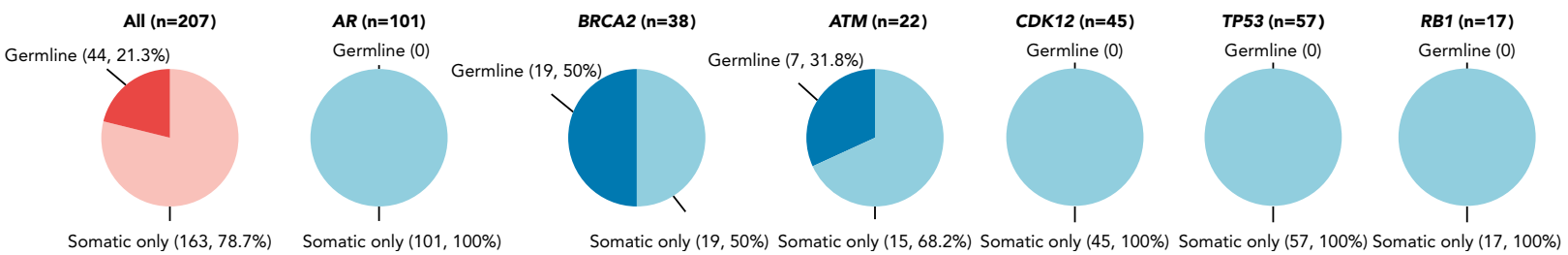

eFigure 2. Genomic alterations of 292 patients with mCRPC assessed using targeted ctDNA sequencing. (A) Genomic landscape of nonsynonymous somatic mutations and deleterious germline mutations. Genes grouped by relevant pathways are represented on the left. The frequency of alteration of each gene is provided on the right. The type of alteration is denoted in the row below. (B) The frequency of somatic and deleterious germline alterations in selected actionable genes such as AR, BRCA2, ATM, CDK12, TP53, and RB1. (C) Oncoprint of somatic and deleterious germline alterations in AR, BRCA2, ATM, CDK12, TP53, and RB1. (D) Location of somatic and deleterious germline mutations in AR, BRCA2, ATM, CDK12, TP53, and RB1.

Abbreviations: ctDNA, circulating tumor DNA; indel, insertions/deletions; mCRPC, metastatic castration-resistant prostate cancer.

(continued) 
C

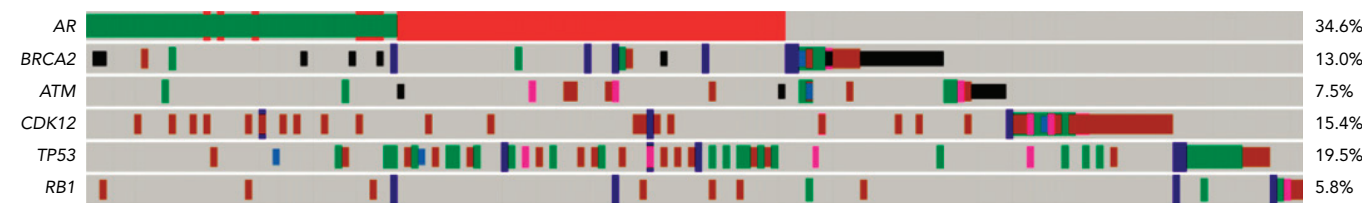

Gain (log ratio >0.6) Deletion (log ratio<-0.7) M Missense $\square$ Splicing $\square$ Truncating $\square$ In-frame indel $\square$ Germline mutation

D
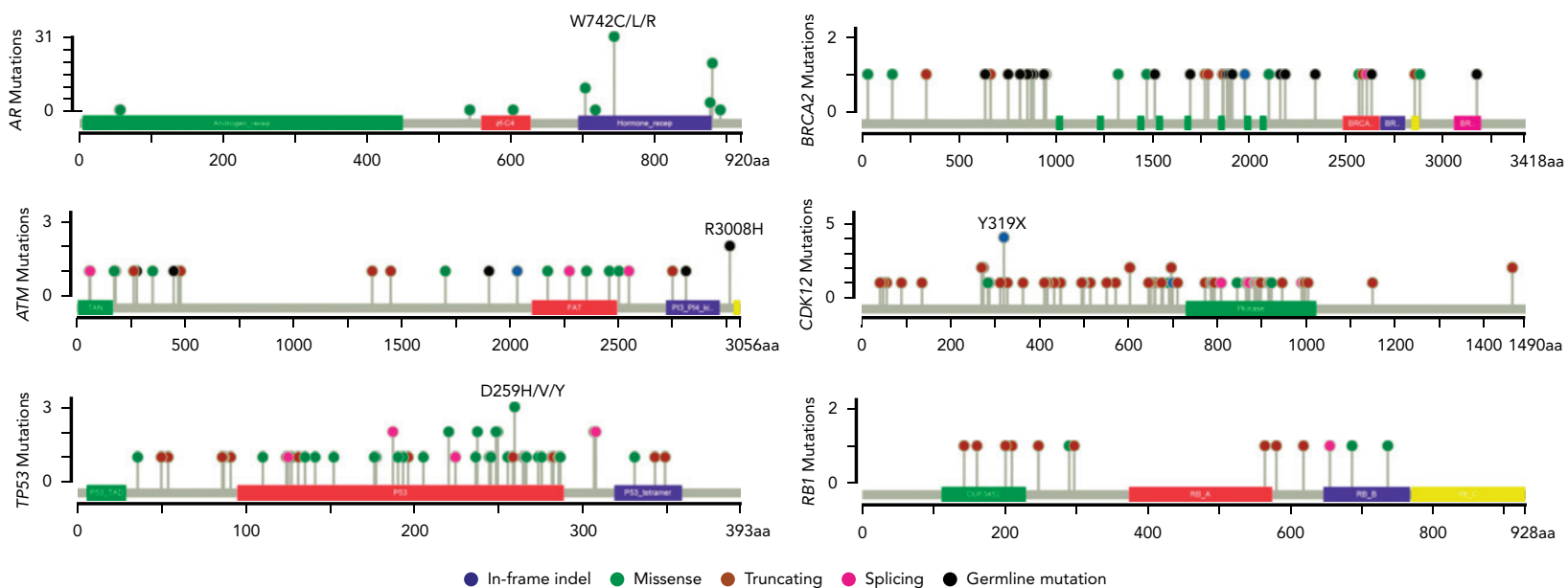

- In-frame indel Missense Truncating Splicing Germline mutation

eFigure 2 (cont.). Genomic alterations of 292 patients with mCRPC assessed using targeted ctDNA sequencing. (A) Genomic landscape of nonsynonymous somatic mutations and deleterious germline mutations. Genes grouped by relevant pathways are represented on the left. The frequency of alteration of each gene is provided on the right. The type of alteration is denoted in the row below. (B) The frequency of somatic and deleterious germline alterations in selected actionable genes such as $A R, B R C A 2, A T M, C D K 12, T P 53$, and RB1. (C) Oncoprint of somatic and deleterious germline alterations in AR, BRCA2, ATM, CDK12, TP53, and RB1. (D) Location of somatic and deleterious germline mutations in AR, BRCA2, ATM, CDK12, TP53, and RB1.

Abbreviations: ctDNA, circulating tumor DNA; indel, insertions/deletions; mCRPC, metastatic castration-resistant prostate cancer. 


\section{4 - Dong et al}

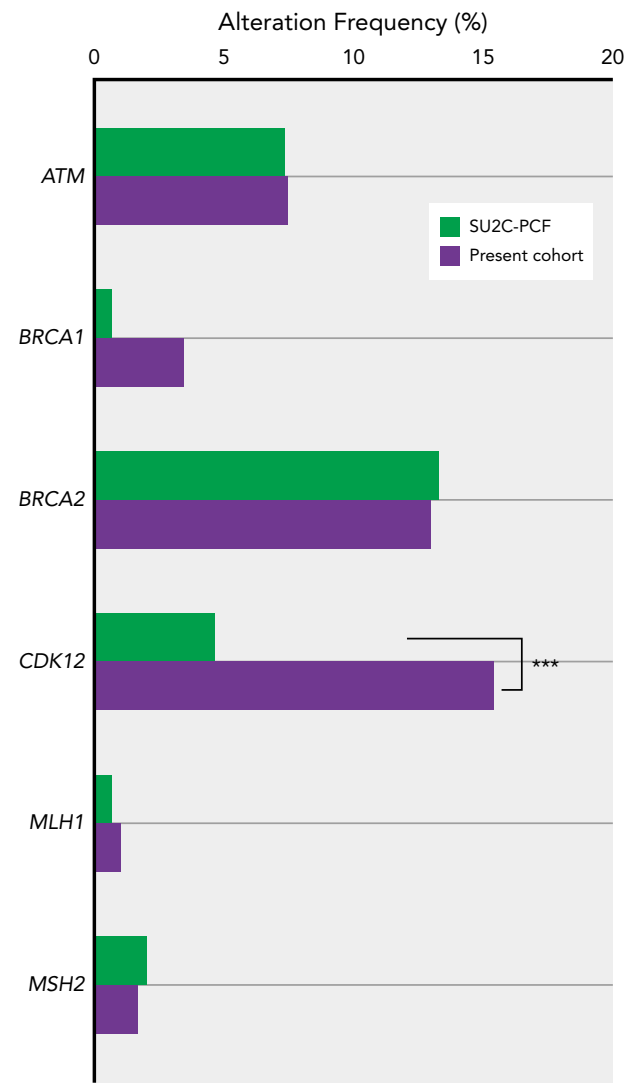

eFigure 3. Comparison of the alteration frequency of the selected DDR genes between the SU2C-PCF and the present cohorts. Abbreviations: DDR, DNA damage repair; SU2C-PCF, Stand Up to Cancer-Prostate Cancer Foundation.

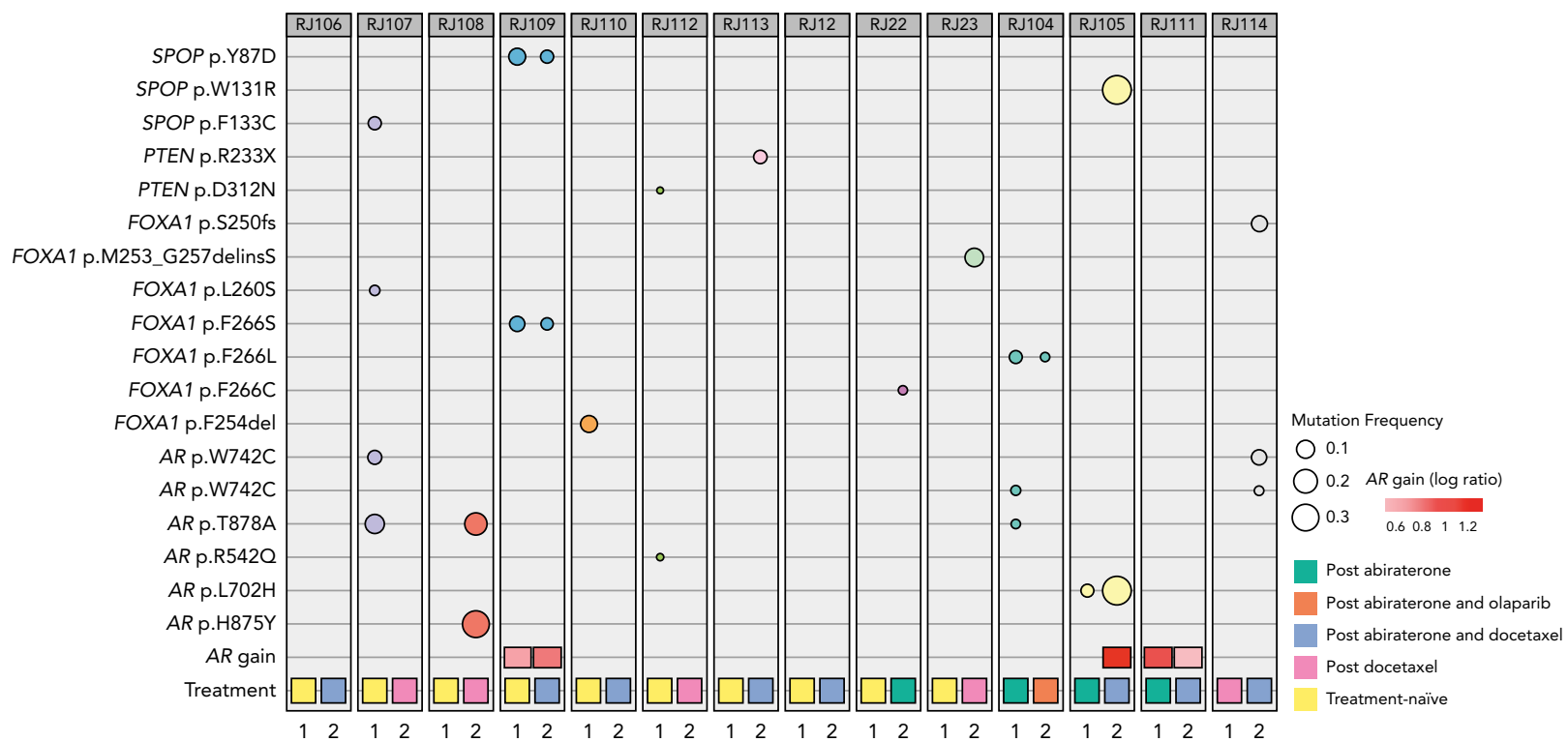

eFigure 4. Somatic profile of 14 patients with $\mathrm{mCRPC}$ from 2 serial ctDNA samples.

Abbreviations: ctDNA, circulating tumor DNA; $\mathrm{mCRPC}$, metastatic castration-resistant prostate cancer. 
A

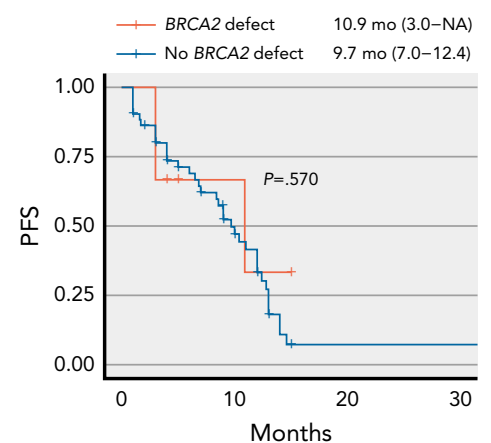

Number at risk

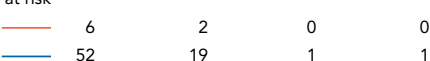

D

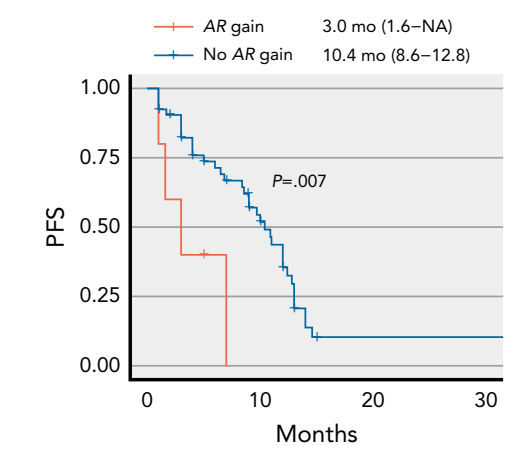

Number at risk

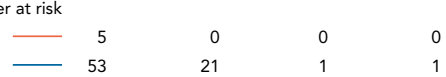

B

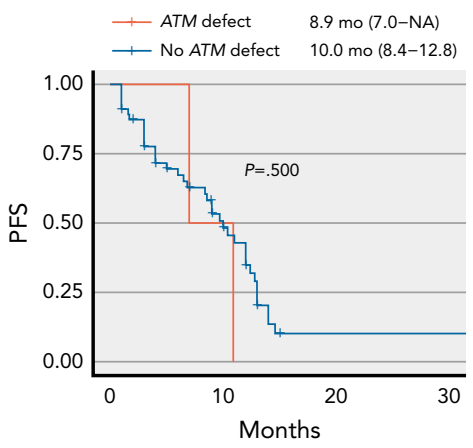

Number at risk$$
\text { (1) }
$$

\section{E}

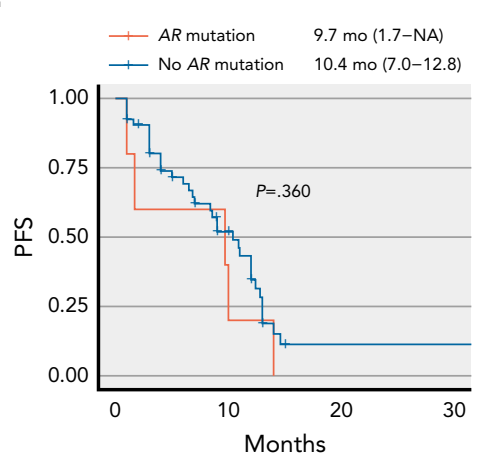

Number at risk
C

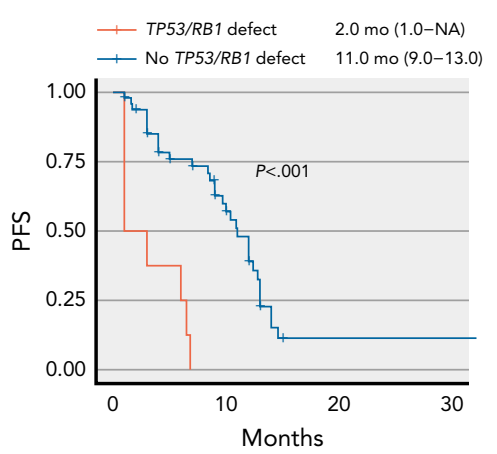

Number at risk

$\begin{array}{rrrrr}- & 8 & 0 & 0 & 0 \\ - & 50 & 21 & 1 & 1\end{array}$

eFigure 5. Association between genomic alterations and clinical outcomes of abiraterone. Kaplan-Meier curves for PFS of patients with and without (A) a BRCA2 defect, (B) an ATM defect, (C) a TP53 or RB1 defect, (D) AR gain, and (E) an AR mutation.

Abbreviations: NA, not available; PFS, progression-free survival. 
A

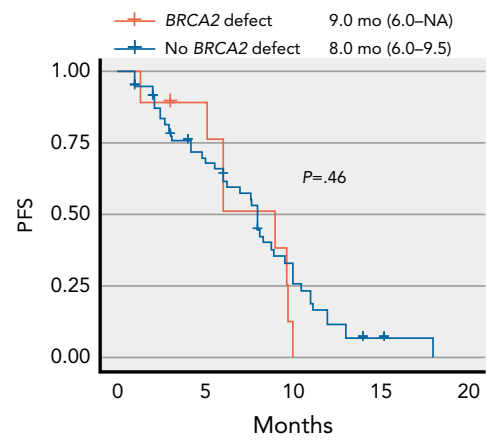

Number at risk

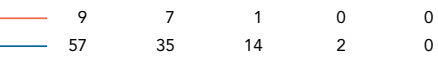

D

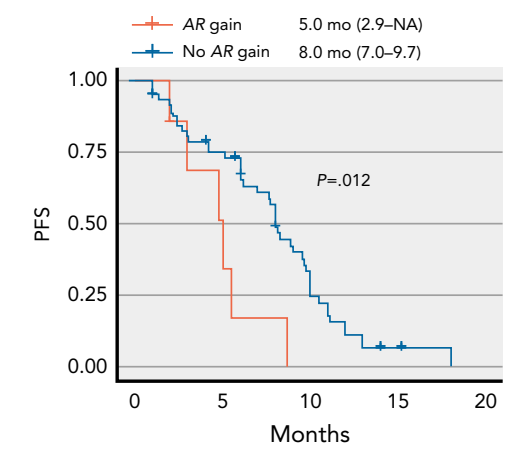

Number at risk

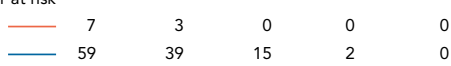

B

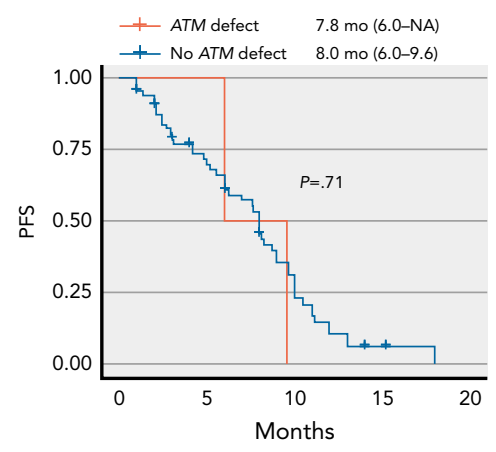

Number at risk

$$
\left[\begin{array}{r}
2 \\
-\quad 64
\end{array}\right.
$$

E

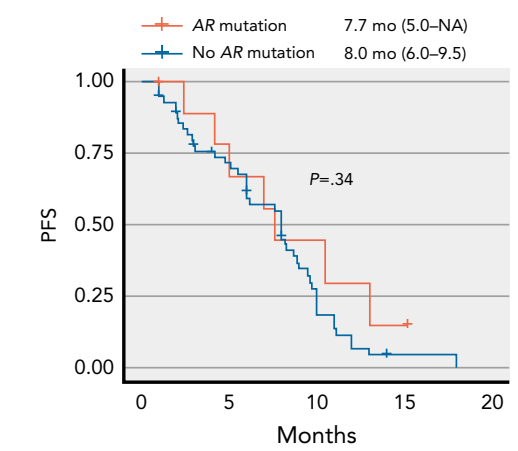

Number at risk
C

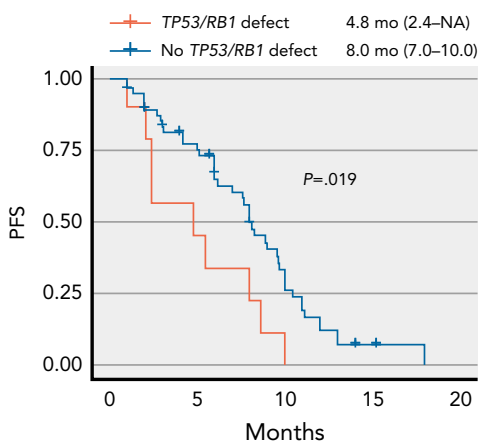

Number at risk

eFigure 6. Association between genomic alterations and clinical outcomes of docetaxel. Kaplan-Meier curves for PFS of patients with and without (A) a BRCA2 defect, (B) an ATM defect, (C) a TP53 or RB1 defect, (D) AR gain, and (E) an AR mutation.

Abbreviations: NA, not available; PFS, progression-free survival. 
A

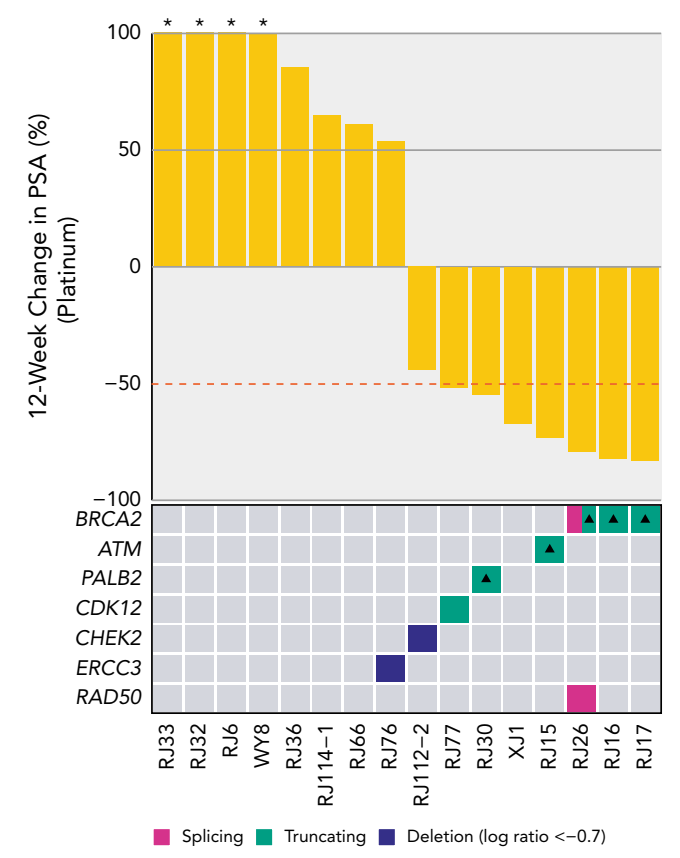

A Germline mutation No alteration detected
B

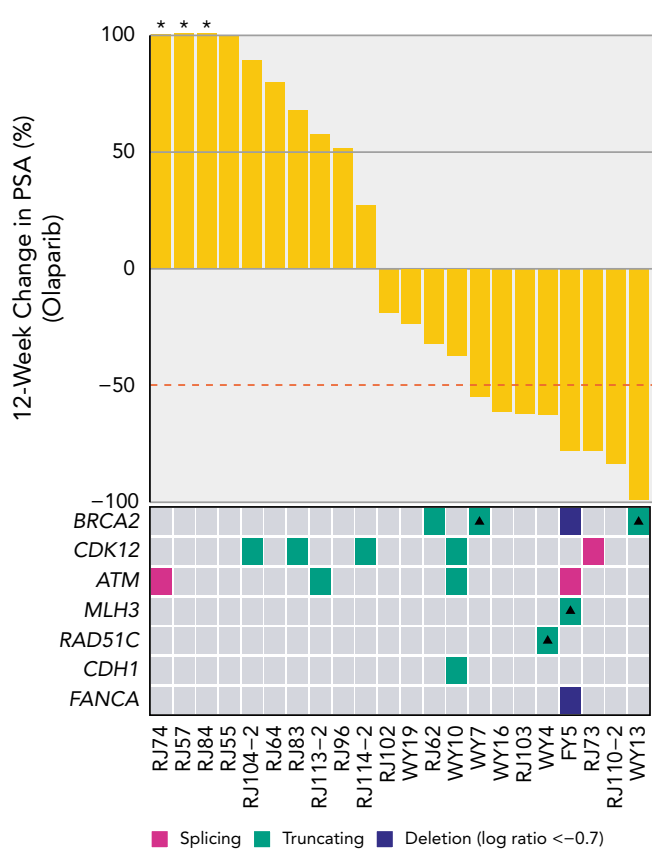

\ Germline mutation $\square$ No alteration detected

eFigure 7. Association between DDR gene defects and clinical outcomes of platinum-based chemotherapy and olaparib. (A) Waterfall plot for percentage of PSA change in response to platinum-based chemotherapy over 12 weeks. (B) Waterfall plot for percentage of PSA change in response to olaparib over 12 weeks. The asterisk $\left({ }^{\star}\right)$ above each bar indicates that it was truncated.

Abbreviations: DDR, DNA damage repair; PSA, prostate-specific antigen. 

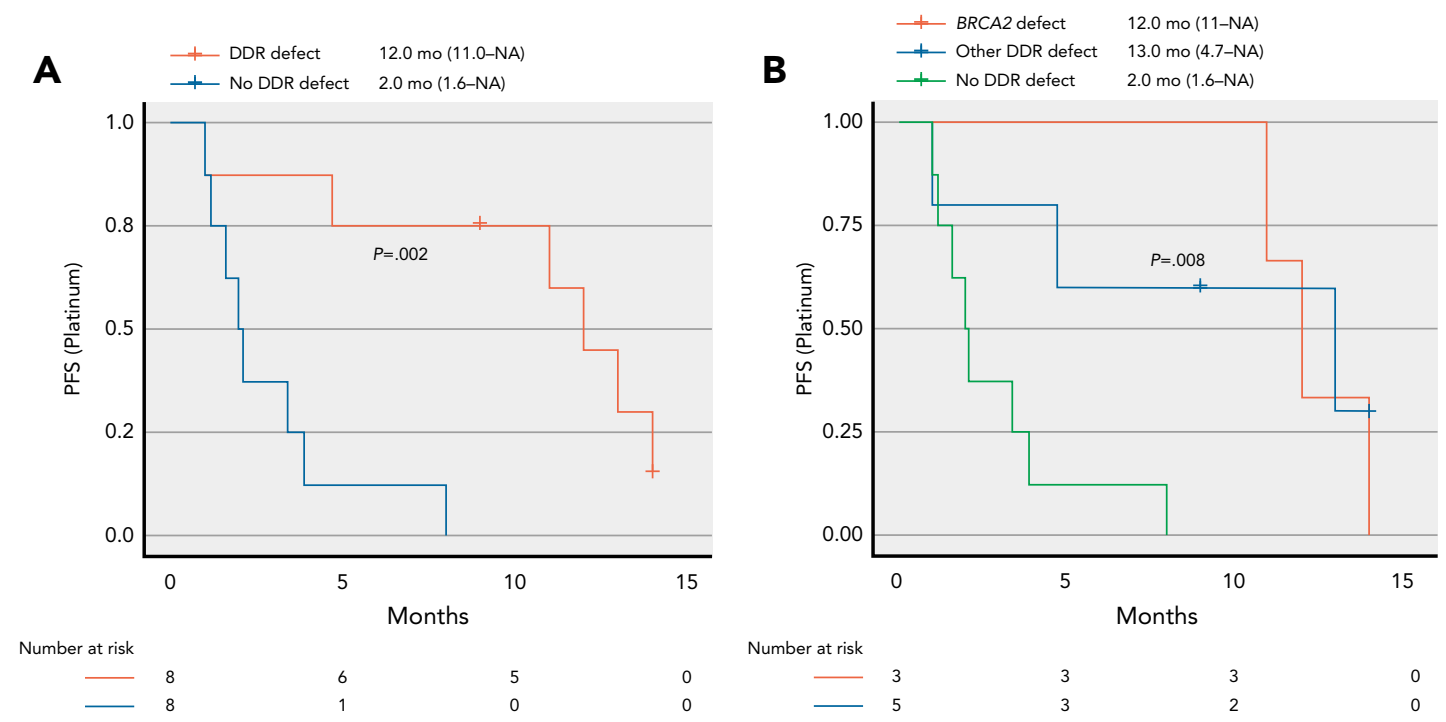

Number at risk
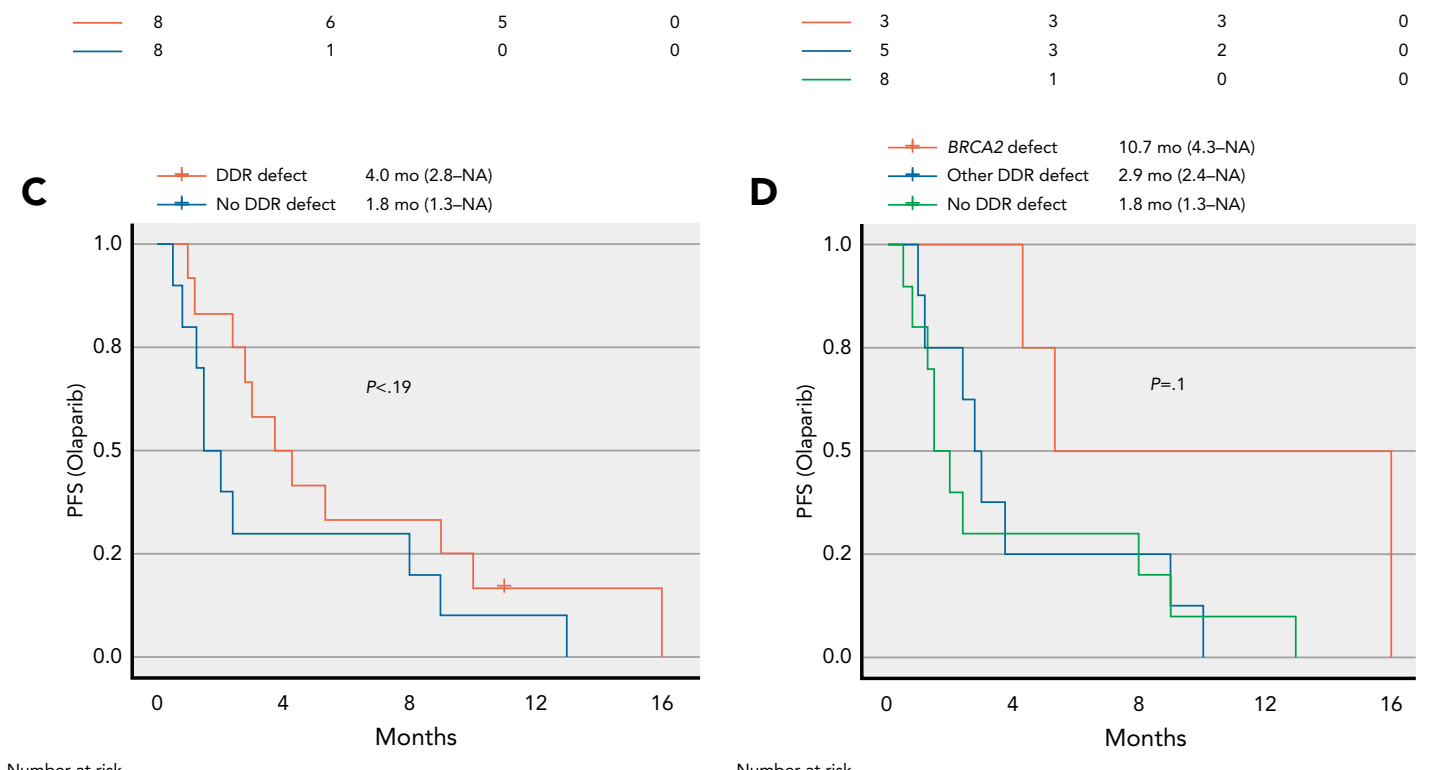

Number at risk

Number at risk

$\begin{array}{rllll}12 & 6 & 4 & 1 & 1 \\ -10 & 3 & 3 & 1 & 0\end{array}$

$\begin{array}{rrrrrr}\square & 4 & 2 & 1 & 1 \\ - & 4 & 2 & 2 & 0 & 0 \\ 10 & 3 & 3 & 1 & 0\end{array}$

eFigure 8. Association between DDR gene defects and clinical outcomes of platinum-based chemotherapy and olaparib. Kaplan-Meier curves for PFS of patients (A) with and without a DDR gene defect after platinum-based chemotherapy; $(B)$ with a BRCA2 defect, other DDR gene defects, and no DDR gene defect after platinum-based chemotherapy; (C) with and without a DDR gene defect after olaparib treatment; and (D) with a BRCA2 defect, other DDR gene defects, and no DDR gene defect after olaparib treatment.

Abbreviations: DDR, DNA damage repair; NA, not available; PSA, prostate-specific antigen. 


\section{eTable 1. Treatment State Before Collection of 306 ctDNA Samples and 23 Tumor Tissues}

Before ctDNA Sample Collection

\begin{tabular}{|c|c|c|c|}
\hline Patient ID & Treatment for mCRPC Before Sequencing & Patient ID & Treatment for mCRPC Before Sequencing \\
\hline RJ1 & Abiraterone & RJ38 & Treatment-naïve \\
\hline RJ2 & Abiraterone & RJ101 & Abiraterone \\
\hline RJ3 & Treatment-naïve & RJ104 & Abiraterone \\
\hline RJ4 & Treatment-naïve & RJ111 & Abiraterone \\
\hline RJ5 & Abiraterone and docetaxel & RJ112 & Treatment-naïve \\
\hline RJ6 & Docetaxel & RJ113 & Abiraterone and docetaxel \\
\hline RJ7 & Treatment-naïve & RJ114 & Docetaxel, abiraterone, and platinum \\
\hline RJ8 & Docetaxel and abiraterone & RJ91 & Abiraterone and docetaxel \\
\hline RJ9 & Treatment-naïve & RJ122 & Abiraterone \\
\hline RJ10 & Treatment-naïve & RJ133 & Abiraterone and docetaxel \\
\hline RJ11 & Abiraterone & RJ157 & Treatment-naïve \\
\hline RJ12-1 & Treatment-naïve & RJ158 & Docetaxel \\
\hline RJ12-2 & Docetaxel and abiraterone & SY3 & Docetaxel and platinum \\
\hline RJ13 & Treatment-naïve & SY4 & Docetaxel \\
\hline RJ14 & Treatment-naïve & SY5 & Abiraterone and docetaxel \\
\hline RJ15 & Treatment-naïve & SY17 & Treatment-naïve \\
\hline RJ16 & Treatment-naïve & SY18 & Docetaxel, abiraterone, and olaparib \\
\hline RJ17 & Treatment-naïve & SY23 & Docetaxel \\
\hline RJ18 & Treatment-naïve & SY26 & Abiraterone \\
\hline RJ19 & Treatment-naïve & SY27 & Docetaxel \\
\hline RJ20 & Treatment-naïve & SY28 & Paclitaxel liposome \\
\hline RJ21 & Treatment-naïve & SY29 & Treatment-naïve \\
\hline RJ22-1 & Treatment-naïve & sY30 & Docetaxel and abiraterone \\
\hline RJ22-2 & Abiraterone & & \\
\hline RJ23-1 & Treatment-naïve & & \\
\hline RJ23-2 & Docetaxel & & \\
\hline RJ24 & Abiraterone & & \\
\hline RJ25 & Abiraterone & & \\
\hline RJ26 & Treatment-naïve & & \\
\hline RJ27 & Docetaxel & & \\
\hline RJ28 & Treatment-naïve & & \\
\hline RJ29 & Treatment-naïve & & \\
\hline RJ30 & Docetaxel & & \\
\hline RJ31 & Treatment-naïve & & \\
\hline RJ32 & Abiraterone, enzalutamide, and docetaxel & & \\
\hline RJ33 & Abiraterone and docetaxel & & \\
\hline RJ34 & Abiraterone & & \\
\hline RJ35 & Docetaxel and abiraterone & & \\
\hline RJ36 & Abiraterone & & \\
\hline RJ37 & Abiraterone & & \\
\hline RJ38 & Treatment-naïve & & \\
\hline RJ39 & Treatment-naïve & & \\
\hline RJ40 & Docetaxel & & \\
\hline
\end{tabular}


eTable 1. Treatment State Before Collection of 306 ctDNA Samples and 23 Tumor Tissues (cont.)

Before ctDNA Sample Collection

Before Tumor Tissue Collection

\begin{tabular}{|c|c|c|}
\hline Patient ID & Treatment for mCRPC Before Sequencing & Treatment for mCRPC Before Sequencing \\
\hline RJ41 & Abiraterone & \\
\hline RJ42 & Treatment-naïve & \\
\hline RJ43 & Treatment-naïve & \\
\hline RJ44 & Treatment-naïve & \\
\hline RJ45 & Abiraterone and docetaxel & \\
\hline RJ46 & Abiraterone & \\
\hline RJ47 & Treatment-naïve & \\
\hline RJ48 & Treatment-naïve & \\
\hline RJ49 & Treatment-naïve & \\
\hline RJ50 & Treatment-naïve & \\
\hline RJ51 & Treatment-naïve & \\
\hline RJ52 & Abiraterone and docetaxel & \\
\hline RJ53 & Docetaxel & \\
\hline RJ54 & Treatment-naïve & \\
\hline RJ55 & Abiraterone & \\
\hline RJ56 & Treatment-naïve & \\
\hline RJ57 & Treatment-naïve & \\
\hline RJ58 & Abiraterone & \\
\hline RJ59 & Abiraterone & \\
\hline RJ60 & Treatment-naïve & \\
\hline RJ61 & Treatment-naïve & \\
\hline RJ62 & Abiraterone and docetaxel & \\
\hline RJ63 & Abiraterone and docetaxel & \\
\hline RJ64 & Abiraterone & \\
\hline RJ65 & Abiraterone & \\
\hline RJ66 & Treatment-naïve & \\
\hline RJ67 & Treatment-naïve & \\
\hline RJ68 & Abiraterone & \\
\hline RJ69 & Abiraterone & \\
\hline RJ70 & Abiraterone and docetaxel & \\
\hline RJ71 & Treatment-naïve & \\
\hline RJ72 & Abiraterone and docetaxel & \\
\hline RJ73 & Abiraterone & \\
\hline RJ74 & Treatment-naïve & \\
\hline RJ75 & Treatment-naïve & \\
\hline RJ76 & Docetaxel & \\
\hline RJ77 & Docetaxel & \\
\hline RJ78 & Abiraterone & \\
\hline RJ79 & Treatment-naïve & \\
\hline RJ80 & Treatment-naïve & \\
\hline RJ81 & Treatment-naïve & \\
\hline RJ82 & Treatment-naïve & \\
\hline RJ83 & Abiraterone & \\
\hline
\end{tabular}




\section{eTable 1. Treatment State Before Collection of 306 ctDNA Samples and 23 Tumor Tissues (cont.)}

Before ctDNA Sample Collection

\begin{tabular}{|c|c|c|}
\hline Patient ID & Treatment for mCRPC Before Sequencing & Treatment for mCRPC Before Sequencing \\
\hline RJ84 & Abiraterone & \\
\hline RJ85 & Abiraterone & \\
\hline RJ86 & Treatment-naïve & \\
\hline RJ87 & Abiraterone & \\
\hline RJ88 & Abiraterone & \\
\hline RJ89 & Abiraterone & \\
\hline RJ90 & Treatment-naïve & \\
\hline RJ91 & Abiraterone and docetaxel & \\
\hline RJ92 & Treatment-naïve & \\
\hline RJ93 & Treatment-naïve & \\
\hline RJ94 & Treatment-naïve & \\
\hline RJ95 & Docetaxel & \\
\hline RJ96 & Abiraterone & \\
\hline RJ97 & Treatment-naïve & \\
\hline RJ98 & Treatment-naïve & \\
\hline RJ99 & Abiraterone and docetaxel & \\
\hline RJ100 & Abiraterone & \\
\hline RJ101 & Abiraterone & \\
\hline RJ102 & Abiraterone and enzalutamide & \\
\hline RJ103 & Abiraterone & \\
\hline RJ104-1 & Abiraterone & \\
\hline RJ104-2 & Abiraterone and olaparib & \\
\hline RJ105-1 & Abiraterone & \\
\hline RJ105-2 & Abiraterone and docetaxel & \\
\hline RJ106-1 & Treatment-naïve & \\
\hline RJ106-2 & Abiraterone and docetaxel & \\
\hline RJ107-1 & Treatment-naïve & \\
\hline RJ107-2 & Docetaxel & \\
\hline RJ108-1 & Treatment-naïve & \\
\hline RJ108-2 & Docetaxel & \\
\hline RJ109-1 & Treatment-naïve & \\
\hline RJ109-2 & Abiraterone and docetaxel & \\
\hline RJ110-1 & Treatment-naïve & \\
\hline RJ110-2 & Abiraterone and docetaxel & \\
\hline RJ111-1 & Abiraterone & \\
\hline RJ111-2 & Abiraterone and docetaxel & \\
\hline RJ112-1 & Treatment-naïve & \\
\hline RJ112-2 & Docetaxel & \\
\hline RJ113-1 & Treatment-naïve & \\
\hline RJ113-2 & Abiraterone and docetaxel & \\
\hline RJ114-1 & Docetaxel & \\
\hline RJ114-2 & Docetaxel and abiraterone & \\
\hline RJ115 & Abiraterone and enzalutamide & \\
\hline
\end{tabular}


eTable 1. Treatment State Before Collection of 306 ctDNA Samples and 23 Tumor Tissues (cont.)

Before ctDNA Sample Collection

Before Tumor Tissue Collection

\begin{tabular}{|c|c|c|}
\hline Patient ID & Treatment for mCRPC Before Sequencing & Treatment for mCRPC Before Sequencing \\
\hline RJ116 & Docetaxel & \\
\hline RJ117 & Treatment-naïve & \\
\hline RJ118 & Treatment-naïve & \\
\hline RJ119 & Abiraterone and olaparib & \\
\hline RJ120 & Abiraterone & \\
\hline RJ121 & Treatment-naïve & \\
\hline RJ122 & Abiraterone & \\
\hline RJ123 & Abiraterone & \\
\hline RJ124 & Abiraterone & \\
\hline RJ125 & Treatment-naïve & \\
\hline RJ126 & Docetaxel & \\
\hline RJ127 & Abiraterone and docetaxel & \\
\hline RJ128 & Abiraterone and docetaxel & \\
\hline RJ129 & Docetaxel & \\
\hline RJ130 & Docetaxel & \\
\hline RJ131 & Docetaxel & \\
\hline RJ132 & Treatment-naïve & \\
\hline RJ133 & Abiraterone and docetaxel & \\
\hline RJ134 & Abiraterone & \\
\hline RJ135 & Docetaxel & \\
\hline RJ136 & Treatment-naïve & \\
\hline RJ137 & Abiraterone & \\
\hline RJ138 & Docetaxel and abiraterone & \\
\hline RJ139 & Abiraterone & \\
\hline RJ140 & Abiraterone & \\
\hline RJ141 & Abiraterone & \\
\hline RJ142 & Docetaxel and abiraterone & \\
\hline RJ143 & Docetaxel & \\
\hline RJ144 & Docetaxel & \\
\hline RJ145 & Treatment-naïve & \\
\hline RJ146 & Abiraterone & \\
\hline RJ147 & Abiraterone & \\
\hline RJ148 & Abiraterone & \\
\hline RJ149 & Abiraterone & \\
\hline RJ150 & Treatment-naïve & \\
\hline RJ151 & Treatment-naïve & \\
\hline RJ152 & Treatment-naïve & \\
\hline RJ153 & Docetaxel and abiraterone & \\
\hline RJ154 & Abiraterone & \\
\hline RJ155 & Abiraterone and olaparib & \\
\hline RJ156 & Abiraterone & \\
\hline RJ157 & Treatment-naïve & \\
\hline RJ158 & Docetaxel & \\
\hline
\end{tabular}




\section{eTable 1. Treatment State Before Collection of 306 ctDNA Samples and 23 Tumor Tissues (cont.)}

Before ctDNA Sample Collection

\begin{tabular}{|c|c|c|c|}
\hline Patient ID & Treatment for mCRPC Before Sequencing & Patient ID & Treatment for mCRPC Before Sequencing \\
\hline SY1 & Abiraterone & & \\
\hline SY2 & Abiraterone & & \\
\hline SY3 & Docetaxel and platinum & & \\
\hline SY4 & Docetaxel & & \\
\hline SY5 & Abiraterone and docetaxel & & \\
\hline SY6 & Treatment-naïve & & \\
\hline SY7 & Docetaxel and abiraterone & & \\
\hline SY8 & Docetaxel & & \\
\hline SY9 & Abiraterone and enzalutamide & & \\
\hline SY10 & Abiraterone and docetaxel & & \\
\hline SY11 & Abiraterone and docetaxel & & \\
\hline SY12 & Docetaxel, abiraterone, and enzalutamide & & \\
\hline SY13 & Abiraterone, docetaxel, and platinum & & \\
\hline SY14 & Abiraterone & & \\
\hline SY15 & Abiraterone, docetaxel, and olaparib & & \\
\hline SY16 & Docetaxel & & \\
\hline SY17 & Treatment-naïve & & \\
\hline SY18 & Docetaxel, abiraterone, and olaparib & & \\
\hline SY19 & Treatment-naïve & & \\
\hline SY20 & Treatment-naïve & & \\
\hline SY21 & Treatment-naïve & & \\
\hline SY22 & Docetaxel & & \\
\hline SY23 & Docetaxel & & \\
\hline SY24 & Treatment-naïve & & \\
\hline SY25 & Treatment-naïve & & \\
\hline SY26 & Abiraterone & & \\
\hline SY27 & Docetaxel & & \\
\hline SY28 & Paclitaxel liposome & & \\
\hline SY29 & Treatment-naïve & & \\
\hline SY30 & Docetaxel and abiraterone & & \\
\hline ZZ1 & Abiraterone & & \\
\hline ZZ2 & Abiraterone & & \\
\hline ZZ3 & Radium-223 and abiraterone & & \\
\hline ZZ4 & Abiraterone & & \\
\hline ZZ5 & Docetaxel & & \\
\hline ZZ6 & Abiraterone & & \\
\hline ZZ7 & Abiraterone & & \\
\hline ZZ8 & Docetaxel and abiraterone & & \\
\hline ZZ9 & Abiraterone and docetaxel & & \\
\hline ZZ10 & Abiraterone & & \\
\hline ZZ11 & Abiraterone & & \\
\hline ZZ12 & Docetaxel & & \\
\hline ZZ13 & Abiraterone & & \\
\hline
\end{tabular}


eTable 1. Treatment State Before Collection of 306 ctDNA Samples and 23 Tumor Tissues (cont.)

Before ctDNA Sample Collection

Before Tumor Tissue Collection

\begin{tabular}{|c|c|c|}
\hline Patient ID & Treatment for mCRPC Before Sequencing & Treatment for mCRPC Before Sequencing \\
\hline ZZ14 & Docetaxel and abiraterone & \\
\hline ZZ15 & Abiraterone & \\
\hline ZZ16 & Docetaxel & \\
\hline ZZ17 & Abiraterone & \\
\hline ZZ18 & Treatment-naïve & \\
\hline ZZ19 & Docetaxel and abiraterone & \\
\hline ZZ20 & Docetaxel and abiraterone & \\
\hline ZZ21 & Abiraterone and docetaxel & \\
\hline ZZ22 & Abiraterone and docetaxel & \\
\hline ZZ23 & Abiraterone and enzalutamide & \\
\hline ZZ24 & Docetaxel and abiraterone & \\
\hline ZZ25 & Abiraterone & \\
\hline ZZ26 & Abiraterone & \\
\hline ZZ27 & Abiraterone & \\
\hline ZZ28 & Abiraterone & \\
\hline ZZ29 & Abiraterone & \\
\hline WY1 & Docetaxel and abiraterone & \\
\hline WY2 & Abiraterone & \\
\hline WY3 & Abiraterone and docetaxel & \\
\hline WY4 & Docetaxel & \\
\hline WY5 & Docetaxel and abiraterone & \\
\hline WY6 & Abiraterone and docetaxel & \\
\hline WY7 & Docetaxel & \\
\hline WY8 & Abiraterone and docetaxel & \\
\hline WY9 & Treatment-naïve & \\
\hline WY10 & Docetaxel and darolutamide & \\
\hline WY11 & Docetaxel and abiraterone & \\
\hline WY12 & Docetaxel and Abiraterone & \\
\hline WY13 & Abiraterone, docetaxel, and enzalutamide & \\
\hline WY14 & Abiraterone, enzalutamide, and docetaxel & \\
\hline WY15 & Abiraterone and docetaxel & \\
\hline WY16 & Abiraterone and docetaxel & \\
\hline WY17 & Abiraterone and docetaxel & \\
\hline WY18 & Abiraterone & \\
\hline WY19 & Abiraterone & \\
\hline WY20 & Treatment-naïve & \\
\hline WY21 & Abiraterone & \\
\hline WY22 & Abiraterone and docetaxel & \\
\hline WY23 & Docetaxel & \\
\hline WY24 & Docetaxel and abiraterone & \\
\hline WY25 & Docetaxel and abiraterone & \\
\hline WY26 & Docetaxel and abiraterone & \\
\hline WY27 & Treatment-naïve & \\
\hline
\end{tabular}




\section{eTable 1. Treatment State Before Collection of 306 ctDNA Samples and 23 Tumor Tissues (cont.)}

Before ctDNA Sample Collection

\begin{tabular}{|c|c|c|}
\hline Patient ID & Treatment for mCRPC Before Sequencing & Treatment for mCRPC Before Sequencing \\
\hline BYY1 & Treatment-naïve & \\
\hline BYY2 & Abiraterone and docetaxel & \\
\hline BYY3 & Abiraterone & \\
\hline BYY4 & Abiraterone & \\
\hline BYY5 & Docetaxel & \\
\hline BYY6 & Abiraterone & \\
\hline BYY7 & Enzalutamide and abiraterone & \\
\hline BYY8 & Abiraterone & \\
\hline BYY9 & Abiraterone and enzalutamide & \\
\hline BYY10 & Treatment-naïve & \\
\hline BYY11 & Treatment-naïve & \\
\hline BYY12 & Abiraterone and docetaxel & \\
\hline BYY13 & Abiraterone & \\
\hline BYY14 & Abiraterone & \\
\hline BYY15 & Abiraterone & \\
\hline BYY16 & Abiraterone & \\
\hline BYY17 & Abiraterone & \\
\hline BYY18 & Abiraterone & \\
\hline BYY19 & Abiraterone & \\
\hline BYY20 & Docetaxel and abiraterone & \\
\hline BYY21 & Abiraterone & \\
\hline BYY22 & Abiraterone & \\
\hline BYY23 & Treatment-naïve & \\
\hline BYY24 & Abiraterone & \\
\hline BYY25 & Abiraterone & \\
\hline BYY26 & Abiraterone & \\
\hline XJ1 & Docetaxel & \\
\hline $\mathrm{XJ} 2$ & Treatment-naïve & \\
\hline $\mathrm{XJ3}$ & Docetaxel & \\
\hline $\mathrm{XJ} 4$ & Docetaxel & \\
\hline XJ5 & Docetaxel and abiraterone & \\
\hline XJ6 & Abiraterone & \\
\hline $\mathrm{XJ7}$ & Abiraterone and docetaxel & \\
\hline $\mathrm{XJ8}$ & Docetaxel & \\
\hline XJ9 & Abiraterone & \\
\hline $\mathrm{FY} 1$ & Treatment-naïve & \\
\hline FY2 & Treatment-naïve & \\
\hline FY3 & Treatment-naïve & \\
\hline FY4 & Treatment-naïve & \\
\hline FY5 & Docetaxel and abiraterone & \\
\hline FY6 & Abiraterone & \\
\hline FY7 & Treatment-naïve & \\
\hline ZR1 & Treatment-naïve & \\
\hline
\end{tabular}


16 - Dong et al

\section{eTable 1. Treatment State Before Collection of 306 ctDNA Samples and 23 Tumor Tissues (cont.)}

Before ctDNA Sample Collection

Before Tumor Tissue Collection

\begin{tabular}{|c|c|c|c|}
\hline Patient ID & Treatment for mCRPC Before Sequencing & Patient ID & Treatment for mCRPC Before Sequencing \\
\hline ZR2 & Abiraterone and docetaxel & & \\
\hline ZR3 & Abiraterone & & \\
\hline ZR4 & Docetaxel and abiraterone & & \\
\hline ZR5 & Abiraterone & & \\
\hline ZR6 & Abiraterone and docetaxel & & \\
\hline
\end{tabular}

Abbreviations: ctDNA, circulating tumor DNA; mCRPC, metastatic castration-resistant prostate cancer. 


\section{eTable 2. List of Common 50 Genes in 50-Gene,} 66-Gene, 620-Gene, and 642-Gene Capture Panels

\begin{tabular}{|ll|}
\hline AR & CHEK2 \\
\hline BARD1 & ERCC2 \\
\hline BRIPH1 & ERCC3 \\
\hline EPCAM & ERCC4 \\
\hline ESR1 & ERCC5 \\
\hline FAM175A & FANCA \\
\hline FOXA1 & FANCD2 \\
\hline GEN1 & HDAC2 \\
\hline IDH1 & MLH1 \\
\hline MUTYH & MLH3 \\
\hline NBN & MRE11A \\
\hline NCOR1 & MSH2 \\
\hline NCOR2 & MSH6 \\
\hline PTEN & PALB2 \\
\hline SPOP & PMS1 \\
\hline STK11 & PMS2 \\
\hline ZBTB16 & POLD1 \\
\hline RB1 & POLE \\
\hline TP53 & RAD51 \\
\hline ATM & RAD51B \\
\hline ATR & RAD51C \\
\hline BRCA1 & XRCC4 \\
\hline BRCA2 & RAD50 \\
\hline CDK12 & RAD51D \\
\hline & HOXB13 \\
\hline
\end{tabular}


eTable 3. Clinical Characteristics of 306 ctDNA Samples From 292 Patients

\begin{tabular}{|c|c|c|c|c|c|c|c|c|c|c|c|c|}
\hline $\begin{array}{l}\text { Patient } \\
\text { ID }\end{array}$ & $\begin{array}{c}\text { Age at } \\
\text { Baseline } \\
\text { (y) }\end{array}$ & $\begin{array}{c}\text { Gleason } \\
\text { Score }\end{array}$ & $\begin{array}{c}\text { PSA } \\
\text { (ng/mL) }\end{array}$ & $\begin{array}{c}\text { Time From } \\
\text { ADT } \\
\text { Initiation } \\
\text { to mCRPC } \\
\text { (mo) }\end{array}$ & $\begin{array}{c}\text { cfDNA } \\
\text { Yield } \\
\text { (ng/mL } \\
\text { plasma) }\end{array}$ & $\begin{array}{c}\text { ctDNA } \\
(\%)\end{array}$ & $\begin{array}{c}\text { Lymph } \\
\text { Node } \\
\text { Metastasis }\end{array}$ & $\begin{array}{c}\text { Bone } \\
\text { Metastases }\end{array}$ & $\begin{array}{c}\text { Visceral } \\
\text { Metastasis }\end{array}$ & $\begin{array}{l}\text { Follow- } \\
\text { Up (d) }\end{array}$ & $\begin{array}{c}\text { Status at } \\
\text { Last } \\
\text { Follow- } \\
\text { Up }\end{array}$ & $\begin{array}{c}\text { Gene } \\
\text { Panel } \\
\text { Sequenced }\end{array}$ \\
\hline RJ2 & 72 & 8 & 22.2 & 7.7 & 14.8 & 32.7 & Yes & Yes & No & 933 & Alive & 50-gene \\
\hline RJ3 & 66 & 7 & 6.4 & 13.7 & 16.5 & 30.8 & Yes & Yes & No & 933 & Alive & 50-gene \\
\hline RJ5 & 74 & 8 & 96.2 & 10.8 & 14.9 & 0 & Yes & Yes & No & 1,133 & Alive & 50-gene \\
\hline RJ6 & 71 & 8 & 52.3 & 10.8 & 9.8 & 0 & Yes & Yes & No & 1,115 & Alive & 50-gene \\
\hline RJ7 & 74 & 7 & 46 & 28 & 70.2 & 22.8 & Yes & Yes & No & 1,121 & Alive & 50-gene \\
\hline RJ8 & 71 & 7 & 17.7 & 102 & 27 & 2.4 & Yes & Yes & No & 779 & Alive & 50-gene \\
\hline RJ9 & 68 & 7 & 68 & 35.5 & 9 & 0 & Yes & Yes & No & 699 & Alive & 50-gene \\
\hline RJ12-2 & 61 & 9 & Unknown & 52.4 & 18.6 & 0 & Yes & Yes & No & 171 & Alive & 66-gene \\
\hline RJ13 & 69 & 8 & 5 & 20.4 & 15.9 & 0 & Yes & Yes & No & 954 & Alive & 50-gene \\
\hline RJ14 & 72 & 7 & 77.7 & 6.6 & 16.1 & 22.7 & Yes & Yes & No & 993 & Alive & 50-gene \\
\hline RJ15 & 66 & 10 & 15.3 & 14.5 & 18.6 & 2.3 & Yes & Yes & No & 1,032 & Alive & 50-gene \\
\hline RJ16 & 67 & 9 & 5.5 & 11.5 & 14.4 & 28.9 & Yes & Yes & No & 1,049 & Alive & 50-gene \\
\hline RJ17 & 78 & 9 & $>154$ & 9.9 & 13.5 & 0 & Yes & Yes & No & 1,032 & Alive & 50-gene \\
\hline RJ18 & 76 & 7 & $>154$ & 12.3 & 9.1 & 3.7 & Yes & Yes & No & 963 & Alive & 50-gene \\
\hline RJ19 & 84 & 7 & 10.6 & 30 & 12 & 2.3 & Yes & Yes & No & 1,052 & Alive & 50-gene \\
\hline RJ20 & 64 & 8 & 25.6 & 40.9 & 6 & 6 & Yes & Yes & No & 1,053 & Alive & 50-gene \\
\hline RJ25 & 68 & 9 & 126.9 & 17.1 & 130.5 & 64.8 & Yes & Yes & No & 1,004 & Alive & 50-gene \\
\hline RJ26 & 67 & 9 & 10.9 & 14.1 & 4.1 & 6.5 & Yes & Yes & No & 1,034 & Alive & 50-gene \\
\hline RJ27 & 62 & 8 & $>152$ & 27 & 29.6 & 38.6 & Yes & Yes & No & 911 & Alive & 50-gene \\
\hline RJ28 & 67 & 9 & 46 & 21.7 & 13.7 & 0 & Yes & Yes & No & 1,002 & Alive & 50-gene \\
\hline RJ29 & 67 & 7 & $2,067.5$ & 11.9 & 80.9 & 2.3 & Yes & Yes & No & 841 & Alive & 50-gene \\
\hline RJ30 & 68 & 9 & 30 & 27.3 & 10.5 & 3.5 & Yes & Yes & No & 1,060 & Alive & 50-gene \\
\hline RJ31 & 62 & 8 & 2,234 & 1.1 & 9.4 & 15.9 & Yes & Yes & No & 902 & Alive & 50-gene \\
\hline RJ32 & 72 & 7 & $>154$ & 30 & 13.8 & 15.5 & Yes & Yes & No & 705 & Alive & 50-gene \\
\hline RJ33 & 66 & 6 & $>154$ & 19 & 89.2 & 80.4 & Yes & Yes & No & 705 & Alive & 50-gene \\
\hline RJ34 & 66 & 8 & 6.7 & 18 & 7.3 & 0 & Yes & Yes & No & 699 & Alive & 50-gene \\
\hline RJ35 & 66 & 8 & $>100$ & 23 & 6.8 & 0 & Yes & Yes & No & 673 & Alive & 50-gene \\
\hline RJ36 & 78 & 8 & 220 & 16 & 8.1 & 0 & Yes & Yes & No & 671 & Alive & 50-gene \\
\hline RJ37 & 68 & 9 & 11 & 16 & 10.5 & 32.6 & Yes & Yes & No & 671 & Alive & 50-gene \\
\hline RJ38 & 54 & NEPC & 56 & Unknown & 160.8 & 73.7 & Yes & Yes & No & 659 & Alive & 50-gene \\
\hline
\end{tabular}




\section{eTable 3. Clinical Characteristics of 306 ctDNA Samples From 292 Patients (cont.)}

\begin{tabular}{|c|c|c|c|c|c|c|c|c|c|c|c|c|}
\hline $\begin{array}{l}\text { Patient } \\
\text { ID }\end{array}$ & $\begin{array}{c}\text { Age at } \\
\text { Baseline } \\
\text { (y) }\end{array}$ & $\begin{array}{c}\text { Gleason } \\
\text { Score }\end{array}$ & $\begin{array}{c}\text { PSA } \\
(\mathbf{n g} / \mathrm{mL})\end{array}$ & $\begin{array}{c}\text { Time From } \\
\text { ADT } \\
\text { Initiation } \\
\text { to mCRPC } \\
\text { (mo) }\end{array}$ & $\begin{array}{c}\text { cfDNA } \\
\text { Yield } \\
\text { (ng/mL } \\
\text { plasma) }\end{array}$ & $\begin{array}{c}\text { ctDNA } \\
(\%)\end{array}$ & $\begin{array}{c}\text { Lymph } \\
\text { Node } \\
\text { Metastasis }\end{array}$ & $\begin{array}{c}\text { Bone } \\
\text { Metastases }\end{array}$ & $\begin{array}{c}\text { Visceral } \\
\text { Metastasis }\end{array}$ & $\begin{array}{l}\text { Follow- } \\
\text { Up (d) }\end{array}$ & $\begin{array}{c}\text { Status at } \\
\text { Last } \\
\text { Follow- } \\
\text { Up }\end{array}$ & $\begin{array}{c}\text { Gene } \\
\text { Panel } \\
\text { Sequenced }\end{array}$ \\
\hline RJ39 & 59 & 9 & 3.7 & 27 & 8.4 & 0 & Yes & Yes & No & 659 & Alive & 50 -gene \\
\hline RJ40 & 78 & 7 & 32.2 & 7 & 16.6 & 11.5 & Yes & Yes & No & 649 & Alive & 50-gene \\
\hline RJ41 & 71 & 8 & 19.8 & 24 & 9 & 0 & Yes & Yes & No & 642 & Alive & 50-gene \\
\hline RJ42 & 63 & 7 & 173 & 41 & 13.4 & 35.3 & Yes & Yes & No & 613 & Alive & 50-gene \\
\hline RJ43 & 76 & 7 & 12.2 & 84 & 10.9 & 0 & Yes & Yes & No & 596 & Alive & 50-gene \\
\hline RJ44 & 77 & 8 & 1,132 & 108 & 50.2 & 39 & Yes & No & Yes & 596 & Alive & 50-gene \\
\hline RJ45 & 72 & 9 & $>154$ & 24 & 8.2 & 8.5 & Yes & Yes & No & 593 & Alive & 50-gene \\
\hline RJ46 & 69 & 7 & 42.9 & 20 & 3.3 & 1.4 & Yes & Yes & No & 589 & Alive & 50-gene \\
\hline RJ47 & 84 & 8 & 456 & 18 & 14.1 & 1.9 & Yes & Yes & No & 586 & Alive & 50-gene \\
\hline RJ48 & 80 & 6 & 17.5 & 96 & 10.8 & 3.8 & Yes & Yes & No & 579 & Alive & 50-gene \\
\hline RJ49 & 70 & 7 & 34.6 & 41 & 14.1 & 0 & Yes & Yes & No & 568 & Alive & 50-gene \\
\hline RJ50 & 66 & 9 & 42.5 & 28 & 10 & 0 & Yes & Yes & No & 564 & Alive & 50-gene \\
\hline RJ51 & 68 & 9 & 77 & 36 & 10.7 & 28.5 & Yes & Yes & No & 558 & Alive & 50-gene \\
\hline RJ52 & 72 & 9 & 27 & 16 & 11 & 1.8 & Yes & Yes & No & 719 & Alive & 50-gene \\
\hline RJ53 & 71 & NEPC & 0.7 & 96 & 36.3 & 31.3 & Yes & No & Yes & 533 & Alive & 50-gene \\
\hline RJ54 & 71 & 9 & 12.3 & 22 & 12.4 & 0 & Yes & Yes & No & 511 & Alive & 50-gene \\
\hline RJ55 & 70 & 8 & 46 & 50 & 15.8 & 6.7 & Yes & Yes & No & 509 & Alive & 50-gene \\
\hline RJ56 & 69 & 7 & 34.5 & 48 & 11.4 & 0 & Yes & Yes & No & 509 & Alive & 50-gene \\
\hline RJ57 & 74 & 8 & 6.8 & 120 & 12.4 & 0 & Yes & Yes & No & 509 & Alive & 50-gene \\
\hline RJ58 & 55 & 9 & 5.9 & 9 & 7.7 & 0 & Yes & Yes & No & 502 & Alive & 50-gene \\
\hline RJ59 & 80 & 7 & 13.4 & 12 & 8.7 & 0 & Yes & Yes & No & 498 & Alive & 50-gene \\
\hline RJ60 & 65 & NEPC & 2.2 & Unknown & 1,060 & 0 & Yes & Yes & Yes & 725 & Alive & 620-gene \\
\hline RJ61 & 68 & NEPC & 1.9 & Unknown & 57.4 & 0 & Yes & Yes & Yes & 558 & Alive & 620-gene \\
\hline RJ62 & 68 & 8 & 47.9 & 60 & 16 & 9.8 & Yes & Yes & No & 756 & Alive & 620-gene \\
\hline RJ63 & 76 & 7 & 110 & 40 & 26.1 & 22.3 & Yes & Yes & No & 551 & Alive & 620-gene \\
\hline RJ64 & 66 & 8 & 11.9 & 18 & 38 & 0 & Yes & Yes & No & 532 & Alive & 620-gene \\
\hline RJ65 & 83 & 7 & 1231 & 48 & 47 & 55.6 & Yes & Yes & No & 381 & Alive & 620-gene \\
\hline RJ66 & 61 & 9 & 16.7 & 10 & 5.8 & 1.7 & Yes & Yes & No & 367 & Alive & 620-gene \\
\hline RJ67 & 64 & 8 & 18.4 & 19 & 11.1 & 0 & Yes & Yes & No & 366 & Alive & 620-gene \\
\hline RJ68 & 74 & 8 & 32 & 19 & 11.7 & 13.4 & Yes & Yes & No & 428 & Alive & 620-gene \\
\hline RJ69 & 80 & 8 & 34.6 & 26 & 41.8 & 0 & Yes & Yes & No & 484 & Alive & 66-gene \\
\hline RJ70 & 70 & 7 & 327 & 20 & 485.8 & 66.3 & Yes & Yes & No & 480 & Alive & 66-gene \\
\hline RJ71 & 71 & 7 & 13.8 & 24 & 10.8 & 5.7 & Yes & Yes & No & 479 & Alive & 66-gene \\
\hline RJ72 & 78 & 8 & 52.3 & 32 & 1.1 & 3 & Yes & Yes & No & 469 & Alive & 66-gene \\
\hline RJ73 & 68 & 8 & 571.4 & 17 & 19.3 & 52.7 & Yes & Yes & No & 462 & Alive & 66-gene \\
\hline RJ74 & 67 & 7 & 313.9 & 36 & 105.6 & 59.5 & Yes & Yes & No & 459 & Alive & 66-gene \\
\hline RJ75 & 65 & 8 & 17.8 & 23 & 15 & 1 & Yes & Yes & No & 459 & Alive & 66-gene \\
\hline RJ76 & 83 & 10 & 372 & 20 & 11.4 & 50.4 & Yes & Yes & No & 458 & Alive & 66-gene \\
\hline RJ77 & 59 & 9 & 278 & 29 & 11.5 & 7.2 & Yes & Yes & No & 449 & Alive & 66-gene \\
\hline RJ78 & 72 & 8 & 32.7 & 20 & 6.2 & 0 & Yes & Yes & No & 449 & Alive & 66-gene \\
\hline RJ79 & 73 & 7 & 22.6 & 20 & 8.3 & 2.4 & Yes & Yes & No & 438 & Alive & 66-gene \\
\hline
\end{tabular}


eTable 3. Clinical Characteristics of 306 ctDNA Samples From 292 Patients (cont.)

\begin{tabular}{|c|c|c|c|c|c|c|c|c|c|c|c|c|}
\hline $\begin{array}{l}\text { Patient } \\
\text { ID }\end{array}$ & $\begin{array}{c}\text { Age at } \\
\text { Baseline } \\
\text { (y) }\end{array}$ & $\begin{array}{c}\text { Gleason } \\
\text { Score }\end{array}$ & $\underset{\text { (ng/mL) }}{\text { PSA }}$ & $\begin{array}{c}\text { Time From } \\
\text { ADT } \\
\text { Initiation } \\
\text { to mCRPC } \\
(\mathrm{mo})\end{array}$ & $\begin{array}{c}\text { cfDNA } \\
\text { Yield } \\
\text { (ng/mL } \\
\text { plasma) }\end{array}$ & $\begin{array}{c}\text { ctDNA } \\
(\%)\end{array}$ & $\begin{array}{c}\text { Lymph } \\
\text { Node } \\
\text { Metastasis }\end{array}$ & $\begin{array}{c}\text { Bone } \\
\text { Metastases }\end{array}$ & $\begin{array}{c}\text { Visceral } \\
\text { Metastasis }\end{array}$ & $\begin{array}{l}\text { Follow- } \\
\text { Up (d) }\end{array}$ & $\begin{array}{c}\text { Status at } \\
\text { Last } \\
\text { Follow- } \\
\text { Up }\end{array}$ & $\begin{array}{c}\text { Gene } \\
\text { Panel } \\
\text { Sequenced }\end{array}$ \\
\hline RJ81 & 73 & 8 & 33.8 & 19 & 124.6 & 5.2 & Yes & Yes & No & 154 & Dead & 66-gene \\
\hline RJ82 & 72 & 7 & 12.6 & 24 & 27.9 & 2.1 & Yes & Yes & No & 428 & Alive & 66-gene \\
\hline RJ84 & 82 & 8 & 4.5 & 36 & 20 & 0 & Yes & Yes & No & 413 & Alive & 66-gene \\
\hline RJ85 & 63 & 9 & 243.2 & 8 & 31 & 35.4 & Yes & Yes & No & 413 & Alive & 66-gene \\
\hline RJ86 & 63 & 8 & 72.8 & Unknown & 18.6 & 32.6 & Yes & Yes & No & 413 & Alive & 66-gene \\
\hline RJ87 & 78 & 10 & 158 & 10 & 33.8 & 25.9 & Yes & Yes & No & 406 & Alive & 66-gene \\
\hline RJ88 & 65 & 8 & 277.2 & 48 & 71.5 & 35.5 & Yes & Yes & No & 406 & Alive & 66-gene \\
\hline RJ92 & 62 & 7 & 45.2 & 12 & 960 & 3.8 & Yes & Yes & No & 60 & Dead & 66-gene \\
\hline RJ93 & 68 & 8 & 3.2 & 60 & 13.4 & 0 & Yes & Yes & No & 386 & Alive & 66-gene \\
\hline RJ94 & 86 & 8 & 1,234 & 40 & 18.7 & 43.7 & Yes & Yes & No & 383 & Alive & 66-gene \\
\hline RJ95 & 73 & 8 & 10.8 & 22 & 8.1 & 2.9 & Yes & Yes & No & 378 & Alive & 66-gene \\
\hline RJ96 & 83 & 8 & 29.8 & 36 & 12.5 & 0 & Yes & Yes & No & 375 & Alive & 66-gene \\
\hline RJ97 & 70 & 8 & 4.9 & 30 & 10.1 & 1.7 & Yes & No & No & 372 & Alive & 66-gene \\
\hline RJ98 & 80 & 7 & 9.7 & 22 & 10.3 & 0 & Yes & Yes & No & 370 & Alive & 66-gene \\
\hline RJ99 & 62 & 9 & 233.2 & 16 & 113 & 27.8 & Yes & Yes & No & 418 & Alive & 66-gene \\
\hline RJ100 & 76 & 9 & 32 & 15 & 5.3 & 0 & Yes & No & No & 431 & Alive & 66-gene \\
\hline RJ105-2 & 67 & 8 & 4.4 & 38.6 & 39.2 & 50.2 & Yes & Yes & No & 705 & Alive & 50-gene \\
\hline RJ106-1 & 55 & 7 & 36.5 & 9.9 & 5.9 & 3 & Yes & Yes & No & 1,052 & Alive & 50-gene \\
\hline RJ106-2 & 55 & 7 & 36.5 & 9.9 & 7.7 & 2.4 & Yes & Yes & No & 656 & Alive & 50-gene \\
\hline RJ107-1 & 80 & 8 & 13 & 19.1 & 7.8 & 10.2 & Yes & Yes & No & 1,034 & Alive & 50-gene \\
\hline RJ107-2 & 80 & 8 & 32.2 & 19.1 & 8.4 & 0 & Yes & Yes & No & 498 & Alive & 620-gene \\
\hline RJ108-1 & 75 & 7 & 226.6 & 38.6 & 7.8 & 18.8 & Yes & Yes & No & 1,052 & Alive & 50-gene \\
\hline RJ108-2 & 75 & 7 & 65.9 & 38.6 & 23.9 & 38.2 & Yes & Yes & No & 488 & Alive & 620-gene \\
\hline RJ109-1 & 70 & 9 & 43.8 & 13 & 6.5 & 17.5 & Yes & Yes & No & 699 & Alive & 50-gene \\
\hline RJ109-2 & 70 & 9 & 16.9 & 5 & 16 & 6.6 & Yes & Yes & No & 528 & Alive & 50-gene \\
\hline RJ110-1 & 68 & 7 & 26 & 16 & 41 & 13.9 & Yes & Yes & No & 697 & Alive & 50-gene \\
\hline RJ110-2 & 68 & 7 & 137.1 & 16 & 9.4 & 2 & Yes & Yes & No & 372 & Alive & 50-gene \\
\hline RJ111-1 & 71 & 8 & 394.7 & 11 & 10 & 23 & Yes & Yes & No & 699 & Alive & 50-gene \\
\hline RJ111-2 & 71 & 8 & 1,256 & 11 & 114.3 & 80.9 & Yes & Yes & No & 537 & Alive & 620-gene \\
\hline RJ112-1 & 67 & 9 & 3.6 & 25.8 & 6.5 & 6.8 & Yes & Yes & No & 699 & Alive & 50-gene \\
\hline
\end{tabular}




\section{eTable 3. Clinical Characteristics of 306 ctDNA Samples From 292 Patients (cont.)}

\begin{tabular}{|c|c|c|c|c|c|c|c|c|c|c|c|c|}
\hline $\begin{array}{l}\text { Patient } \\
\text { ID }\end{array}$ & $\begin{array}{c}\text { Age at } \\
\text { Baseline } \\
\text { (y) }\end{array}$ & $\begin{array}{c}\text { Gleason } \\
\text { Score }\end{array}$ & $\begin{array}{c}\text { PSA } \\
(\mathbf{n g} / \mathrm{mL})\end{array}$ & $\begin{array}{c}\text { Time From } \\
\text { ADT } \\
\text { Initiation } \\
\text { to mCRPC } \\
\text { (mo) }\end{array}$ & $\begin{array}{c}\text { cfDNA } \\
\text { Yield } \\
\text { (ng/mL } \\
\text { plasma) }\end{array}$ & $\begin{array}{c}\text { ctDNA } \\
(\%)\end{array}$ & $\begin{array}{c}\text { Lymph } \\
\text { Node } \\
\text { Metastasis }\end{array}$ & $\begin{array}{c}\text { Bone } \\
\text { Metastases }\end{array}$ & $\begin{array}{c}\text { Visceral } \\
\text { Metastasis }\end{array}$ & $\begin{array}{l}\text { Follow- } \\
\text { Up (d) }\end{array}$ & $\begin{array}{c}\text { Status at } \\
\text { Last } \\
\text { Follow- } \\
\text { Up }\end{array}$ & $\begin{array}{c}\text { Gene } \\
\text { Panel } \\
\text { Sequenced }\end{array}$ \\
\hline RJ112-2 & 67 & 9 & 6.3 & 25.8 & 14.5 & 3.5 & Yes & Yes & No & 428 & Alive & 66-gene \\
\hline RJ113-1 & 67 & 8 & 26 & 10 & 15.2 & 4.2 & Yes & Yes & No & 719 & Alive & 50-gene \\
\hline RJ113-2 & 67 & 8 & 120 & 10 & 14.3 & 10.9 & Yes & Yes & No & 470 & Alive & 66-gene \\
\hline RJ114-1 & 47 & 9 & 20.4 & 12 & 8.8 & 0 & Yes & Yes & No & 523 & Alive & 50-gene \\
\hline RJ114-2 & 47 & 9 & 131 & 12 & 12.6 & 12.1 & Yes & Yes & No & 377 & Alive & 66-gene \\
\hline RJ115 & 74 & 8 & 49 & 36 & 15.5 & 51.9 & Yes & Yes & No & 719 & Alive & 50-gene \\
\hline RJ116 & 60 & 9 & 20 & 15 & 11.4 & 0 & Yes & Yes & No & 365 & Alive & 66-gene \\
\hline RJ117 & 70 & 7 & 1.2 & 84 & 11.3 & 1.6 & Yes & No & No & 320 & Alive & 66-gene \\
\hline RJ118 & 76 & 8 & $>100$ & 12 & 1,590 & 83 & Yes & Yes & No & 119 & Dead & 66-gene \\
\hline RJ119 & 44 & 9 & 2.6 & 12 & 9.2 & 3.2 & Yes & No & No & 294 & Alive & 66-gene \\
\hline RJ120 & 68 & Unknown & $>1,000$ & 18 & 144 & 31.9 & Yes & Yes & No & 126 & Dead & 66-gene \\
\hline RJ121 & 83 & 8 & 50 & 23 & 14.1 & 2.1 & Yes & Yes & No & 274 & Alive & 66-gene \\
\hline RJ122 & 72 & 9 & $>100$ & 18 & 44.4 & 49.9 & Yes & Yes & No & 89 & Dead & 66-gene \\
\hline RJ123 & 89 & Unknown & 98 & 16 & 36.8 & 78.1 & Yes & Yes & No & 83 & Dead & 66-gene \\
\hline RJ124 & 70 & Unknown & $>100$ & 24 & 144 & 33.6 & Yes & Yes & No & 264 & Alive & 66-gene \\
\hline RJ125 & 66 & 8 & 4 & 28 & 11.9 & 0 & Yes & No & No & 253 & Alive & 66-gene \\
\hline RJ126 & 73 & 8 & 2.8 & 18 & 15 & 0 & Yes & No & No & 311 & Alive & 66-gene \\
\hline RJ127 & 66 & 8 & 52.7 & 18 & 28.6 & 0 & Yes & No & No & 302 & Alive & 66-gene \\
\hline RJ128 & 55 & 8 & 552 & 8 & 9.6 & 0 & Yes & Yes & No & 297 & Alive & 66-gene \\
\hline RJ129 & 60 & Unknown & 99.4 & 24 & 19.1 & 4 & Yes & Yes & No & 255 & Alive & 66-gene \\
\hline RJ130 & 74 & 7 & 6.7 & 45 & 21.6 & 1.5 & Yes & Yes & No & 255 & Alive & 66-gene \\
\hline RJ131 & 75 & 7 & 17.6 & 36 & 49.8 & 82.7 & Yes & Yes & No & 287 & Alive & 66-gene \\
\hline RJ132 & 78 & 8 & 53 & 36 & 11.3 & 0 & Yes & Yes & No & 285 & Alive & 66-gene \\
\hline RJ133 & 67 & 9 & 160 & 24 & 266.9 & 71.5 & Yes & Yes & Yes & 110 & Dead & 66-gene \\
\hline RJ134 & 69 & 7 & 17.1 & 28 & 10.7 & 3.8 & Yes & Yes & No & 355 & Alive & 66-gene \\
\hline RJ135 & 71 & 10 & 38 & 19 & 9.7 & 56.5 & Yes & Yes & No & 346 & Alive & 66-gene \\
\hline RJ136 & 79 & 9 & 20 & 30 & 27.8 & 0 & Yes & Yes & No & 249 & Alive & 66-gene \\
\hline RJ137 & 82 & Unknown & 43 & 16 & 63.5 & 5.2 & Yes & Yes & No & 249 & Alive & 66-gene \\
\hline RJ138 & 78 & 8 & 145 & 8 & 26.9 & 38.5 & Yes & Yes & No & 241 & Alive & 66-gene \\
\hline RJ139 & 86 & 8 & 180 & 18 & 410 & 57.7 & Yes & Yes & No & 238 & Alive & 66-gene \\
\hline RJ140 & 66 & 9 & 2 & 13 & 11.1 & 2.2 & Yes & No & No & 225 & Alive & 66-gene \\
\hline RJ141 & 73 & 7 & $>100$ & 168 & 23.4 & 42.1 & Yes & Yes & No & 221 & Alive & 66-gene \\
\hline RJ142 & 66 & 9 & 1.6 & 25 & 19.1 & 0 & Yes & No & No & 220 & Alive & 66-gene \\
\hline RJ143 & 63 & 10 & 50.7 & 8 & 92.6 & 76.3 & Yes & Yes & No & 215 & Alive & 642-gene \\
\hline RJ144 & 60 & 9 & 3.6 & 20 & 10.3 & 1.1 & Yes & Yes & No & 210 & Alive & 66-gene \\
\hline RJ145 & 69 & 9 & 41.5 & 26 & 12.8 & 2.5 & Yes & Yes & No & 204 & Alive & 642-gene \\
\hline RJ146 & 78 & Unknown & 60 & 10 & 55 & 0 & Yes & Yes & No & 201 & Alive & 642-gene \\
\hline RJ147 & 71 & 8 & 4.1 & 48 & 60.3 & 0 & Yes & No & No & 201 & Alive & 66-gene \\
\hline RJ148 & 75 & 8 & 0.9 & 12 & 14 & 0 & Yes & No & No & 188 & Alive & 66-gene \\
\hline RJ149 & 91 & Unknown & 40 & 60 & 19.2 & 2.8 & Yes & Yes & No & 185 & Alive & 642-gene \\
\hline RJ150 & 75 & Unknown & 41.5 & 24 & 12.3 & 34.4 & Yes & Yes & No & 178 & Alive & 66-gene \\
\hline
\end{tabular}




\section{eTable 3. Clinical Characteristics of 306 ctDNA Samples From 292 Patients (cont.)}

\begin{tabular}{|c|c|c|c|c|c|c|c|c|c|c|c|c|}
\hline $\begin{array}{l}\text { Patient } \\
\text { ID }\end{array}$ & $\begin{array}{c}\text { Age at } \\
\text { Baseline } \\
\text { (y) }\end{array}$ & $\begin{array}{c}\text { Gleason } \\
\text { Score }\end{array}$ & $\begin{array}{c}\text { PSA } \\
\text { (ng/mL) }\end{array}$ & $\begin{array}{c}\text { Time From } \\
\text { ADT } \\
\text { Initiation } \\
\text { to mCRPC } \\
(\mathrm{mo})\end{array}$ & $\begin{array}{l}\text { cfDNA } \\
\text { Yield } \\
\text { (ng/mL } \\
\text { plasma) }\end{array}$ & $\begin{array}{c}\text { ctDNA } \\
(\%)\end{array}$ & $\begin{array}{c}\text { Lymph } \\
\text { Node } \\
\text { Metastasis }\end{array}$ & $\begin{array}{c}\text { Bone } \\
\text { Metastases }\end{array}$ & $\begin{array}{l}\text { Visceral } \\
\text { Metastasis }\end{array}$ & $\begin{array}{l}\text { Follow- } \\
\text { Up (d) }\end{array}$ & $\begin{array}{c}\text { Status at } \\
\text { Last } \\
\text { Follow- } \\
\text { Up }\end{array}$ & $\begin{array}{c}\text { Gene } \\
\text { Panel } \\
\text { Sequenced }\end{array}$ \\
\hline RJ152 & 64 & 9 & 3.7 & 18 & 29.5 & 27.4 & Yes & Yes & No & 172 & Alive & 66-gene \\
\hline RJ153 & 61 & 8 & $>100$ & 20 & 29.8 & 19.1 & Yes & Yes & No & 172 & Alive & 642-gene \\
\hline RJ155 & 82 & 10 & 36 & 22 & 23.9 & 0 & Yes & Yes & Yes & 166 & Alive & 642-gene \\
\hline RJ156 & 69 & 9 & Unknown & 18 & 12.8 & 0 & Yes & No & No & 161 & Alive & 642-gene \\
\hline RJ157 & 81 & 9 & 8.8 & 6 & 19.3 & 71.6 & Yes & No & No & 680 & Alive & 66-gene \\
\hline RJ158 & 68 & NEPC & Unknown & 10 & 12.5 & 29.5 & Yes & Yes & Yes & 90 & Dead & 66-gene \\
\hline SY1 & 80 & 7 & 1.3 & 3 & 8.2 & 0 & Yes & Yes & No & 449 & Alive & 66-gene \\
\hline SY5 & 72 & 9 & 11 & 7 & 5.3 & 2.2 & Yes & Yes & No & 418 & Alive & 642-gene \\
\hline SY6 & 66 & 8 & 111.6 & 3 & 9.9 & 1.3 & Yes & Yes & No & 411 & Alive & 66-gene \\
\hline SY7 & 64 & 8 & 172.6 & 4 & 29.6 & 63.7 & Yes & Yes & No & 722 & Alive & 620-gene \\
\hline SY8 & 63 & 9 & 15.7 & 7.6 & 7.8 & 1.4 & Yes & Yes & Yes & 614 & Alive & 50 -gene \\
\hline SY9 & 78 & 7 & 68.8 & 15 & 8.3 & 6.2 & Yes & No & No & 554 & Alive & 620-gene \\
\hline SY10 & 79 & 7 & 5.7 & 16 & 7 & 16.1 & Yes & Yes & No & 449 & Alive & 620-gene \\
\hline SY11 & 65 & 7 & 42.8 & Unknown & 30.6 & 1.5 & Yes & No & No & 418 & Alive & 620-gene \\
\hline SY12 & 56 & Unknown & 3.4 & 3 & 36.4 & 1.2 & Yes & Yes & No & 410 & Alive & 620-gene \\
\hline SY13 & 52 & 9 & 122.6 & 20 & 136 & 0 & Yes & Yes & Yes & 367 & Alive & 620-gene \\
\hline SY20 & 57 & 9 & 0.2 & 17 & 39 & 44.8 & Yes & Yes & No & 188 & Alive & 642-gene \\
\hline SY21 & 63 & 10 & 3.4 & 25 & 20.6 & 0 & Yes & Yes & No & 187 & Alive & 642-gene \\
\hline SY22 & 73 & 10 & 10.1 & 6 & 24.8 & 0 & Yes & Yes & No & 187 & Alive & 642-gene \\
\hline SY23 & 69 & 6 & 15.4 & 21 & 16.7 & 16.8 & Yes & No & Yes & 180 & Alive & 642-gene \\
\hline SY24 & 71 & 7 & 0.5 & 34 & 18.7 & 0 & Yes & Yes & No & 158 & Alive & 642-gene \\
\hline SY25 & 68 & Unknown & 0 & 28 & 23.8 & 0 & Unknown & Yes & No & 157 & Alive & 642-gene \\
\hline SY26 & 58 & 7 & 0.741 & 36 & 37.3 & 55.9 & Yes & Yes & Yes & 104 & Alive & 642-gene \\
\hline SY27 & 54 & Unknown & 0.731 & Unknown & 9.2 & 0 & Yes & Yes & No & 75 & Alive & 642-gene \\
\hline SY28 & 63 & 7 & 0.082 & Unknown & 12.1 & 33.5 & Yes & Yes & Yes & 69 & Alive & 642-gene \\
\hline SY29 & 69 & Unknown & 36.44 & Unknown & 19.2 & 12.4 & Yes & Yes & No & 63 & Alive & 642-gene \\
\hline SY30 & 59 & 8 & 0.819 & Unknown & 7.4 & 2 & Yes & Yes & No & 59 & Alive & 642-gene \\
\hline ZZ1 & 71 & 8 & 724.2 & 15 & 12.5 & 1.6 & No & Yes & No & 390 & Alive & 66-gene \\
\hline $\mathrm{ZZ2}$ & 78 & Unknown & 21.7 & Unknown & 13.6 & 14.8 & No & Yes & No & 385 & Alive & 66-gene \\
\hline ZZ3 & 67 & Unknown & 0.2 & Unknown & 13 & 0 & No & Yes & No & 375 & Alive & 66-gene \\
\hline
\end{tabular}




\section{eTable 3. Clinical Characteristics of 306 ctDNA Samples From 292 Patients (cont.)}

\begin{tabular}{|c|c|c|c|c|c|c|c|c|c|c|c|c|}
\hline $\begin{array}{l}\text { Patient } \\
\text { ID }\end{array}$ & $\begin{array}{c}\text { Age at } \\
\text { Baseline } \\
\text { (y) }\end{array}$ & $\begin{array}{c}\text { Gleason } \\
\text { Score }\end{array}$ & $\begin{array}{c}\text { PSA } \\
\text { (ng/mL) }\end{array}$ & $\begin{array}{c}\text { Time From } \\
\text { ADT } \\
\text { Initiation } \\
\text { to mCRPC } \\
(\mathrm{mo})\end{array}$ & $\begin{array}{c}\text { cfDNA } \\
\text { Yield } \\
\text { (ng/mL } \\
\text { plasma) }\end{array}$ & $\begin{array}{c}\text { ctDNA } \\
(\%)\end{array}$ & $\begin{array}{c}\text { Lymph } \\
\text { Node } \\
\text { Metastasis }\end{array}$ & $\begin{array}{c}\text { Bone } \\
\text { Metastases }\end{array}$ & $\begin{array}{c}\text { Visceral } \\
\text { Metastasis }\end{array}$ & $\begin{array}{l}\text { Follow- } \\
\text { Up (d) }\end{array}$ & $\begin{array}{c}\text { Status at } \\
\text { Last } \\
\text { Follow- } \\
\text { Up }\end{array}$ & $\begin{array}{c}\text { Gene } \\
\text { Panel } \\
\text { Sequenced }\end{array}$ \\
\hline ZZ4 & 78 & 10 & 45.2 & Unknown & 13.4 & 8.7 & No & Yes & No & 375 & Alive & 66-gene \\
\hline ZZ5 & 60 & 9 & 17 & Unknown & 14.6 & 1.4 & Yes & Yes & No & 371 & Alive & 66-gene \\
\hline ZZ6 & 80 & 9 & 20 & 11.5 & 8.6 & 44.3 & No & Yes & No & 371 & Alive & 66-gene \\
\hline $\mathrm{ZZ7}$ & 73 & Unknown & 11.3 & Unknown & 11.1 & 11.9 & Yes & No & No & 371 & Alive & 66-gene \\
\hline ZZ8 & 60 & 9 & 592.2 & 25 & 12.1 & 9.9 & No & Yes & No & 371 & Alive & 66-gene \\
\hline ZZ9 & 76 & Unknown & 2,175 & 20 & 44.2 & 23.8 & No & Yes & No & 369 & Alive & 66-gene \\
\hline $\mathrm{ZZ10}$ & 68 & 7 & 0 & 24 & 11.1 & 0 & No & Yes & No & 369 & Alive & 66-gene \\
\hline ZZ11 & 69 & 8 & 135.7 & 6 & 22.8 & 2.6 & No & Yes & No & 369 & Alive & 66-gene \\
\hline ZZ12 & 66 & 7 & 8.1 & 4 & 16.1 & 0 & No & Yes & No & 362 & Alive & 66-gene \\
\hline ZZ13 & 78 & 8 & 108.4 & 12 & 10.8 & 1.7 & No & Yes & No & 362 & Alive & 66-gene \\
\hline ZZ14 & 66 & 9 & 24.2 & Unknown & 21.1 & 7.4 & Yes & Yes & No & 356 & Alive & 66-gene \\
\hline ZZ15 & 67 & Unknown & 16.4 & Unknown & 16 & 0 & No & Yes & No & 356 & Alive & 66-gene \\
\hline ZZ16 & 75 & 8 & 0.4 & 7 & 7.6 & 0 & Yes & Yes & No & 356 & Alive & 66-gene \\
\hline ZZ17 & 82 & Unknown & 13.1 & Unknown & 15.3 & 0 & Yes & Yes & No & 411 & Alive & 66-gene \\
\hline ZZ18 & 62 & 10 & 10.1 & 7 & 22.4 & 11.2 & No & Yes & No & 356 & Alive & 66-gene \\
\hline ZZ19 & 74 & 9 & 225 & 8 & 76.5 & 49.6 & No & Yes & No & 343 & Alive & 66-gene \\
\hline ZZ20 & 75 & 6 & 557.6 & 13 & 14.7 & 19.3 & No & Yes & No & 322 & Alive & 66-gene \\
\hline ZZ21 & 78 & 8 & 90 & 42 & 145 & 75.7 & Yes & No & No & 320 & Alive & 66-gene \\
\hline ZZ22 & 68 & 8 & 427.2 & 94 & 32.2 & 15.2 & No & Yes & No & 314 & Alive & 66-gene \\
\hline ZZ23 & 75 & 6 & Unknown & 28 & 12.3 & 2.2 & No & Yes & No & 277 & Alive & 66-gene \\
\hline ZZ24 & 54 & 8 & 301.3 & 6 & 55 & 11.4 & Yes & Yes & No & 271 & Alive & 66-gene \\
\hline ZZ25 & 81 & 9 & 25.3 & 9 & 18.7 & 21.6 & No & Yes & No & 257 & Alive & 66-gene \\
\hline ZZ26 & 78 & 8 & 33.2 & 10 & 10.6 & 1.7 & No & Yes & No & 238 & Alive & 66-gene \\
\hline ZZ27 & 63 & 9 & 8.4 & 27 & 10.8 & 1.6 & Yes & Yes & No & 193 & Alive & 66-gene \\
\hline ZZ28 & 78 & 9 & 28 & 36 & 27.7 & 0 & No & Yes & No & 186 & Alive & 66-gene \\
\hline ZZ29 & 72 & 6 & 3.3 & 9 & 11 & 0 & Yes & Yes & No & 161 & Alive & 66-gene \\
\hline WY1 & 71 & 10 & 114.6 & 10 & 50.6 & 0 & Yes & Yes & Yes & 432 & Alive & 620-gene \\
\hline WY2 & 63 & 10 & 334.1 & 18 & 110 & 12.5 & Yes & Yes & Yes & 30 & Dead & 66-gene \\
\hline WY3 & 60 & 9 & Unknown & Unknown & 226 & 40.3 & Yes & Yes & No & 396 & Alive & 620 -gene \\
\hline WY4 & 50 & 9 & 466.7 & 9 & 440 & 81.9 & Yes & Yes & Yes & 391 & Alive & 620-gene \\
\hline WY5 & 81 & Unknown & 404.3 & 8 & 24.6 & 20.2 & Yes & Yes & No & 391 & Alive & 620-gene \\
\hline WY6 & 59 & 9 & 589.4 & 4 & 43.2 & 38.8 & Yes & Yes & No & 96 & Dead & 620 -gene \\
\hline WY7 & 60 & 9 & 87.9 & 17 & 9.3 & 10.2 & Yes & Yes & No & 392 & Alive & 620-gene \\
\hline WY8 & 70 & 10 & 370.2 & 7 & 14.2 & 0 & Yes & Yes & No & 383 & Alive & 620-gene \\
\hline WY9 & 70 & NEPC & 9.7 & Unknown & 12.5 & 0 & Yes & No & No & 377 & Alive & 620-gene \\
\hline WY10 & 65 & 10 & 28.8 & Unknown & 27.2 & 40.9 & Yes & Yes & No & 376 & Alive & 620-gene \\
\hline WY11 & 70 & 10 & 1 & Unknown & 12.7 & 0 & Yes & Yes & No & 371 & Alive & 620-gene \\
\hline WY12 & 64 & 10 & 20.6 & 46 & 82 & 49.7 & Yes & No & No & 371 & Alive & 620-gene \\
\hline WY13 & 67 & 10 & 73.9 & 6 & 26.8 & 30.2 & Yes & Yes & Yes & 509 & Alive & 620-gene \\
\hline WY14 & 52 & 9 & Unknown & 8 & 35.9 & 3.7 & Yes & Yes & No & 538 & Dead & 50-gene \\
\hline WY15 & 77 & 9 & 20.9 & 8 & 20.4 & 44.1 & Yes & Yes & Yes & 451 & Alive & 620-gene \\
\hline
\end{tabular}


eTable 3. Clinical Characteristics of 306 ctDNA Samples From 292 Patients (cont.)

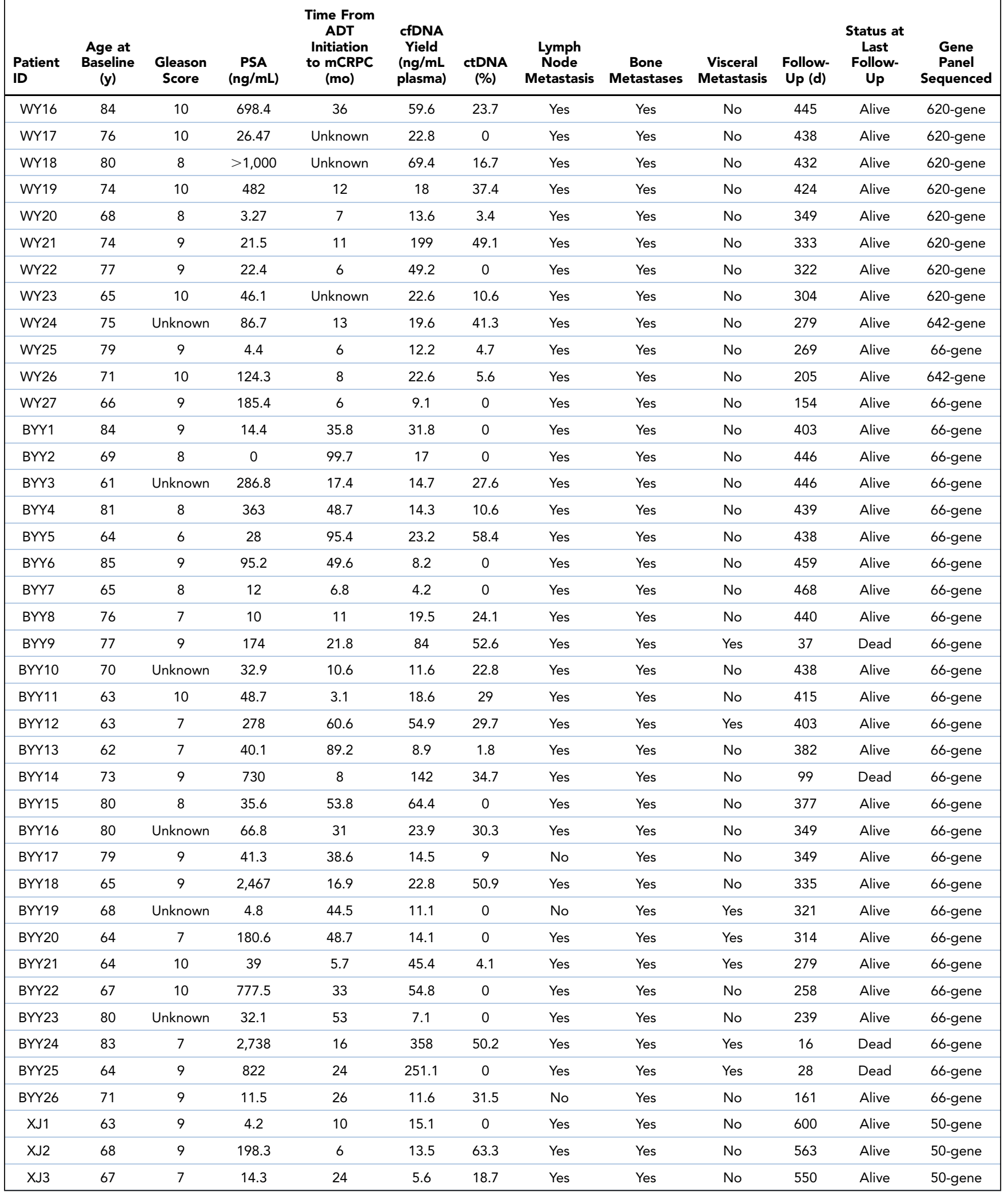




\begin{tabular}{|c|c|c|c|c|c|c|c|c|c|c|c|c|}
\hline XJ4 & 71 & 9 & 0 & Unknown & 10.5 & 0 & No & No & Yes & 550 & Alive & 50 -gene \\
\hline XJ7 & 62 & Unknown & 937.6 & 8 & 59.2 & 54.8 & Unknown & Yes & No & 357 & Alive & 66-gene \\
\hline XJ8 & 67 & 9 & 20.8 & 8 & 55.6 & 1.6 & No & Yes & No & 314 & Alive & 66-gene \\
\hline XJ9 & 64 & Unknown & 86.9 & 120 & 17.4 & 1.6 & Yes & Yes & Yes & 282 & Alive & 66-gene \\
\hline FY1 & 80 & Unknown & Unknown & Unknown & 15.2 & 0 & Yes & Yes & No & 473 & Alive & 66-gene \\
\hline FY5 & 76 & Unknown & 4,737 & 15 & 369.2 & 72 & Yes & Yes & No & 518 & Alive & 50-gene \\
\hline FY6 & 69 & Unknown & Unknown & Unknown & 8.8 & 0 & Yes & Yes & No & 511 & Alive & 50-gene \\
\hline FY7 & 79 & Unknown & Unknown & Unknown & 24.4 & 19.3 & Yes & Yes & No & 369 & Alive & 66-gene \\
\hline ZR1 & 64 & 8 & 8.2 & 11 & 6.3 & 1.6 & No & Yes & No & 468 & Alive & 66-gene \\
\hline ZR2 & 49 & Unknown & $>600$ & 5 & 73.2 & 59.1 & Yes & Yes & No & 427 & Alive & 620-gene \\
\hline ZR3 & 91 & 9 & 206 & 96 & 21 & 11.4 & Yes & Yes & No & 395 & Alive & 620-gene \\
\hline ZR4 & 47 & 9 & 111.3 & 10 & 13.6 & 7.6 & Yes & Yes & No & 285 & Alive & 66-gene \\
\hline ZR5 & 78 & 8 & 69.9 & Unknown & 45.6 & 57 & Yes & Yes & No & 281 & Alive & 642-gene \\
\hline ZR6 & 68 & 9 & 0 & 4 & 367.2 & 75 & Yes & Yes & No & 265 & Alive & 642-gene \\
\hline
\end{tabular}

Abbreviations: cfDNA, circulating free DNA; ctDNA, circulating tumor DNA; $m C R P C$, metastatic castration-resistant prostate cancer; NEPC, neuroendocrine prostate cancer; PSA, prostate-specific antigen. 
eTable 4. Somatic Mutations Detected in ctDNA and Matched Tumor Tissue of 23 Patients

\begin{tabular}{|c|c|c|c|c|c|c|c|c|}
\hline Sample & Chrom & Position & Ref & Alt & Gene & Effect & Tumor Tissue AF (\%) & ctDNA AF (\%) \\
\hline \multicolumn{9}{|c|}{ Mutations detected in both ctDNA and tumor tissue } \\
\hline RJ101 & chr14 & 38060784 & A & G & FOXA1 & $\begin{array}{l}\text { Nonsynonymous } \\
\text { SNV p.1402T }\end{array}$ & $23.10 \%$ & $29.10 \%$ \\
\hline RJ101 & chr14 & 38060785 & $\mathrm{~T}$ & A & FOXA1 & $\begin{array}{l}\text { Nonsynonymous } \\
\text { SNV p.1402F }\end{array}$ & $23.60 \%$ & $29.40 \%$ \\
\hline RJ101 & chr17 & 37627561 & - & A & CDK12 & $\begin{array}{l}\text { Frameshift } \\
\text { insertion p.D494fs }\end{array}$ & $41.20 \%$ & $56.20 \%$ \\
\hline RJ113-2 & chr22 & 29095882 & G & A & CHEK2 & $\begin{array}{l}\text { Nonsynonymous } \\
\text { SNV p.R318C }\end{array}$ & $11.60 \%$ & $4.00 \%$ \\
\hline RJ113-2 & chr10 & 89717672 & C & $\mathrm{T}$ & PTEN & Stopgain p.R233X & $23.80 \%$ & $5.00 \%$ \\
\hline RJ114-2 & chr14 & 38061218 & $\begin{array}{l}\text { GCCGTTCTCGAA } \\
\text { CATGTTGCCGGAG }\end{array}$ & - & FOXA1 & $\begin{array}{l}\text { Frameshift deletion } \\
\text { p.S250fs }\end{array}$ & $55.60 \%$ & $7.10 \%$ \\
\hline RJ114-2 & chr17 & 37619206 & CTACGTAG & $\mathrm{T}$ & CDK12 & $\begin{array}{l}\text { Frameshift deletion } \\
\text { p.Y295fs }\end{array}$ & $30.30 \%$ & $3.60 \%$ \\
\hline RJ114-2 & chr17 & 37627919 & C & T & CDK12 & Stopgain p.Q612X & $29.80 \%$ & $3.40 \%$ \\
\hline RJ38 & chr10 & 89720799 & TA & $\begin{array}{l}\text { CTTTAACAAAAAATGAT } \\
\text { CTTACTTTAACAAAAAA } \\
\text { TATCTTACTTTAACAAA } \\
\text { AAATTTTTTGTTTACTT } \\
\text { AAAGTAAAATAT }\end{array}$ & PTEN & $\begin{array}{l}\text { Nonframeshift } \\
\text { insertion } \\
\text { p.V317delinsAL }\end{array}$ & $56.90 \%$ & $35.00 \%$ \\
\hline RJ38 & chr13 & 48955572 & G & $A$ & $R B 1$ & Stopgain p.W563X & $72.80 \%$ & $60.80 \%$ \\
\hline RJ104-1 & chr14 & 38061191 & G & $\mathrm{T}$ & FOXA1 & $\begin{array}{l}\text { Nonsynonymous } \\
\text { SNV p.F266L }\end{array}$ & $46.90 \%$ & $3.90 \%$ \\
\hline RJ104-1 & chr17 & 37627619 & - & $\mathrm{T}$ & CDK12 & $\begin{array}{l}\text { Frameshift } \\
\text { insertion p.V513fs }\end{array}$ & $49.20 \%$ & $9.70 \%$ \\
\hline RJ111-1 & chr17 & 7577505 & $\mathrm{~T}$ & A & TP53 & $\begin{array}{l}\text { Nonsynonymous } \\
\text { SNV p.D259V }\end{array}$ & $51.10 \%$ & $11.90 \%$ \\
\hline RJ111-1 & chr12 & 124810826 & G & C & NCOR2 & $\begin{array}{l}\text { Nonsynonymous } \\
\text { SNV p.P2425R }\end{array}$ & $35.20 \%$ & $13.70 \%$ \\
\hline RJ112-1 & chr17 & 37627793 & C & $\mathrm{T}$ & CDK12 & Stopgain p.Q570X & $31.40 \%$ & $3.80 \%$ \\
\hline SY18 & $\operatorname{chr} 16$ & 23641351 & TAAAGGAGTA & - & PALB2 & $\begin{array}{l}\text { Frameshift deletion } \\
\text { p.Y705fs }\end{array}$ & 0.427 & 0.027 \\
\hline SY18 & chr13 & 48919259 & ACCAAAGT & - & RB1 & $\begin{array}{l}\text { Frameshift deletion } \\
\text { p.T142fs }\end{array}$ & 0.605 & 0.031 \\
\hline SY18 & chr17 & 7578550 & G & A & TP53 & $\begin{array}{l}\text { Nonsynonymous } \\
\text { SNV p.S127F }\end{array}$ & 0.889 & 0.1 \\
\hline SY18 & chr14 & 38061226 & CGAACATGTTGC & - & FOXA1 & $\begin{array}{l}\text { Nonframeshift } \\
\text { deletion } \\
\text { p.G251_F254del }\end{array}$ & 0.472 & 0.086 \\
\hline RJ133 & chr17 & 37618588 & $\begin{array}{l}\text { CTTCAAACTA } \\
\text { GACCGAAGG }\end{array}$ & - & CDK12 & $\begin{array}{l}\text { Frameshift deletion } \\
\text { p.F89fs }\end{array}$ & 0.286 & 0.572 \\
\hline SY29 & chr17 & 7577575 & $A$ & G & TP53 & $\begin{array}{l}\text { Nonsynonymous } \\
\text { SNV p.Y236H }\end{array}$ & 0.664 & 0.074 \\
\hline RJ158 & $\operatorname{chr} 13$ & 49033917 & $A$ & C & RB1 & $\begin{array}{l}\text { Nonsynonymous } \\
\text { SNV p.Q685P }\end{array}$ & 0.25 & 0.186 \\
\hline RJ157 & chr14 & 38061200 & CTGGCGGCG & - & FOXA1 & $\begin{array}{l}\text { Nonframeshift } \\
\text { deletion } \\
\text { p.R261_Q263del }\end{array}$ & 0.32 & 0.234 \\
\hline RJ157 & chr11 & 108202285 & G & C & ATM & Splicing & 0.89 & 0.577 \\
\hline SY28 & chr3 & 37081761 & A & G & MLH1 & $\begin{array}{l}\text { Nonsynonymous } \\
\text { SNV p.Y548C }\end{array}$ & 0.448 & 0.219 \\
\hline SY28 & $\operatorname{chrX}$ & 66937372 & G & $\mathrm{T}$ & $A R$ & $\begin{array}{l}\text { Nonsynonymous } \\
\text { SNV p.W742C }\end{array}$ & 0.467 & 0.229 \\
\hline SY26 & chr2 & 209113113 & G & A & IDH1 & $\begin{array}{l}\text { Nonsynonymous } \\
\text { SNV p.R132C }\end{array}$ & 0.609 & 0.354 \\
\hline
\end{tabular}


eTable 4. Somatic Mutations Detected in ctDNA and Matched Tumor Tissue of 23 Patients (cont.)

\begin{tabular}{|c|c|c|c|c|c|c|c|c|}
\hline Sample & Chrom & Position & Ref & Alt & Gene & Effect & Tumor Tissue AF (\%) & ctDNA AF (\%) \\
\hline SY26 & chr7 & 6042213 & C & G & PMS2 & $\begin{array}{l}\text { Nonsynonymous } \\
\text { SNV p.M1361 }\end{array}$ & 0.261 & 0.127 \\
\hline SY26 & chr17 & 7577147 & AG & - & TP53 & $\begin{array}{l}\text { Frameshift deletion } \\
\text { p.L264fs }\end{array}$ & 0.911 & 0.406 \\
\hline SY30 & chr17 & 37619280 & - & $A$ & CDK12 & Stopgain p.Y319X & 0.259 & 0.01 \\
\hline SY30 & chr17 & 37657610 & CT & AA & CDK12 & $\begin{array}{l}\text { Nonsynonymous } \\
\text { SNV p.L843K }\end{array}$ & 0.257 & 0.015 \\
\hline SY5 & chr10 & 89711982 & $\mathrm{~T}$ & - & PTEN & $\begin{array}{l}\text { Frameshift deletion } \\
\text { p.F200fs }\end{array}$ & 0.632 & 0.018 \\
\hline SY5 & chr17 & 47696644 & A & C & SPOP & $\begin{array}{l}\text { Nonsynonymous } \\
\text { SNV p.F102V }\end{array}$ & 0.486 & 0.015 \\
\hline \multicolumn{9}{|c|}{$\begin{array}{l}\text { Mutations detected in tumor tissue but missed in } \\
\text { ctDNA }\end{array}$} \\
\hline RJ113-2 & chr13 & 48878126 & - & $\mathrm{C}$ & RB1 & $\begin{array}{l}\text { Frameshift } \\
\text { insertion p.P29fs }\end{array}$ & $14.90 \%$ & \\
\hline RJ114-2 & chr16 & 23641352 & A & - & PALB2 & Stopgain p.L708X & $7.70 \%$ & \\
\hline SY30 & chr14 & 38060682 & - & $\mathrm{T}$ & FOXA1 & $\begin{array}{l}\text { Frameshift } \\
\text { insertion p.S436fs }\end{array}$ & $23.50 \%$ & \\
\hline \multicolumn{9}{|c|}{$\begin{array}{l}\text { Mutations detected in ctDNA but missed in tumor } \\
\text { tissue }\end{array}$} \\
\hline RJ114-2 & $\operatorname{chrX}$ & 66937372 & G & C & $A R$ & $\begin{array}{l}\text { Nonsynonymous } \\
\text { SNV p.W742C }\end{array}$ & & $1.50 \%$ \\
\hline RJ114-2 & $\operatorname{chrX}$ & 66937371 & G & T & $A R$ & $\begin{array}{l}\text { Nonsynonymous } \\
\text { SNV p.W742L }\end{array}$ & & $5.10 \%$ \\
\hline SY4 & chr6 & 152265487 & C & A & ESR1 & $\begin{array}{l}\text { Nonsynonymous } \\
\text { SNV p.Q314K }\end{array}$ & & $22.00 \%$ \\
\hline SY4 & chr13 & 32945148 & A & - & BRCA2 & $\begin{array}{l}\text { Frameshift deletion } \\
\text { p.K2849fs }\end{array}$ & & $31.60 \%$ \\
\hline RJ104-1 & chr11 & 114113039 & G & A & ZBTB16 & $\begin{array}{l}\text { Nonsynonymous } \\
\text { SNV p.R535H }\end{array}$ & & $1.20 \%$ \\
\hline RJ104-1 & $\operatorname{chrX}$ & 66937372 & G & C & $A R$ & $\begin{array}{l}\text { Nonsynonymous } \\
\text { SNV p.W742C }\end{array}$ & & $2.20 \%$ \\
\hline RJ104-1 & $\operatorname{chrX}$ & 66943552 & A & G & $A R$ & $\begin{array}{l}\text { Nonsynonymous } \\
\text { SNV p.T878A }\end{array}$ & & $1.60 \%$ \\
\hline RJ101 & $\operatorname{chrX}$ & 66937372 & G & $\mathrm{T}$ & $A R$ & $\begin{array}{l}\text { Nonsynonymous } \\
\text { SNV p.W742C }\end{array}$ & & $1.40 \%$ \\
\hline RJ101 & $\operatorname{chrX}$ & 66765158 & $\mathrm{~T}$ & A & $A R$ & $\begin{array}{l}\text { Nonsynonymous } \\
\text { SNV p.L57Q }\end{array}$ & & $9.50 \%$ \\
\hline RJ112-1 & chr3 & 142183998 & G & $\mathrm{T}$ & ATR & $\begin{array}{l}\text { Nonsynonymous } \\
\text { SNV p.P2328T }\end{array}$ & & $1.90 \%$ \\
\hline RJ112-1 & chr2 & 47641507 & C & $A$ & $\mathrm{MSH} 2$ & $\begin{array}{l}\text { Nonsynonymous } \\
\text { SNV p.Q298K }\end{array}$ & & $1.10 \%$ \\
\hline RJ112-1 & chr10 & 89720783 & G & $A$ & PTEN & $\begin{array}{l}\text { Nonsynonymous } \\
\text { SNV p.D312N }\end{array}$ & & $1.10 \%$ \\
\hline RJ112-1 & $\operatorname{chrX}$ & 66905791 & G & $A$ & $A R$ & $\begin{array}{l}\text { Nonsynonymous } \\
\text { SNV p.R542Q }\end{array}$ & & $1.30 \%$ \\
\hline RJ112-1 & chr13 & 32914782 & C & $\mathrm{T}$ & BRCA2 & $\begin{array}{l}\text { Nonsynonymous } \\
\text { SNV p.T2097M }\end{array}$ & & $1.80 \%$ \\
\hline RJ112-1 & chr16 & 14024643 & - & GGGA & $E R C C 4$ & $\begin{array}{l}\text { Frameshift } \\
\text { insertion p.1290fs }\end{array}$ & & $1.20 \%$ \\
\hline RJ113-2 & chr11 & 108098542 & G & $\mathrm{T}$ & ATM & Stopgain p.E38X & & $1.20 \%$ \\
\hline RJ133 & $\operatorname{chrX}$ & 66943552 & A & G & $A R$ & $\begin{array}{l}\text { Nonsynonymous } \\
\text { SNV p.T878A }\end{array}$ & & $8.10 \%$ \\
\hline
\end{tabular}


28 - Dong et al

\section{eTable 4. Somatic Mutations Detected in ctDNA and Matched Tumor Tissue of 23 Patients (cont.)}

\begin{tabular}{|c|c|c|c|c|c|c|c|c|}
\hline Sample & Chrom & Position & Ref & Alt & Gene & Effect & Tumor Tissue AF (\%) & ctDNA AF (\%) \\
\hline RJ157 & chr12 & 124819159 & $A$ & C & NCOR2 & $\begin{array}{l}\text { Nonsynonymous } \\
\text { SNV p.V2139G }\end{array}$ & & $1.90 \%$ \\
\hline SY28 & chr17 & 7577548 & C & $\mathrm{T}$ & TP53 & $\begin{array}{l}\text { Nonsynonymous } \\
\text { SNV p.G245S }\end{array}$ & & $7.80 \%$ \\
\hline RJ122 & $\operatorname{chrX}$ & 66931463 & $\mathrm{~T}$ & $A$ & $A R$ & $\begin{array}{l}\text { Nonsynonymous } \\
\text { SNV p.L702H }\end{array}$ & & $15.00 \%$ \\
\hline RJ122 & chr14 & 38061220 & CGTTCT & - & FOXA1 & $\begin{array}{l}\text { Nonframeshift } \\
\text { deletion } \\
\text { p.E255_N256del }\end{array}$ & & $34.20 \%$ \\
\hline
\end{tabular}

Abbreviations: AF, allele fraction; Alt, alteration; Chrom, chromosome; ctDNA, circulating tumor DNA; Ref, reference. 


\section{eTable 5. All Filtered Somatic Mutations and Deleterious Germline Mutations Detected}

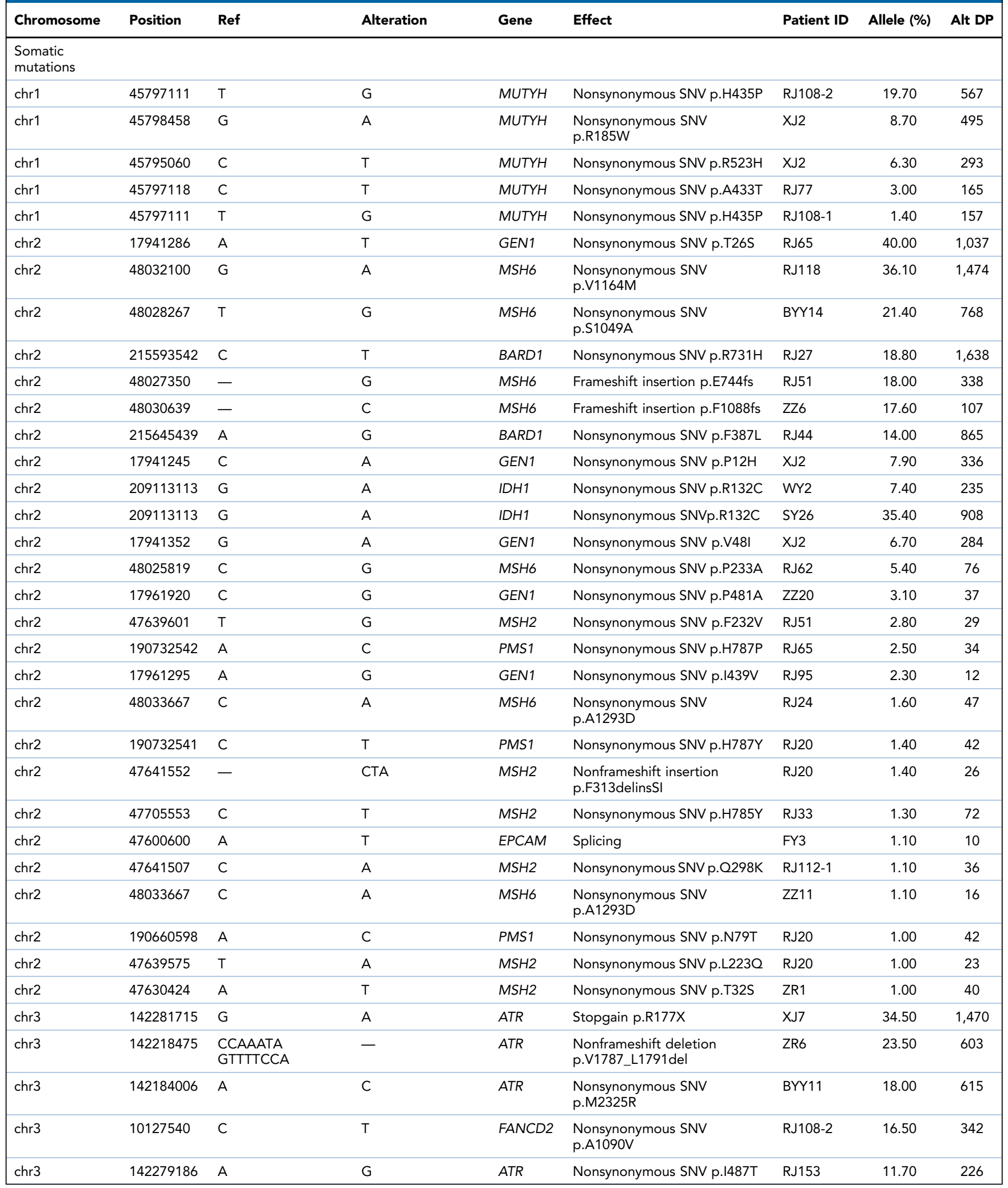


eTable 5. All Filtered Somatic Mutations and Deleterious Germline Mutations Detected (cont.)

\begin{tabular}{|c|c|c|c|c|c|c|c|c|}
\hline Chromosome & Position & Ref & Alteration & Gene & Effect & Patient ID & Allele (\%) & Alt DP \\
\hline chr3 & 142180827 & $\mathrm{~T}$ & - & ATR & Frameshift deletion p.T2383fs & SY7 & 9.60 & 364 \\
\hline chr3 & 142180870 & A & C & ATR & $\begin{array}{l}\text { Nonsynonymous SNV } \\
\text { p.12368M }\end{array}$ & WY13 & 8.30 & 145 \\
\hline chr3 & 10089729 & C & G & FANCD2 & $\begin{array}{l}\text { Nonsynonymous SNV } \\
\text { p.C469W }\end{array}$ & WY23 & 6.40 & 127 \\
\hline chr3 & 142171980 & A & C & ATR & $\begin{array}{l}\text { Nonsynonymous SNV } \\
\text { p.V2584G }\end{array}$ & BYY4 & 4.20 & 61 \\
\hline chr3 & 142215203 & C & G & ATR & $\begin{array}{l}\text { Nonsynonymous SNV } \\
\text { p.K1966N }\end{array}$ & RJ4 & 2.40 & 119 \\
\hline chr3 & 142183998 & G & $\mathrm{T}$ & ATR & $\begin{array}{l}\text { Nonsynonymous SNV } \\
\text { p.P2328T }\end{array}$ & RJ112-1 & 1.90 & 49 \\
\hline chr3 & 142188309 & G & $\mathrm{T}$ & ATR & $\begin{array}{l}\text { Nonsynonymous SNV } \\
\text { p.A2141D }\end{array}$ & RJ106-2 & 1.90 & 13 \\
\hline chr3 & 37045901 & A & G & MLH1 & Nonsynonymous SNV p.S106G & BYY14 & 1.20 & 36 \\
\hline chr3 & 37045892 & G & A & MLH1 & Nonsynonymous SNV p.A103T & BYY14 & 1.20 & 34 \\
\hline chr3 & 37081761 & A & G & MLH1 & Nonsynonymous SNVp.Y548C & SY28 & 21.90 & 291 \\
\hline chr3 & 142242899 & G & $\mathrm{T}$ & ATR & $\begin{array}{l}\text { Nonsynonymous SNV } \\
\text { p.A1363E }\end{array}$ & RJ115 & 1.20 & 27 \\
\hline chr3 & 10122811 & - & $\begin{array}{l}\text { AACAACTTGC } \\
\text { AAATAGGCTTTAT } \\
\text { ACAAGAATC }\end{array}$ & FANCD2 & $\begin{array}{l}\text { Stopgain } \\
\text { p.S1002_H1003delinsX }\end{array}$ & $\mathrm{ZZ2}$ & 1.20 & 35 \\
\hline chr3 & 10076451 & - & $\begin{array}{l}\text { TCATTTCATCC } \\
\text { TTTCACTTCTTT } \\
\text { CCCTTCCTCC } \\
\text { GTC }\end{array}$ & FANCD2 & $\begin{array}{l}\text { Nonframeshift insertion } \\
\text { p.S116delins } \\
\text { FISSFHFFP } \\
\text { FLRP }\end{array}$ & RJ26 & 1.10 & 16 \\
\hline chr3 & 142266710 & A & G & ATR & $\begin{array}{l}\text { Nonsynonymous SNV } \\
\text { p.F1072L }\end{array}$ & RJ18 & 1.00 & 72 \\
\hline chr5 & 131915013 & G & $\mathrm{C}$ & RAD50 & Nonsynonymous SNV p.G124R & RJ124 & 16.50 & 458 \\
\hline chr5 & 131940599 & C & A & RAD50 & Nonsynonymous SNV p.Q876K & $\mathrm{xJ} 2$ & 4.90 & 174 \\
\hline chr5 & 131927569 & G & $\mathrm{T}$ & RAD50 & Nonsynonymous SNV p.A546S & RJ110-2 & 1.40 & 22 \\
\hline chr5 & 131923615 & G & $\mathrm{T}$ & RAD50 & Splicing & RJ26 & 1.30 & 19 \\
\hline chr5 & 131915722 & - & ATAG & RAD50 & Frameshift insertion p.V241fs & RJ24 & 1.30 & 27 \\
\hline chr5 & 131930581 & A & $\mathrm{T}$ & RAD50 & Nonsynonymous SNV p.E605V & RJ20 & 1.10 & 38 \\
\hline chr5 & 82554396 & G & A & $X R C C 4$ & $\begin{array}{l}\text { Nonsynonymous SNV } \\
\text { p.D265N }\end{array}$ & RJ20 & 1.00 & 36 \\
\hline chr6 & 152265487 & C & A & ESR1 & Nonsynonymous SNVp.Q314K & SY4 & 22.00 & 859 \\
\hline chr6 & 152382194 & $\mathrm{~T}$ & C & ESR1 & Nonsynonymous SNV p.F435S & FY3 & 18.40 & 304 \\
\hline chr6 & 152129177 & C & A & ESR1 & Nonsynonymous SNV p.L44M & RJ51 & 13.20 & 497 \\
\hline chr6 & 114270400 & A & C & HDAC2 & Nonsynonymous SNV p.Y222D & FY7 & 11.40 & 565 \\
\hline chr6 & 152129323 & c & A & ESR1 & Nonsynonymous SNV p.N92K & RJ31 & 4.60 & 604 \\
\hline
\end{tabular}




\section{eTable 5. All Filtered Somatic Mutations and Deleterious Germline Mutations Detected (cont.)}

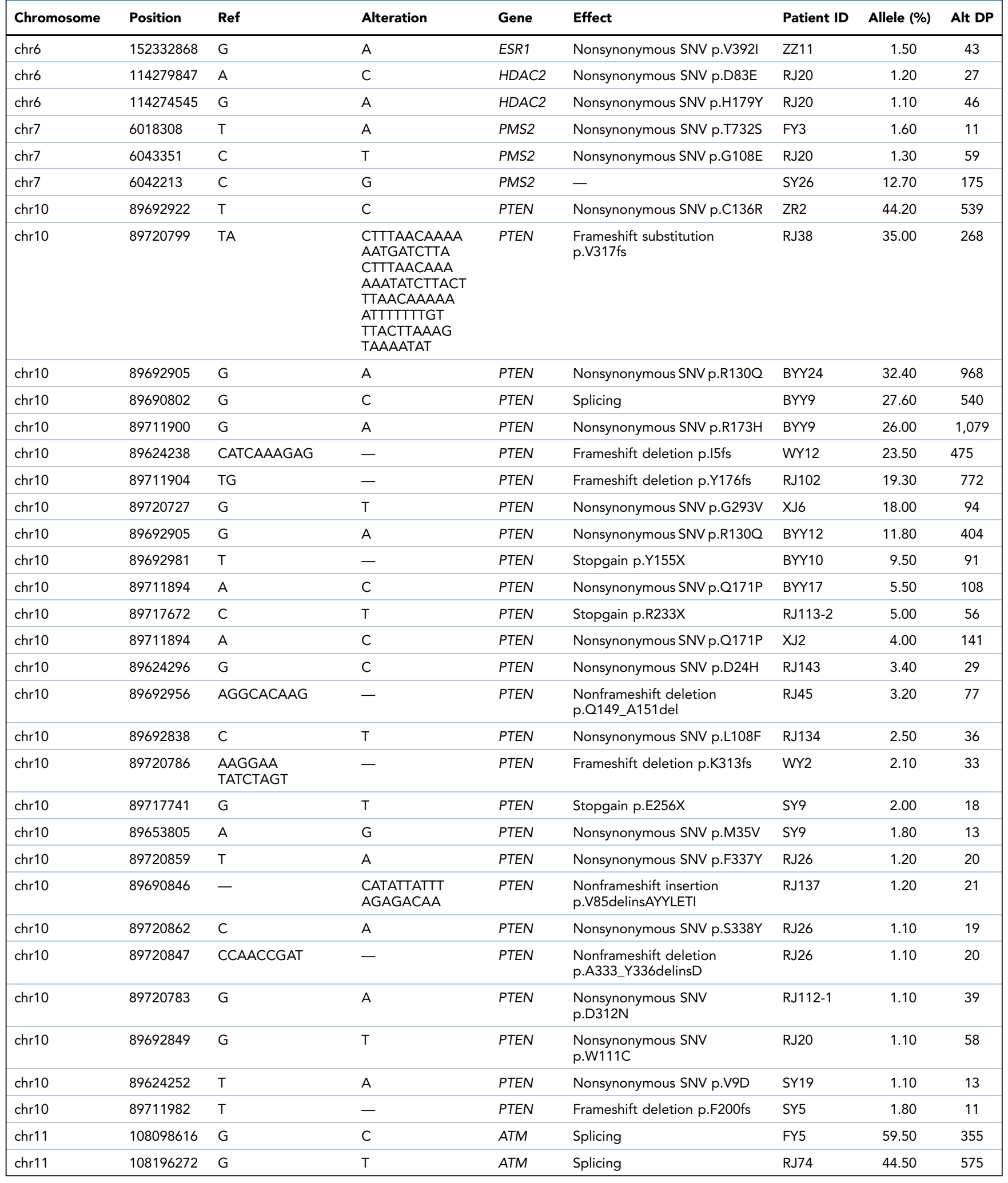


eTable 5. All Filtered Somatic Mutations and Deleterious Germline Mutations Detected (cont.)

\begin{tabular}{|c|c|c|c|c|c|c|c|c|}
\hline Chromosome & Position & Ref & Alteration & Gene & Effect & Patient ID & Allele (\%) & Alt DP \\
\hline chr11 & 94204767 & G & $\mathrm{T}$ & MRE11 & Nonsynonymous SNV p.S273Y & RJ139 & 42.20 & 991 \\
\hline chr11 & 108158414 & C & $\mathrm{T}$ & ATM & Stopgain p.Q1361X & BYY24 & 35.30 & 652 \\
\hline chr11 & 108124767 & G & C & ATM & Splicing & RJ23-2 & 33.70 & 897 \\
\hline chr11 & 108115634 & CTTTG & - & ATM & Frameshift deletion p.L263fs & RJ37 & 20.80 & 451 \\
\hline chr11 & 108206650 & G & $\mathrm{T}$ & ATM & Stopgain p.E2744X & WY10 & 17.60 & 425 \\
\hline chr11 & 108121625 & C & A & ATM & Stopgain p.S478X & RJ63 & 13.70 & 289 \\
\hline chr11 & 113934488 & A & G & ZBTB16 & Nonsynonymous SNV p.I156V & RJ152 & 13.20 & 603 \\
\hline chr11 & 108200991 & G & $A$ & ATM & $\begin{array}{l}\text { Nonsynonymous SNV } \\
\text { p.R2453H }\end{array}$ & ZZ6 & 10.20 & 124 \\
\hline chr11 & 108160424 & - & $\mathrm{T}$ & ATM & Frameshift insertion p.V1446fs & RJ109-1 & 5.30 & 245 \\
\hline chr11 & 108160424 & - & $\mathrm{T}$ & ATM & Frameshift insertion p.V1446fs & RJ109-2 & 3.30 & 35 \\
\hline chr11 & 108098606 & - & $\begin{array}{l}\text { CCTCAGAA } \\
\text { ACTTAAA }\end{array}$ & ATM & $\begin{array}{l}\text { Nonframeshift insertion } \\
\text { p.A59_V60insLRNLN }\end{array}$ & RJ20 & 2.10 & 28 \\
\hline chr11 & 108198439 & C & $\mathrm{T}$ & ATM & $\begin{array}{l}\text { Nonsynonymous SNV } \\
\text { p.T2348M }\end{array}$ & RJ29 & 1.50 & 46 \\
\hline chr11 & 108114700 & A & $\mathrm{T}$ & ATM & $\begin{array}{l}\text { Nonsynonymous SNV } \\
\text { p.R173W }\end{array}$ & RJ52 & 1.50 & 10 \\
\hline chr11 & 94197398 & $\mathrm{~T}$ & C & MRE11 & Nonsynonymous SNV p.Y369C & RJ82 & 1.50 & 24 \\
\hline chr11 & 108114719 & C & A & ATM & Stopgain p.S179X & RJ19 & 1.30 & 28 \\
\hline chr11 & 114113039 & G & A & ZBTB16 & Nonsynonymous SNV p.R535H & RJ104-1 & 1.20 & 33 \\
\hline chr11 & 108098542 & G & $\mathrm{T}$ & ATM & Stopgain p.E38X & RJ113-2 & 1.20 & 10 \\
\hline chr11 & 108186630 & - & $\begin{array}{l}\text { GAATGGAA } \\
\text { TGGAATGTA } \\
\text { ATGGAGAGT } \\
\text { AAGGGAGTG } \\
\text { GAATAGAAACA } \\
\text { ATCCGAATGTA } \\
\text { ATGGAATGGA } \\
\text { ACGGAATGCAA } \\
\text { TGGAATGGAAT } \\
\text { GGAATGGAATGG }\end{array}$ & ATM & $\begin{array}{l}\text { Stopgain p.P2029_ } \\
\text { I2030delins } \\
\text { PEWNGMX }\end{array}$ & RJ20 & 1.20 & 38 \\
\hline chr11 & 108192080 & C & A & ATM & Nonsynonymous SNV p.L2169l & RJ20 & 1.10 & 54 \\
\hline chr11 & 108117837 & G & A & ATM & Nonsynonymous SNV p.A350T & RJ20 & 1.10 & 33 \\
\hline chr11 & 108201123 & $\mathrm{~T}$ & $A$ & ATM & $\begin{array}{l}\text { Nonsynonymous SNV } \\
\text { p.V2497D }\end{array}$ & SY6 & 1.00 & 15 \\
\hline chr11 & 108202285 & G & C & ATM & Splicing & RJ157 & 57.70 & 965 \\
\hline chr11 & 108170527 & A & C & ATM & $\begin{array}{l}\text { Nonsynonymous SNV } \\
\text { p.K16980 }\end{array}$ & RJ24 & 1.00 & 19 \\
\hline chr12 & 133220142 & G & A & POLE & $\begin{array}{l}\text { Nonsynonymous SNV } \\
\text { p.P1432L }\end{array}$ & BYY12 & 18.50 & 590 \\
\hline chr12 & 133219144 & G & A & POLE & $\begin{array}{l}\text { Nonsynonymous SNV } \\
\text { p.R1634C }\end{array}$ & RJ108-2 & 17.40 & 695 \\
\hline chr12 & 124812065 & G & - & NCOR2 & Frameshift deletion p.P2358fs & RJ115 & 17.40 & 419 \\
\hline chr12 & 124819809 & C & $\mathrm{T}$ & NCOR2 & $\begin{array}{l}\text { Nonsynonymous SNV } \\
\text { p.G2095R }\end{array}$ & BYY12 & 15.00 & 581 \\
\hline chr12 & 133225959 & G & $A$ & POLE & $\begin{array}{l}\text { Nonsynonymous SNV } \\
\text { p.T1313M }\end{array}$ & RJ51 & 14.90 & 696 \\
\hline chr12 & 124810826 & G & C & NCOR2 & $\begin{array}{l}\text { Nonsynonymous SNV } \\
\text { p.P2425R }\end{array}$ & RJ111-1 & 13.70 & 839 \\
\hline chr12 & 124841323 & C & $\mathrm{T}$ & NCOR2 & $\begin{array}{l}\text { Nonsynonymous SNV } \\
\text { p.A1036T }\end{array}$ & ZZ6 & 4.90 & 92 \\
\hline
\end{tabular}


eTable 5. All Filtered Somatic Mutations and Deleterious Germline Mutations Detected (cont.)

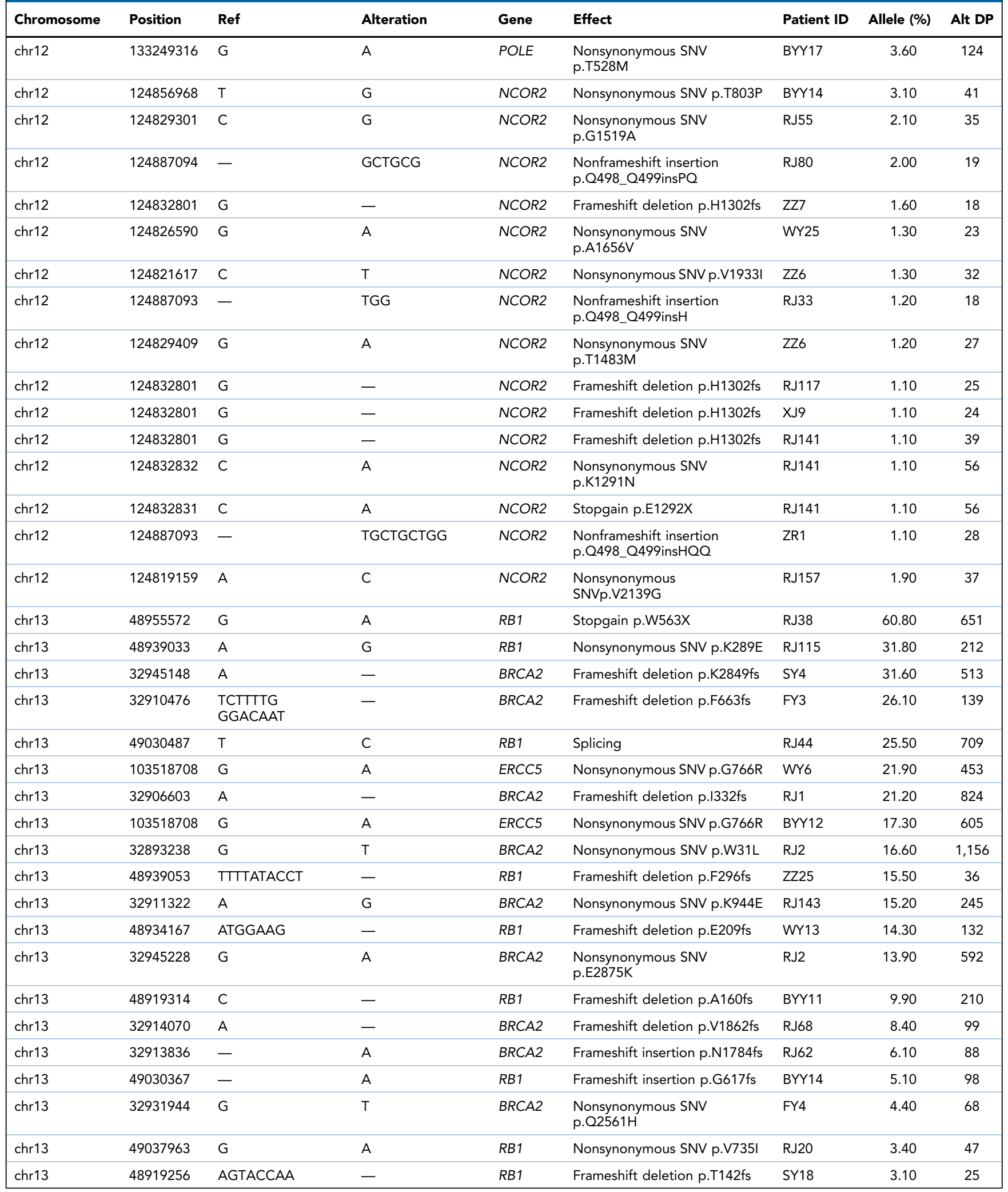


eTable 5. All Filtered Somatic Mutations and Deleterious Germline Mutations Detected (cont.)

\begin{tabular}{|c|c|c|c|c|c|c|c|c|}
\hline Chromosome & Position & Ref & Alteration & Gene & Effect & Patient ID & Allele (\%) & Alt DP \\
\hline chr13 & 49027168 & $\mathrm{C}$ & $\mathrm{T}$ & RB1 & Stopgain p.R579X & ZZ26 & 2.70 & 23 \\
\hline chr13 & 32912895 & C & $\mathrm{T}$ & BRCA2 & $\begin{array}{l}\text { Nonsynonymous SNV } \\
\text { p.S1468F }\end{array}$ & RJ20 & 2.50 & 68 \\
\hline chr13 & 48936968 & AT & - & RB1 & Frameshift deletion p.1246fs & BYY24 & 2.00 & 58 \\
\hline chr13 & 32914782 & C & $\mathrm{T}$ & BRCA2 & $\begin{array}{l}\text { Nonsynonymous SNV } \\
\text { p.T2097M }\end{array}$ & RJ112-1 & 1.80 & 80 \\
\hline chr13 & 103504584 & C & $\mathrm{T}$ & ERCC5 & Stopgain p.R69X & BYY12 & 1.30 & 34 \\
\hline chr13 & 48923150 & - & G & RB1 & Frameshift insertion p.L200fs & RJ106-1 & 1.20 & 30 \\
\hline chr13 & 49033917 & A & C & RB1 & Nonsynonymous SNVp.Q685P & RJ158 & 18.60 & 387 \\
\hline chr13 & 32912455 & $\mathrm{~T}$ & G & BRCA2 & $\begin{array}{l}\text { Nonsynonymous SNV } \\
\text { p.D1321E }\end{array}$ & RJ24 & 1.20 & 22 \\
\hline chr13 & 32913793 & - & $\begin{array}{l}\text { GAAATTAGCCA } \\
\text { GGCATGGTGGC } \\
\text { ATATGCCTGT } \\
\text { AGTCCTAG }\end{array}$ & BRCA2 & Frameshift insertion p.L1768fs & RJ20 & 1.00 & 37 \\
\hline chr13 & 32931989 & $A$ & - & $B R C A 2$ & Frameshift deletion p.G2578fs & RJ19 & 1.00 & 34 \\
\hline chr14 & 38061173 & $\begin{array}{l}\text { CGGCTGCTT } \\
\text { CTCGCACT } \\
\text { TGAAGCG }\end{array}$ & - & FOXA1 & $\begin{array}{l}\text { Nonframeshift deletion } \\
\text { p.R265_P272del }\end{array}$ & RJ25 & 48.90 & 3,487 \\
\hline chr14 & 38061223 & TCTCGA & - & FOXA1 & $\begin{array}{l}\text { Nonframeshift deletion } \\
\text { p.F254_N256delinsY }\end{array}$ & BYY5 & 42.50 & 1,788 \\
\hline chr14 & 38061191 & G & C & FOXA1 & Nonsynonymous SNV p.F266L & BYY18 & 35.10 & 2,136 \\
\hline chr14 & 38061220 & CGTTCT & - & FOXA1 & $\begin{array}{l}\text { Nonframeshift deletion } \\
\text { p.E255_N256del }\end{array}$ & RJ122 & 34.20 & 2,224 \\
\hline chr14 & 38060860 & GTGCCGG & - & FOXA1 & Frameshift deletion p.P375fs & RJ65 & 26.00 & 614 \\
\hline chr14 & 68331719 & G & $\mathrm{T}$ & RAD51B & Splicing & RJ150 & 25.70 & 45 \\
\hline chr14 & 38061249 & $\mathrm{~T}$ & C & FOXA1 & Nonsynonymous SNV p.H247R & ZR2 & 24.50 & 264 \\
\hline chr14 & 38061157 & $\begin{array}{l}\text { CCCCGCCGC } \\
\text { CGGCCCCCGG } \\
\text { CTGCTTCTCGC } \\
\text { ACTTGAAGCGC } \\
\text { TTCT }\end{array}$ & - & FOXA1 & $\begin{array}{l}\text { Nonframeshift deletion } \\
\text { p.Q263_G278delinsR }\end{array}$ & RJ131 & 22.30 & 563 \\
\hline chr14 & 38061240 & GAGT & - & FOXA1 & Frameshift deletion p.D249fs & BYY9 & 22.00 & 1,501 \\
\hline chr14 & 38061241 & AGTC & - & FOXA1 & Frameshift deletion p.D249fs & RJ124 & 20.90 & 1,568 \\
\hline chr14 & 38061178 & $\begin{array}{l}\text { GCTTCTCGC } \\
\text { ACTTGAAGC }\end{array}$ & - & FOXA1 & $\begin{array}{l}\text { Nonframeshift deletion } \\
\text { p.R265_K270del }\end{array}$ & RJ86 & 20.50 & 809 \\
\hline chr14 & 38061240 & G & A & FOXA1 & Nonsynonymous SNV p.S250F & WY6 & 20.10 & 522 \\
\hline chr14 & 38061249 & $T$ & $\mathrm{C}$ & FOXA1 & Nonsynonymous SNV p.H247R & WY13 & 19.30 & 328 \\
\hline chr14 & 38061225 & TCGAACATGTTG & - & FOXA1 & $\begin{array}{l}\text { Nonframeshift deletion } \\
\text { p.M253_N256del }\end{array}$ & WY15 & 18.90 & 348 \\
\hline
\end{tabular}


eTable 5. All Filtered Somatic Mutations and Deleterious Germline Mutations Detected (cont.)

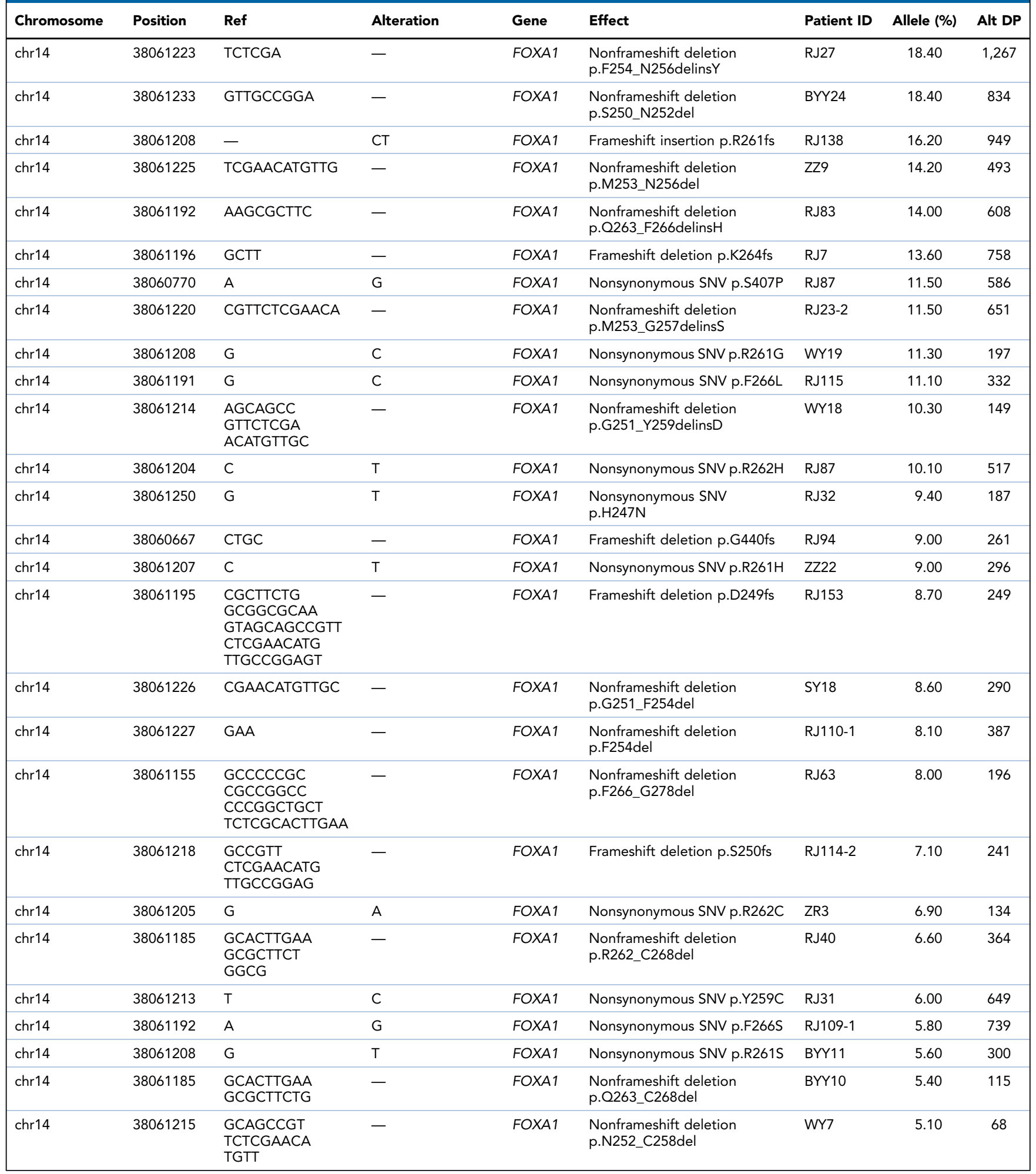


eTable 5. All Filtered Somatic Mutations and Deleterious Germline Mutations Detected (cont.)

\begin{tabular}{|c|c|c|c|c|c|c|c|c|}
\hline Chromosome & Position & Ref & Alteration & Gene & Effect & Patient ID & Allele (\%) & Alt DP \\
\hline chr14 & 38061164 & $\begin{array}{l}\text { GCCGGC } \\
\text { CCCCGGCT } \\
\text { GCTTCTCGCA } \\
\text { CTTGAA }\end{array}$ & - & FOXA1 & $\begin{array}{l}\text { Nonframeshift deletion } \\
\text { p.F266_G275del }\end{array}$ & ZZ20 & 4.50 & 184 \\
\hline chr14 & 75497277 & C & A & MLH3 & $\begin{array}{l}\text { Nonsynonymous SNV } \\
\text { p.G1319V }\end{array}$ & ZZ14 & 4.40 & 133 \\
\hline chr14 & 38061194 & - & $\mathrm{CTT}$ & FOXA1 & $\begin{array}{l}\text { Nonframeshift insertion } \\
\text { p.R265_F266insS }\end{array}$ & RJ55 & 4.20 & 65 \\
\hline chr14 & 38061191 & G & $\mathrm{T}$ & FOXA1 & Nonsynonymous SNV p.F266L & RJ104-1 & 3.90 & 111 \\
\hline chr14 & 38061203 & $\begin{array}{l}\text { GCGGCGC } \\
\text { AAGTAGCA }\end{array}$ & - & FOXA1 & $\begin{array}{l}\text { Nonframeshift deletion } \\
\text { p.C258_R262del }\end{array}$ & RJ71 & 3.40 & 111 \\
\hline chr14 & 38061202 & G & $A$ & FOXA1 & Stopgain p.Q263X & RJ4 & 3.20 & 324 \\
\hline chr14 & 38061192 & $A$ & G & FOXA1 & Nonsynonymous SNV p.F266S & RJ109-2 & 2.90 & 115 \\
\hline chr14 & 38061151 & $\begin{array}{l}\text { TCCCGCCCC } \\
\text { CGCCGCCGG } \\
\text { CCCCCGGCTGC } \\
\text { TTCTCGC } \\
\text { ACTTGA }\end{array}$ & - & FOXA1 & $\begin{array}{l}\text { Nonframeshift deletion } \\
\text { p.F266_S280delinsC }\end{array}$ & RJ68 & 2.60 & 38 \\
\hline chr14 & 38061227 & $\begin{array}{l}\text { GAACATGT } \\
\text { TGCCGGA }\end{array}$ & - & FOXA1 & $\begin{array}{l}\text { Nonframeshift deletion } \\
\text { p.S250_F254del }\end{array}$ & FY4 & 2.50 & 109 \\
\hline chr14 & 38061193 & - & GCGCTTCTG & FOXA1 & $\begin{array}{l}\text { Nonframeshift insertion } \\
\text { p.Q263_R265dup }\end{array}$ & RJ62 & 2.50 & 32 \\
\hline chr14 & 38061193 & $A$ & $\mathrm{C}$ & FOXA1 & Nonsynonymous SNV p.F266V & RJ129 & 2.50 & 55 \\
\hline chr14 & 38061136 & $\begin{array}{l}\text { TGCCCCCGC } \\
\text { TTCCGCTCCC } \\
\text { GCCCCCGCCGC } \\
\text { CGGCCCCCGGC } \\
\text { TGCTTCTCGCA } \\
\text { CTTGAAGCGCT }\end{array}$ & - & FOXA1 & $\begin{array}{l}\text { Nonframeshift deletion } \\
\text { p.K264_G284del }\end{array}$ & BYY3 & 2.40 & 110 \\
\hline chr14 & 38061249 & $\mathrm{~T}$ & C & FOXA1 & Nonsynonymous SNV p.H247R & RJ48 & 2.40 & 50 \\
\hline chr14 & 38061210 & $A$ & G & FOXA1 & Nonsynonymous SNV p.L260S & RJ107-1 & 2.20 & 213 \\
\hline chr14 & 38061218 & GCCGTTCTCGAAC & - & FOXA1 & Frameshift deletion p.M253fs & RJ145 & 1.70 & 31 \\
\hline chr14 & 38061222 & - & $\mathrm{TC}$ & FOXA1 & Frameshift insertion p.N256fs & BYY17 & 1.70 & 60 \\
\hline chr14 & 38061191 & G & $\mathrm{T}$ & FOXA1 & Nonsynonymous SNV p.F266L & RJ104-2 & 1.50 & 11 \\
\hline chr14 & 38061192 & $A$ & $\mathrm{C}$ & FOXA1 & Nonsynonymous SNV p.F266C & RJ22-2 & 1.50 & 100 \\
\hline chr14 & 38061249 & T & C & FOXA1 & Nonsynonymous SNV p.H247R & RJ80 & 1.50 & 42 \\
\hline chr14 & 38061193 & - & GCGCTTCTGGCG & FOXA1 & $\begin{array}{l}\text { Nonframeshift insertion } \\
\text { p.R262_R265dup }\end{array}$ & RJ47 & 1.30 & 29 \\
\hline chr14 & 38061249 & $\mathrm{~T}$ & C & FOXA1 & Nonsynonymous SNV p.H247R & RJ121 & 1.30 & 55 \\
\hline chr14 & 38061229 & ACATGTT & - & FOXA1 & Frameshift deletion p.N252fs & RJ77 & 1.20 & 76 \\
\hline chr14 & 38061249 & $\mathrm{~T}$ & C & FOXA1 & Nonsynonymous SNV p.H247R & ZZ11 & 1.20 & 33 \\
\hline chr14 & 38061221 & $\begin{array}{l}\text { GTTCTCGAA } \\
\text { CATGTTGCCGGA }\end{array}$ & - & FOXA1 & $\begin{array}{l}\text { Nonframeshift deletion } \\
\text { p.S250_N256del }\end{array}$ & RJ18 & 1.10 & 124 \\
\hline chr14 & 38061200 & CTGGCGGCG & - & FOXA1 & $\begin{array}{l}\text { Nonframeshift deletion } \\
\text { p.R261_Q263del }\end{array}$ & RJ157 & 23.40 & 1,246 \\
\hline chr15 & 41021753 & A & G & RAD51 & Nonsynonymous SNV p.Y233C & WY25 & 1.00 & 33 \\
\hline chr16 & 23647232 & G & - & PALB2 & Frameshift deletion p.P212fs & $\mathrm{FY} 3$ & 28.10 & 265 \\
\hline chr16 & 68835781 & C & - & $\mathrm{CDH} 1$ & Frameshift deletion p.P126fs & RJ108-2 & 25.00 & 631 \\
\hline chr16 & 23647133 & G & A & PALB2 & Nonsynonymous SNV p.A245V & RJ123 & 12.30 & 468 \\
\hline chr16 & 89825027 & G & A & FANCA & Nonsynonymous SNV p.A980V & $\mathrm{xJ} 2$ & 10.30 & 428 \\
\hline chr16 & 68847375 & G & A & $\mathrm{CDH} 1$ & $\begin{array}{l}\text { Nonsynonymous SNV } \\
\text { p.D433N }\end{array}$ & RJ74 & 5.60 & 184 \\
\hline
\end{tabular}


eTable 5. All Filtered Somatic Mutations and Deleterious Germline Mutations Detected (cont.)

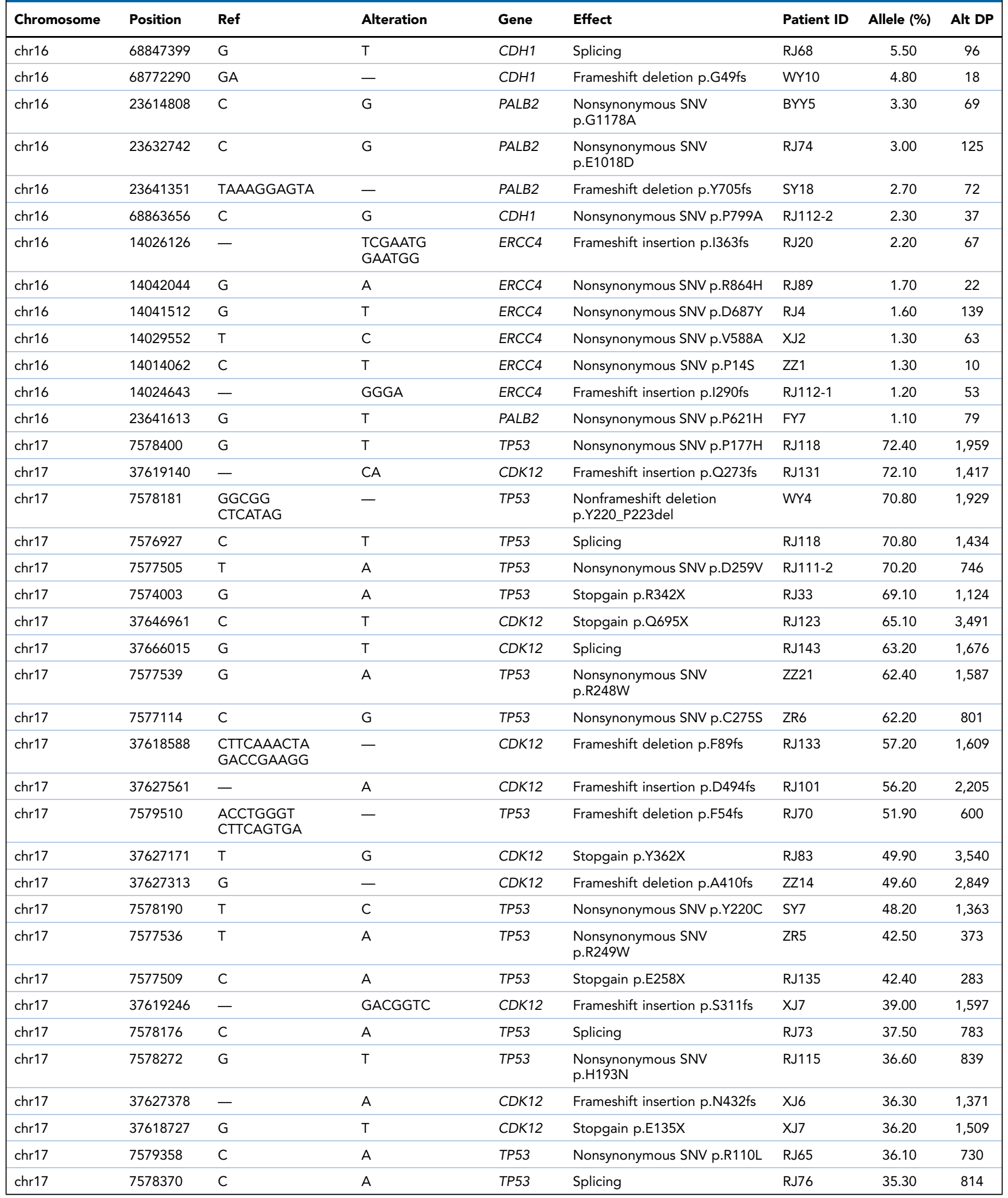


eTable 5. All Fltered Somatic Mutations and Deleterious Germline Mutations Detected (cont.)

\begin{tabular}{|c|c|c|c|c|c|c|c|c|}
\hline Chromosome & Position & Ref & Alteration & Gene & Effect & Patient ID & Allele (\%) & Alt DP \\
\hline chr17 & 47696426 & $A$ & G & SPOP & Nonsynonymous SNV p.F133L & RJ139 & 35.00 & 890 \\
\hline chr17 & 47696644 & $A$ & $\mathrm{C}$ & SPOP & Nonsynonymous SNV p.F102V & ZZ21 & 35.00 & 1,639 \\
\hline chr17 & 7577085 & C & A & TP53 & Stopgain p.E285X & WY12 & 34.50 & 907 \\
\hline chr17 & 47696644 & $A$ & C & SPOP & Nonsynonymous SNV p.F102V & WY21 & 34.30 & 629 \\
\hline chr17 & 7576857 & $A$ & C & TP53 & Nonsynonymous SNV p.L330R & BYY24 & 32.90 & 801 \\
\hline chr17 & 7577506 & C & G & TP53 & Nonsynonymous SNV p.D259H & WY21 & 32.50 & 452 \\
\hline chr17 & 56809886 & C & $\mathrm{T}$ & RAD51C & Nonsynonymous SNV p.T336I & ZR6 & 32.10 & 467 \\
\hline chr17 & 7577022 & G & A & TP53 & Stopgain p.R306X & ZZ6 & 30.60 & 358 \\
\hline chr17 & 15967502 & C & A & NCOR1 & Splicing & ZZ9 & 29.20 & 528 \\
\hline chr17 & 16004850 & C & A & NCOR1 & Stopgain p.E802X & BYY9 & 28.00 & 1,691 \\
\hline chr17 & 37682248 & C & $\mathrm{T}$ & CDK12 & Stopgain p.Q1147X & RJ141 & 27.50 & 1,810 \\
\hline chr17 & 37667797 & - & A & CDK12 & Frameshift insertion p.V896fs & WY10 & 27.20 & 583 \\
\hline chr17 & 47696467 & C & $\mathrm{T}$ & SPOP & Nonsynonymous SNV p.S119N & RJ135 & 27.10 & 49 \\
\hline chr17 & 37665992 & C & $\mathrm{T}$ & CDK12 & $\begin{array}{l}\text { Nonsynonymous SNV } \\
\text { p.R882W }\end{array}$ & RJ73 & 26.60 & 779 \\
\hline chr17 & 37619128 & TACC & - & CDK12 & Frameshift deletion p.T269fs & WY3 & 26.40 & 1,004 \\
\hline chr17 & 37650948 & G & A & CDK12 & Splicing & RJ73 & 26.00 & 562 \\
\hline chr17 & 7577096 & $\mathrm{~T}$ & - & TP53 & Frameshift deletion p.D281fs & WY6 & 25.50 & 598 \\
\hline chr17 & 37646895 & C & - & CDK12 & Frameshift deletion p.P673fs & WY10 & 23.00 & 501 \\
\hline chr17 & 37667862 & CCAT & - & CDK12 & Frameshift deletion p.A916fs & WY3 & 22.90 & 510 \\
\hline chr17 & 7578526 & C & A & TP53 & Nonsynonymous SNV p.C135F & RJ88 & 22.80 & 649 \\
\hline chr17 & 47696431 & C & G & SPOP & $\begin{array}{l}\text { Nonsynonymous SNV } \\
\text { p.W131S }\end{array}$ & RJ85 & 22.70 & 734 \\
\hline chr17 & 37627418 & A & - & CDK12 & Frameshift deletion p.K446fs & BYY14 & 22.10 & 757 \\
\hline chr17 & 37627733 & CCTTT & - & CDK12 & Frameshift deletion p.P550fs & $\mathrm{XJ} 6$ & 21.50 & 1,098 \\
\hline chr17 & 7578370 & C & G & TP53 & Splicing & RJ2 & 20.40 & 1,195 \\
\hline chr17 & 37646903 & C & - & CDK12 & Frameshift deletion p.P676fs & BYY14 & 20.30 & 619 \\
\hline chr17 & 7579580 & G & A & TP53 & Nonsynonymous SNV p.P36L & RJ108-2 & 20.30 & 665 \\
\hline chr17 & 47696424 & G & C & SPOP & Nonsynonymous SNV p.F133L & WY24 & 20.20 & 189 \\
\hline chr17 & 37646970 & - & A & CDK12 & Stopgain p.Y698_K699delinsX & RJ120 & 20.00 & 740 \\
\hline chr17 & 7577534 & C & G & TP53 & Nonsynonymous SNV p.R249S & BYY26 & 20.00 & 480 \\
\hline chr17 & 47696424 & G & C & SPOP & Nonsynonymous SNV p.F133L & BYY16 & 19.20 & 399 \\
\hline
\end{tabular}




\section{eTable 5. All Filtered Somatic Mutations and Deleterious Germline Mutations Detected (cont.)}

\begin{tabular}{|c|c|c|c|c|c|c|c|c|}
\hline Chromosome & Position & Ref & Alteration & Gene & Effect & Patient ID & Allele (\%) & Alt DP \\
\hline chr17 & 37657671 & C & $A$ & CDK12 & Nonsynonymous SNV p.S863Y & RJ3 & 19.10 & 962 \\
\hline chr17 & 37650890 & AAC & - & CDK12 & $\begin{array}{l}\text { Nonframeshift deletion } \\
\text { p.N788del }\end{array}$ & RJ3 & 18.60 & 719 \\
\hline chr17 & 7576923 & AGTGCTAGGA & - & TP53 & Frameshift deletion p.A307fs & WY19 & 18.20 & 444 \\
\hline chr17 & 47696425 & $A$ & G & SPOP & Nonsynonymous SNV p.F133S & RJ76 & 18.10 & 632 \\
\hline chr17 & 37618464 & C & - & CDK12 & Frameshift deletion p.K48fs & BYY3 & 17.10 & 478 \\
\hline chr17 & 47696426 & A & C & SPOP & Nonsynonymous SNV p.F133V & RJ37 & 16.80 & 501 \\
\hline chr17 & 37628017 & G & $\mathrm{T}$ & CDK12 & Splicing & RJ152 & 16.80 & 644 \\
\hline chr17 & 37619299 & - & C & CDK12 & Frameshift insertion p.Y327fs & RJ87 & 15.80 & 603 \\
\hline chr17 & 7577506 & C & A & TP53 & Nonsynonymous SNV p.D259Y & WY16 & 14.50 & 388 \\
\hline chr17 & 7579414 & C & $\mathrm{T}$ & TP53 & Stopgain p.W91X & BYY10 & 14.00 & 306 \\
\hline chr17 & 37627334 & G & $\mathrm{T}$ & CDK12 & Stopgain p.G417X & BYY3 & 13.80 & 452 \\
\hline chr17 & 7578475 & G & A & TP53 & Nonsynonymous SNV p.P152L & RJ152 & 13.80 & 528 \\
\hline chr17 & 7577022 & G & A & TP53 & Stopgain p.R306X & RJ14 & 13.40 & 1,139 \\
\hline chr17 & 37650878 & C & $\mathrm{T}$ & CDK12 & Stopgain p.R784X & $\mathrm{ZZ14}$ & 12.70 & 511 \\
\hline chr17 & 7577570 & C & $\mathrm{T}$ & TP53 & Nonsynonymous SNV p.M237I & WY5 & 12.40 & 229 \\
\hline chr17 & 7577505 & $\mathrm{~T}$ & A & TP53 & Nonsynonymous SNV p.D259V & RJ111-1 & 11.90 & 392 \\
\hline chr17 & 7577121 & G & A & TP53 & Nonsynonymous SNV p.R273C & BYY16 & 11.80 & 297 \\
\hline chr17 & 7578403 & C & $\mathrm{T}$ & TP53 & Nonsynonymous SNV p.C176Y & SY10 & 10.00 & 133 \\
\hline chr17 & 7578550 & G & $A$ & TP53 & Nonsynonymous SNV p.S127F & SY18 & 10.00 & 177 \\
\hline chr17 & 37627619 & - & $\mathrm{T}$ & CDK12 & Frameshift insertion p.V513fs & RJ104-1 & 9.70 & 182 \\
\hline chr17 & 46805694 & A & C & HOXB13 & Nonsynonymous SNV p.Y88D & RJ135 & 9.70 & 223 \\
\hline chr17 & 47696601 & G & C & SPOP & Nonsynonymous SNV p.A116G & RJ102 & 9.40 & 412 \\
\hline chr17 & 37619279 & - & A & CDK12 & Stopgain p.Y319_S320delinsX & BYY11 & 9.10 & 429 \\
\hline chr17 & 37618491 & $\mathrm{~T}$ & - & CDK12 & Frameshift deletion p.V56fs & RJ31 & 9.10 & 778 \\
\hline chr17 & 37646821 & CT & - & CDK12 & Frameshift deletion p.L649fs & ZZ22 & 8.90 & 89 \\
\hline chr17 & 47696424 & G & $\mathrm{T}$ & SPOP & Nonsynonymous SNV p.F133L & $\mathrm{ZZ2}$ & 8.80 & 262 \\
\hline chr17 & 37619279 & - & A & CDK12 & Stopgain p.Y319_S320delinsX & RJ31 & 8.70 & 883 \\
\hline chr17 & 47696689 & A & C & SPOP & Nonsynonymous SNV p.Y87D & RJ109-1 & 8.60 & 694 \\
\hline chr17 & 7579285 & $\begin{array}{l}\text { GGAAGCCA } \\
\text { GCCCCTCAGG } \\
\text { GCAACTGACC }\end{array}$ & - & TP53 & Frameshift deletion p.T125fs & RJ124 & 7.90 & 400 \\
\hline
\end{tabular}


eTable 5. All Flltered Somatic Mutations and Deleterious Germline Mutations Detected (cont.)

\begin{tabular}{|c|c|c|c|c|c|c|c|c|}
\hline Chromosome & Position & Ref & Alteration & Gene & Effect & Patient ID & Allele (\%) & Alt DP \\
\hline chr17 & 41246511 & G & $\mathrm{T}$ & BRCA1 & Nonsynonymous SNV p.P346H & WY7 & 7.70 & 18 \\
\hline chr17 & 37619141 & C & $\mathrm{T}$ & CDK12 & Stopgain p.Q273X & RJ143 & 7.70 & 364 \\
\hline chr17 & 37619281 & C & G & CDK12 & Stopgain p.Y319X & RJ123 & 7.10 & 471 \\
\hline chr17 & 37646854 & A & - & CDK12 & Frameshift deletion p.E659fs & RJ152 & 6.70 & 396 \\
\hline chr17 & 37646961 & C & $\mathrm{T}$ & CDK12 & Stopgain p.Q695X & BYY4 & 6.40 & 129 \\
\hline chr17 & 47696424 & G & C & SPOP & Nonsynonymous SNV p.F133L & $\mathrm{xJ3}$ & 6.30 & 87 \\
\hline chr17 & 37687471 & - & G & CDK12 & Frameshift insertion p.T1463fs & RJ108-2 & 6.00 & 145 \\
\hline chr17 & 7577081 & $\mathrm{~T}$ & A & TP53 & Nonsynonymous SNV p.E286V & ZZ8 & 5.90 & 155 \\
\hline chr17 & 37676223 & C & $\mathrm{T}$ & $C D K 12$ & Nonsynonymous SNV p.A993V & ZZ18 & 5.20 & 175 \\
\hline chr17 & 37650899 & - & A & CDK12 & Frameshift insertion p.1792fs & RJ77 & 4.90 & 35 \\
\hline chr17 & 16021203 & $\mathrm{~T}$ & A & NCOR1 & Nonsynonymous SNV p.K685I & ZR4 & 4.60 & 79 \\
\hline chr17 & 37676207 & A & G & $C D K 12$ & Splicing & BYY4 & 4.40 & 118 \\
\hline chr17 & 7578263 & G & A & TP53 & Stopgain p.R196X & ZZ4 & 4.40 & 144 \\
\hline chr17 & 37627315 & $\mathrm{~T}$ & - & CDK12 & Frameshift deletion p.A411fs & RJ80 & 4.20 & 142 \\
\hline chr17 & 15961359 & A & C & NCOR1 & Stopgain p.Y2010X & RJ55 & 4.10 & 55 \\
\hline chr17 & 47696689 & A & C & SPOP & Nonsynonymous SNV p.Y87D & RJ109-2 & 4.10 & 77 \\
\hline chr17 & 47696689 & A & $\mathrm{T}$ & SPOP & Nonsynonymous SNV p.Y87N & SY9 & 4.00 & 51 \\
\hline chr17 & 47679285 & G & C & SPOP & Nonsynonymous SNV p.L308V & ZZ9 & 3.60 & 105 \\
\hline chr17 & 7577570 & C & $\mathrm{T}$ & TP53 & Nonsynonymous SNV p.M237I & WY26 & 3.50 & 69 \\
\hline chr17 & 37627919 & C & $\mathrm{T}$ & $C D K 12$ & Stopgain p.Q612X & RJ114-2 & 3.40 & 88 \\
\hline chr17 & 37676226 & TTGATTTA & - & CDK12 & Frameshift deletion p.D995fs & RJ71 & 3.30 & 75 \\
\hline chr17 & 37666000 & - & A & CDK12 & Frameshift insertion p.N885fs & ZZ22 & 3.20 & 18 \\
\hline chr17 & 7577144 & AGT & - & TP53 & $\begin{array}{l}\text { Nonframeshift deletion } \\
\text { p.L265del }\end{array}$ & RJ137 & 3.10 & 108 \\
\hline chr17 & 37667852 & $\mathrm{~T}$ & G & CDK12 & Nonsynonymous SNV p.Y913D & RJ11 & 2.80 & 191 \\
\hline chr17 & 47696601 & G & C & SPOP & Nonsynonymous SNV p.A116G & RJ4 & 2.80 & 260 \\
\hline chr17 & 37627577 & C & - & CDK12 & Frameshift deletion p.Q498fs & WY20 & 2.80 & 11 \\
\hline chr17 & 16001704 & G & A & NCOR1 & Stopgain p.R933X & ZZ19 & 2.80 & 75 \\
\hline chr17 & 47696456 & A & G & SPOP & Nonsynonymous SNV p.Y123H & RJ92 & 2.20 & 140 \\
\hline chr17 & 7579427 & G & - & TP53 & Frameshift deletion p.P87fs & RJ10 & 2.10 & 212 \\
\hline chr17 & 37657693 & G & $\mathrm{T}$ & CDK12 & Splicing & RJ11 & 2.00 & 127 \\
\hline
\end{tabular}




\section{eTable 5. All Filtered Somatic Mutations and Deleterious Germline Mutations Detected (cont.)}

\begin{tabular}{|c|c|c|c|c|c|c|c|c|}
\hline Chromosome & Position & Ref & Alteration & Gene & Effect & Patient ID & Allele (\%) & Alt DP \\
\hline chr17 & 37650838 & - & G & CDK12 & Frameshift insertion p.A771fs & RJ40 & 2.00 & 73 \\
\hline chr17 & 37676249 & ACAC & - & CDK12 & Frameshift deletion p.T1002fs & RJ71 & 1.80 & 38 \\
\hline chr17 & 41245327 & A & $\mathrm{T}$ & BRCA1 & Nonsynonymous SNV p.S741T & RJ27 & 1.70 & 119 \\
\hline chr17 & 7577532 & GGCCTCC & - & TP53 & Frameshift deletion p.R248fs & RJ83 & 1.60 & 30 \\
\hline chr17 & 37687472 & G & - & CDK12 & Frameshift deletion p.G1461fs & $\mathrm{ZZ7}$ & 1.50 & 17 \\
\hline chr17 & 37619180 & C & $\mathrm{T}$ & CDK12 & Stopgain p.Q286X & ZZ23 & 1.50 & 29 \\
\hline chr17 & 41219700 & $\mathrm{~T}$ & A & BRCA1 & Stopgain p.K1667X & RJ88 & 1.40 & 23 \\
\hline chr17 & 7579534 & TTCAA & - & TP53 & Frameshift deletion p.150fs & RJ140 & 1.40 & 49 \\
\hline chr17 & 7579580 & G & A & TP53 & Nonsynonymous SNV p.P36L & RJ108-1 & 1.30 & 151 \\
\hline chr17 & 15968814 & A & C & NCOR1 & $\begin{array}{l}\text { Nonsynonymous SNV } \\
\text { p.Y1646D }\end{array}$ & RJ24 & 1.30 & 43 \\
\hline chr17 & 37619172 & C & $\mathrm{T}$ & CDK12 & Nonsynonymous SNV p.S283L & RJ66 & 1.20 & 20 \\
\hline chr17 & 41199713 & $\mathrm{~T}$ & $A$ & BRCA1 & $\begin{array}{l}\text { Nonsynonymous SNV } \\
\text { p.H1805L }\end{array}$ & $\mathrm{FY} 3$ & 1.20 & 27 \\
\hline chr17 & 41201161 & G & $\mathrm{T}$ & BRCA1 & Nonsynonymous SNV p.L1795I & RJ24 & 1.20 & 35 \\
\hline chr17 & 37657673 & A & G & CDK12 & $\begin{array}{l}\text { Nonsynonymous SNV } \\
\text { p.N864D }\end{array}$ & RJ80 & 1.20 & 25 \\
\hline chr17 & 7577548 & C & $\mathrm{T}$ & TP53 & Nonsynonymous SNVp.G245S & SY28 & 7.80 & 155 \\
\hline chr17 & 7577575 & A & G & TP53 & Nonsynonymous SNVp.Y236H & SY29 & 7.40 & 199 \\
\hline chr17 & 37619280 & - & $A$ & CDK12 & Stopgain p.Y319_S320delinsX & SY30 & 1.00 & 26 \\
\hline chr17 & 37657610 & CT & AA & CDK12 & Nonsynonymous SNVp.L843K & sY30 & 1.50 & 17 \\
\hline chr17 & 47696644 & A & C & SPOP & Nonsynonymous SNVp.F102V & SY5 & 1.50 & 19 \\
\hline chr19 & 50917071 & G & $\mathrm{T}$ & POLD1 & $\begin{array}{l}\text { Nonsynonymous SNV } \\
\text { p.G775W }\end{array}$ & RJ108-2 & 19.40 & 427 \\
\hline chr19 & 1207048 & A & C & STK11 & Nonsynonymous SNV p.146L & SY10 & 6.30 & 71 \\
\hline chr19 & 50909469 & G & $\mathrm{T}$ & POLD1 & Nonsynonymous SNV p.A425S & WY12 & 2.20 & 80 \\
\hline chr19 & 50919866 & G & - & POLD1 & Frameshift deletion p.D987fs & RJ119 & 1.50 & 23 \\
\hline chr19 & 45855582 & $\mathrm{~T}$ & G & $E R C C 2$ & Nonsynonymous SNV p.K692T & SY11 & 1.20 & 11 \\
\hline chr19 & 50917071 & G & $\mathrm{T}$ & POLD1 & $\begin{array}{l}\text { Nonsynonymous SNV } \\
\text { p.G775W }\end{array}$ & RJ108-1 & 1.20 & 161 \\
\hline chr22 & 29095882 & G & A & CHEK2 & Nonsynonymous SNV p.R318C & RJ113-2 & 4.00 & 51 \\
\hline
\end{tabular}


eTable 5. All Flltered Somatic Mutations and Deleterious Germline Mutations Detected (cont.)

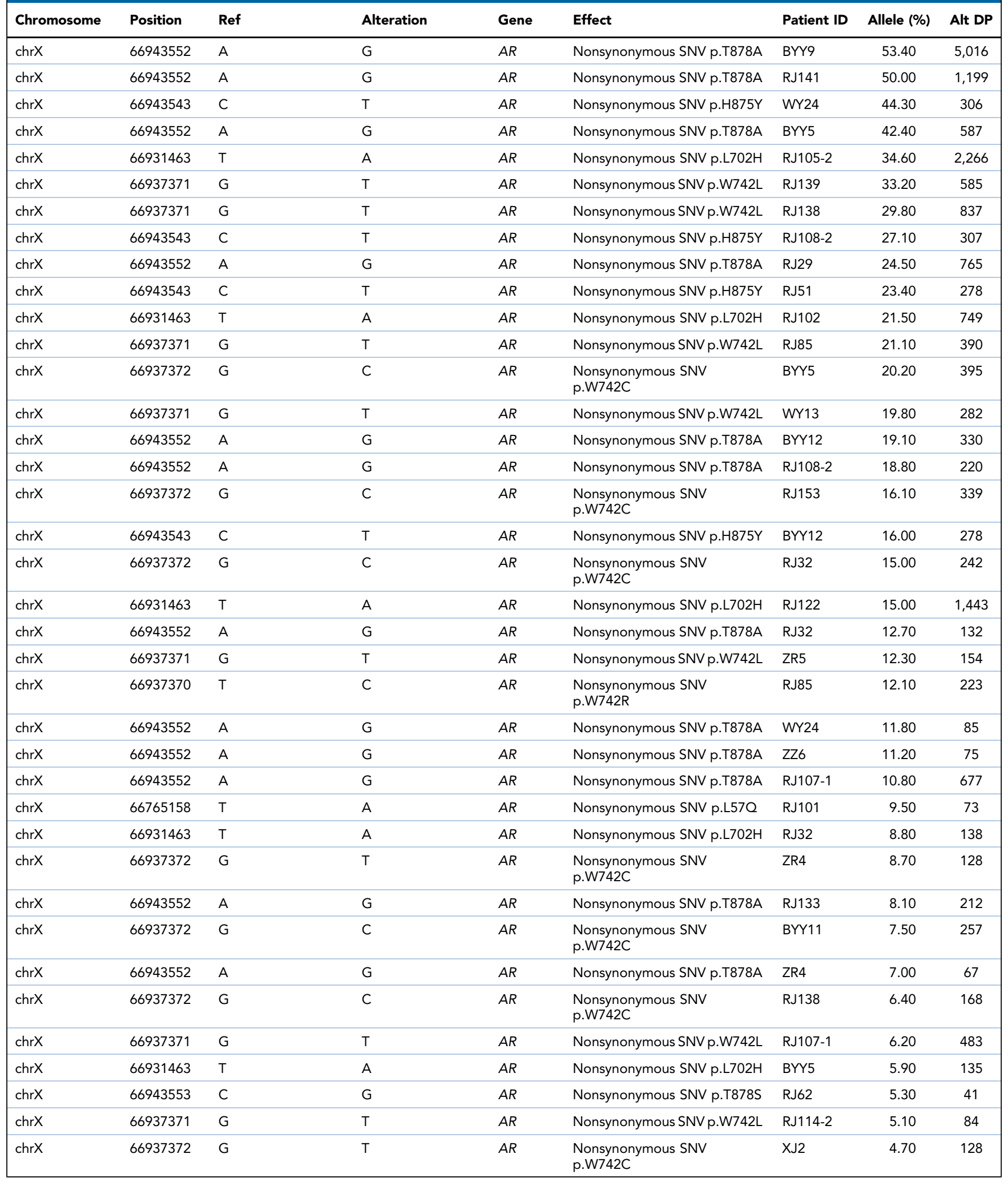




\section{eTable 5. All Filtered Somatic Mutations and Deleterious Germline Mutations Detected (cont.)}

\begin{tabular}{|c|c|c|c|c|c|c|c|c|}
\hline Chromosome & Position & Ref & Alteration & Gene & Effect & Patient ID & Allele (\%) & Alt DP \\
\hline $\operatorname{chrX}$ & 66937372 & G & $\mathrm{T}$ & $A R$ & $\begin{array}{l}\text { Nonsynonymous SNV } \\
\text { p.W742C }\end{array}$ & RJ149 & 3.50 & 50 \\
\hline $\operatorname{chrX}$ & 66937372 & G & C & $A R$ & $\begin{array}{l}\text { Nonsynonymous SNV } \\
\text { p.W742C }\end{array}$ & ZR5 & 3.50 & 43 \\
\hline $\operatorname{chr} X$ & 66931463 & $\mathrm{~T}$ & $A$ & $A R$ & Nonsynonymous SNV p.L702H & RJ71 & 3.30 & 46 \\
\hline $\operatorname{chr} X$ & 66943552 & A & G & $A R$ & Nonsynonymous SNV p.T878A & RJ71 & 3.30 & 35 \\
\hline $\operatorname{chr} \mathrm{X}$ & 66937371 & G & $\mathrm{T}$ & $A R$ & Nonsynonymous SNV p.W742L & $\mathrm{XJ} 2$ & 3.30 & 90 \\
\hline $\operatorname{chrX}$ & 66931463 & $\mathrm{~T}$ & $A$ & $A R$ & Nonsynonymous SNV p.L702H & RJ62 & 3.10 & 33 \\
\hline $\operatorname{chrX}$ & 66943552 & A & G & $A R$ & Nonsynonymous SNV p.T878A & RJ134 & 3.00 & 32 \\
\hline $\operatorname{chrX}$ & 66943552 & A & G & $A R$ & Nonsynonymous SNV p.T878A & RJ149 & 3.00 & 28 \\
\hline $\operatorname{chr} X$ & 66937371 & G & $\mathrm{T}$ & $A R$ & Nonsynonymous SNV p.W742L & ZZ9 & 3.00 & 90 \\
\hline $\operatorname{chrX}$ & 66943552 & A & G & $A R$ & Nonsynonymous SNV p.T878A & BYY13 & 2.90 & 12 \\
\hline $\operatorname{chrX}$ & 66937372 & G & C & $A R$ & $\begin{array}{l}\text { Nonsynonymous SNV } \\
\text { p.W742C }\end{array}$ & ZZ26 & 2.90 & 72 \\
\hline $\operatorname{chrX}$ & 66937372 & G & $\mathrm{T}$ & $A R$ & $\begin{array}{l}\text { Nonsynonymous SNV } \\
\text { p.W742C }\end{array}$ & BYY12 & 2.70 & 61 \\
\hline $\operatorname{chrX}$ & 66937371 & G & $\mathrm{T}$ & $A R$ & Nonsynonymous SNV p.W742L & ZZ26 & 2.70 & 66 \\
\hline $\operatorname{chrX}$ & 66937371 & G & $\mathrm{T}$ & $A R$ & Nonsynonymous SNV p.W742L & RJ10 & 2.60 & 147 \\
\hline $\operatorname{chrX}$ & 66765161 & $A$ & $\mathrm{~T}$ & $A R$ & Nonsynonymous SNV p.Q58L & SY8 & 1.90 & 28 \\
\hline $\operatorname{chrX}$ & 66931463 & $\mathrm{~T}$ & A & $A R$ & Nonsynonymous SNV p.L702H & RJ141 & 1.90 & 63 \\
\hline $\operatorname{chrX}$ & 66937371 & G & $\mathrm{T}$ & $A R$ & Nonsynonymous SNV p.W742L & BYY11 & 1.80 & 64 \\
\hline $\operatorname{chrX}$ & 66931463 & $\mathrm{~T}$ & A & $A R$ & Nonsynonymous SNV p.L702H & ZZ14 & 1.80 & 93 \\
\hline $\operatorname{chrX}$ & 66943552 & $A$ & G & $A R$ & Nonsynonymous SNV p.T878A & SY12 & 1.70 & 18 \\
\hline $\operatorname{chrX}$ & 66937372 & G & $\mathrm{T}$ & $A R$ & $\begin{array}{l}\text { Nonsynonymous } \\
\text { SNVp.W742C }\end{array}$ & SY28 & 22.90 & 479 \\
\hline $\operatorname{chrX}$ & 66943552 & $A$ & G & $A R$ & Nonsynonymous SNV p.T878A & RJ104-1 & 1.60 & 23 \\
\hline $\operatorname{chrX}$ & 66943552 & A & G & $A R$ & Nonsynonymous SNV p.T878A & RJ62 & 1.60 & 12 \\
\hline $\operatorname{chrX}$ & 66937372 & G & C & $A R$ & $\begin{array}{l}\text { Nonsynonymous SNV } \\
\text { p.W742C }\end{array}$ & RJ114-2 & 1.50 & 24 \\
\hline $\operatorname{chrX}$ & 66943543 & C & $\mathrm{T}$ & $A R$ & Nonsynonymous SNV p.H875Y & RJ144 & 1.50 & 22 \\
\hline $\operatorname{chrX}$ & 66937372 & G & $\mathrm{T}$ & $A R$ & $\begin{array}{l}\text { Nonsynonymous SNV } \\
\text { p.W742C }\end{array}$ & RJ101 & 1.40 & 124 \\
\hline $\operatorname{chr} X$ & 66943585 & A & G & $A R$ & Nonsynonymous SNV p.S889G & RJ75 & 1.40 & 24 \\
\hline
\end{tabular}


eTable 5. All Filtered Somatic Mutations and Deleterious Germline Mutations Detected (cont.)

\begin{tabular}{lllllllll}
\hline Chromosome & Position & Ref & Alteration & Gene & Effect & Patient ID Allele (\%) & Alt DP \\
\hline chrX & 66905791 & G & A & $A R$ & Nonsynonymous SNV p.R542Q & RJ112-1 & 1.30 & 27 \\
chrX & 66937372 & G & C & $A R$ & $\begin{array}{l}\text { Nonsynonymous SNV } \\
\text { p.W742C }\end{array}$ & ZR2 & 1.20 & 139
\end{tabular}

Deleterious

germline

mutations

\begin{tabular}{|c|c|c|c|c|c|c|c|c|}
\hline chr1 & 45800165 & G & $A$ & MUTYH & Stopgain p.R19X & RJ82 & 51.49 & 104 \\
\hline chr1 & 45800165 & G & $A$ & MUTYH & Stopgain p.R19X & RJ82 & 51.49 & 104 \\
\hline chr2 & 128051209 & AA & - & ERCC3 & Frameshift deletion p.V38fs & RJ41 & 46.41 & 207 \\
\hline chr2 & 17962331 & - & $\mathrm{T}$ & GEN1 & Frameshift insertion p.S619fs & RJ54 & 49.91 & 292 \\
\hline chr2 & 190738287 & G & - & PMS1 & Stopgain p.V847X & BYY13 & 50.63 & 161 \\
\hline chr2 & 215645974 & - & $\mathrm{T}$ & BARD1 & Frameshift insertion p.K209fs & ZZ10 & 49.07 & 290 \\
\hline chr2 & 47604177 & - & C & EPCAM & Frameshift insertion p.R173fs & BYY25 & 47.71 & 292 \\
\hline chr2 & 17955667 & C & $\mathrm{T}$ & GEN1 & Stopgain p.R401X & $\mathrm{xJ7}$ & 46.94 & 376 \\
\hline chr2 & 17955667 & C & $\mathrm{T}$ & GEN1 & Stopgain p.R401X & $\mathrm{xJ7}$ & 46.94 & 376 \\
\hline chr3 & 142259780 & G & $A$ & ATR & Stopgain p.R1183X & RJ50 & 49.86 & 366 \\
\hline chr11 & 108115681 & G & $T$ & ATM & Stopgain p.E277X & RJ15 & 53.80 & 262 \\
\hline chr11 & 108236087 & G & $A$ & ATM & $\begin{array}{l}\text { Nonsynonymous SNV } \\
\text { p.R3008H }\end{array}$ & RJ25 & 48.47 & 190 \\
\hline chr11 & 108236087 & G & $A$ & ATM & $\begin{array}{l}\text { Nonsynonymous SNV } \\
\text { p.R3008H }\end{array}$ & $\mathrm{xJ} 3$ & 50.54 & 464 \\
\hline chr11 & 108121594 & AA & - & ATM & Frameshift deletion p.K468fs & ZZ13 & 50.16 & 318 \\
\hline chr11 & 108178646 & C & $A$ & ATM & Stopgain p.C1899X & ZZ27 & 51.08 & 261 \\
\hline chr11 & 108214099 & GTGA & - & ATM & Splicing & ZZ28 & 44.56 & 266 \\
\hline chr11 & 108121531 & C & $\mathrm{T}$ & ATM & Stopgain p.R447X & WY22 & 49.76 & 513 \\
\hline chr13 & 32911298 & AAAC & - & BRCA2 & Frameshift deletion p.A938fs & RJ38 & 50.52 & 343 \\
\hline chr13 & 32911335 & $\mathrm{~T}$ & - & BRCA2 & Frameshift deletion p.Y949fs & RJ16 & 50.44 & 344 \\
\hline chr13 & 32910749 & $\mathrm{~T}$ & - & BRCA2 & Frameshift deletion p.Q754fs & RJ17 & 54.51 & 369 \\
\hline chr13 & 32914954 & ТСТС & - & BRCA2 & Frameshift deletion p.S2156fs & RJ26 & 47.40 & 283 \\
\hline chr13 & 32914174 & C & G & BRCA2 & Stopgain p.Y1894X & WY13 & 51.04 & 713 \\
\hline chr13 & 32911143 & CAGA & - & BRCA2 & Frameshift deletion p.D885fs & BYY7 & 45.77 & 303 \\
\hline chr13 & 32914066 & AATT & - & BRCA2 & Frameshift deletion p.I1859fs & WY7 & 48.38 & 733 \\
\hline $\operatorname{chr} 13$ & 32911100 & - & $\mathrm{T}$ & BRCA2 & Frameshift insertion p.S871fs & ZR2 & 49.86 & 367 \\
\hline chr13 & 103514595 & C & $\mathrm{T}$ & ERCC5 & Stopgain p.R366X & ZZ7 & 46.07 & 299 \\
\hline chr13 & 32913017 & C & $\mathrm{T}$ & BRCA2 & Stopgain p.Q1509X & ZZ9 & 49.38 & 318 \\
\hline chr13 & 32915032 & G & - & BRCA2 & Frameshift deletion p.G2181fs & $\mathrm{ZZ12}$ & 50.41 & 245 \\
\hline $\operatorname{chr} 13$ & 32936732 & G & $A$ & BRCA2 & Stopgain p.W2626X & ZZ15 & 54.86 & 271 \\
\hline chr13 & 32911047 & - & C & BRCA2 & Frameshift insertion p.Q853fs & ZR6 & 47.65 & 284 \\
\hline chr13 & 32971034 & G & $\mathrm{T}$ & BRCA2 & Splicing & RJ119 & 43.55 & 223 \\
\hline $\operatorname{chr} 13$ & 32914130 & AATA & - & BRCA2 & Frameshift deletion p.K1881fs & $\mathrm{xJ7}$ & 48.41 & 396 \\
\hline chr13 & 32910932 & C & - & BRCA2 & Frameshift deletion p.M815fs & RJ144 & 49.59 & 305 \\
\hline chr13 & 32914210 & CT & - & BRCA2 & Frameshift deletion p.L1908fs & SY21 & 51.00 & 637 \\
\hline chr13 & 32913558 & - & A & BRCA2 & Frameshift insertion p.W1692fs & RJ124 & 45.55 & 169 \\
\hline chr13 & 32921033 & G & $A$ & BRCA2 & $\begin{array}{l}\text { Nonsynonymous SNV } \\
\text { p.R2336H }\end{array}$ & RJ117 & 49.55 & 164 \\
\hline
\end{tabular}


eTable 5. All Filtered Somatic Mutations and Deleterious Germline Mutations Detected (cont.)

\begin{tabular}{|lllllllll}
\hline Chromosome & Position & Ref & Alteration & Gene & Effect & Patient ID & Allele (\%) & Alt DP \\
\hline chr13 & 32907522 & C & A & BRCA2 & Stopgain p.S636X & RJ154 & 52.41 & 228 \\
\hline chr14 & 75515744 & T & - & MLH3 & Frameshift deletion p.D206fs & FY5 & 47.14 & 354 \\
\hline chr16 & 23641691 & T & - & PALB2 & Frameshift deletion p.D595fs & RJ45 & 45.96 & 625 \\
\hline chr16 & 23647108 & - & A & PALB2 & Frameshift insertion p.S254fs & RJ30 & 44.71 & 148 \\
\hline chr16 & 23614813 & T & - & PALB2 & Frameshift deletion p.D1177fs & FY2 & 50.27 & 277 \\
\hline chr16 & 23634318 & C & A & PALB2 & Stopgain p.E990X & ZZ25 & 46.28 & 137 \\
\hline chr17 & 41246566 & AT & - & BRCA1 & Frameshift deletion p.C328fs & RJ99 & 49.20 & 308 \\
\hline chr17 & 41245437 & TT & - & BRCA1 & Frameshift deletion p.N704fs & RJ91 & 43.00 & 86 \\
\hline chr17 & 56801451 & C & T & RAD51C & Stopgain p.R319X & WY4 & 46.38 & 480 \\
\hline chr17 & 59876486 & G & A & BRIP1 & Stopgain p.R439X & ZR4 & 47.26 & 311 \\
\hline chr17 & 41197810 & TGCCCAAT & - & BRCA1 & Frameshift deletion p.I1824fs & SY19 & 40.40 & 202 \\
\hline
\end{tabular}

Abbreviations: Alt, alteration; DP, depth; Ref, reference. 
eTable 6. Genomic Alteration Status, PFS, and PSA Change Over 12 Weeks in 58 Patients With ctDNA Samples Collected Before Abiraterone Treatment

\begin{tabular}{|c|c|c|c|c|c|c|c|c|c|c|}
\hline Patient & $\begin{array}{l}\text { PFS } \\
\text { (mo) }\end{array}$ & Censored & $\begin{array}{l}\text { PSA Change } \\
\text { Over } 12 \text { wk } \\
\text { (\%) }\end{array}$ & $\begin{array}{l}\text { CDK12 } \\
\text { Defect }\end{array}$ & $\begin{array}{l}\text { BRCA2 } \\
\text { Defect }\end{array}$ & $\begin{array}{l}\text { ATM } \\
\text { Defect }\end{array}$ & $\begin{array}{l}\text { TP53 } \\
\text { Defect }\end{array}$ & $\begin{array}{l}\text { RB1 } \\
\text { Defect }\end{array}$ & $\begin{array}{l}\text { AR } \\
\text { Gain }\end{array}$ & $\begin{array}{l}\text { AR } \\
\text { Mutation }\end{array}$ \\
\hline RJ19 & 10.90 & No & -76 & & $\begin{array}{l}\text { BRCA2: } \\
\text { p.G2578fs }\end{array}$ & ATM: p.S179X & & & & \\
\hline RJ21 & 12.80 & No & -64 & & & & & & & \\
\hline RJ22-1 & 8.40 & No & -57 & & & & & & & \\
\hline RJ28 & 8.57 & No & -34 & & & & & & & \\
\hline RJ30 & 13.00 & No & -54 & & & & & & & \\
\hline RJ39 & 12.00 & No & -36 & & & & & & & \\
\hline RJ40 & 4.00 & No & 24 & $\begin{array}{l}\text { CDK12: } \\
\text { p.A771fs }\end{array}$ & & & & & & \\
\hline RJ47 & 12.00 & No & -87 & & & & & & & \\
\hline RJ48 & 12.40 & No & -76 & & & & & & & \\
\hline RJ49 & 13.00 & No & -73 & & & & & & & \\
\hline RJ50 & 10.40 & No & -63 & & & & & & & \\
\hline RJ51 & 10.00 & No & -66 & & & & & & & $A R: \mathrm{p} . \mathrm{H} 875 \mathrm{Y}$ \\
\hline RJ53 & 3.00 & No & 125 & & & & TP53: loss & & & \\
\hline RJ54 & 11.00 & No & -83 & & & & & & & \\
\hline RJ56 & 14.60 & No & -89 & & & & & & & \\
\hline RJ94 & 1.60 & No & 121 & $\begin{array}{l}\text { CDK12: } \\
\text { p.E657fs }\end{array}$ & & & & & Yes & \\
\hline RJ95 & 13.00 & No & -79 & & & & & & & \\
\hline RJ98 & 9.00 & No & -68 & & & & & & & \\
\hline RJ106-1 & 6.83 & No & 2 & & & & & RB1: p. L2fs & & \\
\hline RJ109-1 & 7.00 & No & -35 & & & $\begin{array}{l}\text { ATM: } \\
\text { p.V1446fs }\end{array}$ & & & Yes & \\
\hline RJ110-1 & 33.50 & No & -93 & & & & & & & \\
\hline RJ113-1 & 14.00 & No & -94 & & & & & & & \\
\hline RJ116 & 9.00 & No & -96 & & & & & & & \\
\hline RJ117 & 4.00 & Yes & -48 & & $\begin{array}{l}\text { gBRCA2: } \\
\text { p.R2336H }\end{array}$ & & & & & \\
\hline RJ118 & 1.00 & No & 157 & $\begin{array}{l}\text { CDK12: } \\
\text { loss }\end{array}$ & & & $\begin{array}{l}\text { TP53: c.92- } \\
\text { 1G>A, TP53: } \\
\text { p.P177H }\end{array}$ & & Yes & \\
\hline
\end{tabular}




\begin{tabular}{|c|c|c|c|c|c|c|c|c|c|c|}
\hline Patient & $\begin{array}{l}\text { PFS } \\
\text { (mo) }\end{array}$ & Censored & $\begin{array}{c}\text { PSA Change } \\
\text { Over } 12 \text { wk } \\
(\%)\end{array}$ & $\begin{array}{l}\text { CDK12 } \\
\text { Defect }\end{array}$ & $\begin{array}{l}\text { BRCA2 } \\
\text { Defect }\end{array}$ & $\begin{array}{l}\text { ATM } \\
\text { Defect }\end{array}$ & $\begin{array}{l}\text { TP53 } \\
\text { Defect }\end{array}$ & $\begin{array}{l}\text { RB1 } \\
\text { Defect }\end{array}$ & $\begin{array}{l}A R \\
\text { Gain }\end{array}$ & $\begin{array}{l}\text { AR } \\
\text { Mutation }\end{array}$ \\
\hline RJ121 & 10.00 & Yes & -79 & & & & & & & \\
\hline RJ125 & 4.00 & Yes & -58 & & & & & & & \\
\hline RJ143 & 1.00 & No & 72 & $\begin{array}{l}\text { CDK12: } \\
\text { p.Q273X, } \\
\text { CDK12: } \\
\text { c.26 } \\
66+1 G>T\end{array}$ & & & & & & \\
\hline RJ150 & 3.00 & Yes & 22 & & & & & & & \\
\hline SY8 & 4.30 & No & -18 & & & & & & & \\
\hline SY16 & 9.00 & Yes & -67 & & & & & & & \\
\hline SY17 & 1.00 & Yes & 321 & & & & & & & \\
\hline SY19 & 7.00 & Yes & -22 & & & & & & & \\
\hline SY20 & 6.00 & No & -25 & & & & TP53: $\mathrm{p}$. & & & \\
\hline SY21 & 3.00 & No & 67 & & $\begin{array}{l}\text { gBRCA2: } \\
\text { p.L198fs }\end{array}$ & & & & & \\
\hline SY23 & 3.00 & No & 112 & & & & & & & \\
\hline BYY1 & 13.00 & Yes & -87 & & & & & & & \\
\hline $\mathrm{FY} 3$ & 5.00 & Yes & -34 & & $\begin{array}{l}\text { BRCA2: } \\
\text { p.F663fs }\end{array}$ & & & & Yes & \\
\hline FY7 & 3.00 & No & 76 & & & & & & & \\
\hline $\mathrm{XJ4}$ & 1.00 & Yes & 221 & & & & & & & \\
\hline ZZ18 & 1.00 & No & 321 & & & & TP53: $p$. & & & \\
\hline
\end{tabular}

Blank cells indicate no defect.

Abbreviations: ctDNA, circulating tumor DNA; g, germline; PFS, progression-free survival; PSA, prostate-specific antigen. 
eTable 7. Genomic Alteration Status, PFS, and PSA Change Over 12 Weeks in 66 Patients With ctDNA Samples Collected Before Docetaxel Treatment

\begin{tabular}{|c|c|c|c|c|c|c|c|c|c|c|}
\hline Patient & $\begin{array}{l}\text { PFS } \\
\text { (mo) }\end{array}$ & Censored & $\begin{array}{c}\text { PSA } \\
\text { Change } \\
\text { Over } 12 \\
\text { wks (\%) }\end{array}$ & $\begin{array}{l}\text { CDK12 } \\
\text { Defect }\end{array}$ & $\begin{array}{l}\text { BRCA2 } \\
\text { Defect }\end{array}$ & $\begin{array}{l}\text { ATM } \\
\text { Defect }\end{array}$ & $\begin{array}{l}\text { TP53 } \\
\text { Defect }\end{array}$ & $\begin{array}{l}\text { RB1 } \\
\text { Defect }\end{array}$ & $\begin{array}{l}A R \\
\text { Gain }\end{array}$ & $\begin{array}{l}\text { AR } \\
\text { Mutation }\end{array}$ \\
\hline RJ1 & 1.33 & No & 123 & & $\begin{array}{l}\text { BRCA2: } \\
\text { p.I332fs }\end{array}$ & & & & & \\
\hline RJ2 & 2.10 & No & 211 & & & & $\begin{array}{l}\text { TP53: } \\
\text { c. } 559+1 \mathrm{G}>\mathrm{C}\end{array}$ & & & \\
\hline RJ3 & 10.00 & No & -58 & & & & & & & \\
\hline RJ4 & 2.67 & No & 72 & & & & & & & \\
\hline RJ7 & 2.40 & No & 23 & & & & & RB1: loss & & \\
\hline RJ9 & 8.67 & No & -22 & & & & TP53: loss & & Yes & \\
\hline RJ10 & 2.40 & No & 35 & & & & TP53: p.P87fs & & & AR: p.W742L \\
\hline RJ11 & 8.13 & No & -73 & $\begin{array}{l}\text { CDK12: } \\
\text { c. } 269+1 G>T\end{array}$ & & & & & & \\
\hline RJ12-1 & 11.13 & No & -81 & & & & & & & \\
\hline RJ13 & 3.07 & No & -68 & & & & & & & \\
\hline RJ14 & 4.80 & No & 26 & & & & TP53: p.R36X & & Yes & \\
\hline RJ15 & 9.53 & No & -38 & & & $\begin{array}{l}\text { gATM: } \\
\text { p.E277X }\end{array}$ & & & & \\
\hline RJ16 & 9.70 & No & -87 & & $\begin{array}{l}\text { gBRCA2: } \\
\text { p.Y949fs }\end{array}$ & & & & & \\
\hline RJ17 & 6.00 & No & -43 & & $\begin{array}{l}\text { gBRCA2: } \\
\text { p.Q754fs }\end{array}$ & & & & & \\
\hline RJ18 & 8.00 & No & -26 & $\begin{array}{l}\text { CDK12: } \\
\text { p.Q62X }\end{array}$ & & & & & & \\
\hline RJ100 & 12.00 & No & -68 & & & & & & & \\
\hline RJ105-1 & 7.67 & No & -46 & & & & & & & $A R:$ p.L72H \\
\hline RJ107-1 & 13.00 & No & -88 & & & & & & & $\begin{array}{l}\text { AR: p.W742L, } \\
\text { AR: p.T878A }\end{array}$ \\
\hline RJ107-2 & 13.00 & No & -88 & & & & & & & \\
\hline RJ108-1 & 4.20 & No & 16 & & & & & & & \\
\hline RJ108-2 & 4.20 & No & 16 & $\begin{array}{l}\text { CDK12: } \\
\text { p.T1463fs }\end{array}$ & & & & & & $\begin{array}{l}A R: \text { p.H875Y, } \\
\text { AR: p.T878A }\end{array}$ \\
\hline RJ111-1 & 2.93 & No & 46 & & & & & & Yes & \\
\hline RJ112-1 & 8.00 & No & -38 & $\begin{array}{l}\text { CDK12: } \\
\text { p.Q57X }\end{array}$ & & & & & & \\
\hline RJ122 & 5.00 & No & -23 & & & & & & Yes & $A R: p . L 72 \mathrm{H}$ \\
\hline RJ136 & 1.00 & Yes & 112 & & & & & & & \\
\hline RJ137 & 1.00 & Yes & 126 & & & & & & & $\begin{array}{l}\text { AR: p.W742C, } \\
\text { AR: p.T878A }\end{array}$ \\
\hline RJ140 & 8.00 & No & -8 & & & & TP53: p.15fs & & & \\
\hline RJ155 & 2.00 & No & 45 & & & & & & Yes & \\
\hline RJ20 & 10.00 & No & -42 & & $\begin{array}{l}\text { BRCA2: } \\
\text { p.L1768fs }\end{array}$ & & & & & \\
\hline RJ23-1 & 8.23 & No & -58 & & & & & & & \\
\hline RJ24 & 5.13 & No & -23 & & $\begin{array}{l}\text { BRCA2: } \\
\text { p.N1973del }\end{array}$ & & & & & \\
\hline RJ25 & 6.03 & No & -28 & & & gATM: p.R38H & & & & \\
\hline RJ26 & 9.63 & No & -75 & & $\begin{array}{l}\text { BRCA2: c.786- } \\
\text { 2A>T, } \\
\text { gBRCA2: } \\
\text { p.S2156fs }\end{array}$ & & & & & \\
\hline
\end{tabular}




\section{eTable 7. Genomic Alteration Status, PFS, and PSA Change Over 12 Weeks in 66 Patients With ctDNA} Samples Collected Before Docetaxel Treatment (cont.)

\begin{tabular}{|c|c|c|c|c|c|c|c|c|c|c|}
\hline Patient & $\begin{array}{l}\text { PFS } \\
\text { (mo) }\end{array}$ & Censored & $\begin{array}{c}\text { PSA } \\
\text { Change } \\
\text { Over } 12 \\
\text { wks (\%) }\end{array}$ & $\begin{array}{l}\text { CDK12 } \\
\text { Defect }\end{array}$ & $\begin{array}{l}\text { BRCA2 } \\
\text { Defect }\end{array}$ & $\begin{array}{l}\text { ATM } \\
\text { Defect }\end{array}$ & $\begin{array}{l}\text { TP53 } \\
\text { Defect }\end{array}$ & $\begin{array}{l}\text { RB1 } \\
\text { Defect }\end{array}$ & $\begin{array}{l}A R \\
\text { Gain }\end{array}$ & $\begin{array}{l}\text { AR } \\
\text { Mutation }\end{array}$ \\
\hline RJ29 & 10.47 & No & -79 & & & & & & & AR: p.T878A \\
\hline RJ31 & 2.07 & No & 45 & $\begin{array}{l}\text { CDK12: } \\
\text { p.V56fs }\end{array}$ & & & & & & \\
\hline RJ34 & 3.00 & Yes & -59 & & & & & & & \\
\hline RJ36 & 6.00 & No & -43 & & & & & & & \\
\hline RJ41 & 12.00 & No & -68 & & & & & & & \\
\hline RJ58 & 4.00 & Yes & -18 & & & & & & & \\
\hline RJ66 & 6.20 & No & -17 & & & & & & & \\
\hline RJ67 & 10.00 & No & -64 & & & & & & & \\
\hline RJ68 & 3.00 & Yes & -38 & & $\begin{array}{l}\text { BRCA2: } \\
\text { p.V1862fs }\end{array}$ & & & & & \\
\hline RJ78 & 9.00 & No & -55 & & BRCA2: loss & & & & & \\
\hline RJ79 & 11.00 & No & -77 & & & & & & & \\
\hline RJ80 & 11.00 & No & -84 & $\begin{array}{l}\text { CDK12: } \\
\text { p.A411fs }\end{array}$ & & & & & & \\
\hline RJ85 & 8.40 & Yes & -68 & & & & & & & AR: p.W742L \\
\hline RJ88 & 2.00 & Yes & 73 & & & & TP53: p.C135F & & Yes & \\
\hline RJ93 & 8.90 & No & -81 & & & & & & & \\
\hline RJ97 & 7.60 & No & -69 & & & & & & & \\
\hline SY1 & 18.00 & No & -83 & & & & & & & \\
\hline SY2 & 6.00 & No & -82 & & BRCA2: loss & & & & & \\
\hline SY6 & 8.00 & No & -68 & & & & & & & \\
\hline SY9 & 10.00 & No & -72 & $\begin{array}{l}\text { CDK12: } \\
\text { p.Q944X }\end{array}$ & & & TP53: p.G244V & & & \\
\hline SY25 & 6.00 & Yes & -14 & & & & & & & \\
\hline BYY4 & 5.70 & Yes & -36 & $\begin{array}{l}\text { CDK12: } \\
\text { c.2964-2A>G, } \\
\text { CDK12: } \\
\text { p.Q695X }\end{array}$ & & & & & & \\
\hline BYY13 & 1.00 & Yes & 221 & & & & & & & AR: p.T878A \\
\hline BYY19 & 3.00 & No & 112 & & & & & & & \\
\hline WY20 & 7.00 & No & -71 & $\begin{array}{l}\text { CDK12: } \\
\text { p.Q498fs }\end{array}$ & & & & & & AR: p.W742L \\
\hline WY21 & 1.00 & No & 324 & & & & TP53: p.D259H & & & \\
\hline WY27 & 2.00 & No & 78 & & & & & & & \\
\hline $\mathrm{XJ} 2$ & 15.20 & Yes & -90 & & & & & & & $\begin{array}{l}\text { AR: p.W742L, } \\
\text { AR: p.W742C }\end{array}$ \\
\hline XJ6 & 1.00 & No & 97 & $\begin{array}{l}\text { CDK12: } \\
\text { p.N432fs, } \\
\text { CDK12: } \\
\text { p.P55fs }\end{array}$ & & & & & & \\
\hline $\mathrm{XJ8}$ & 14.00 & Yes & -67 & & & & & & & \\
\hline FY4 & 5.50 & No & -67 & & & & TP53: p.L348fs & & Yes & \\
\hline ZR1 & 8.00 & Yes & -84 & & & & & & & \\
\hline ZZ1 & 1.00 & No & 216 & & & & & & & \\
\hline
\end{tabular}

Abbreviations: ctDNA, circulating tumor DNA; g, germline; PFS, progression-free survival; PSA, prostate-specific antigen. 
eTable 8. Genomic Alteration Status, PFS, and PSA Change Over 12 Weeks in 16 Patients With cfDNA Samples Collected Before Platinum-Based Chemotherapy

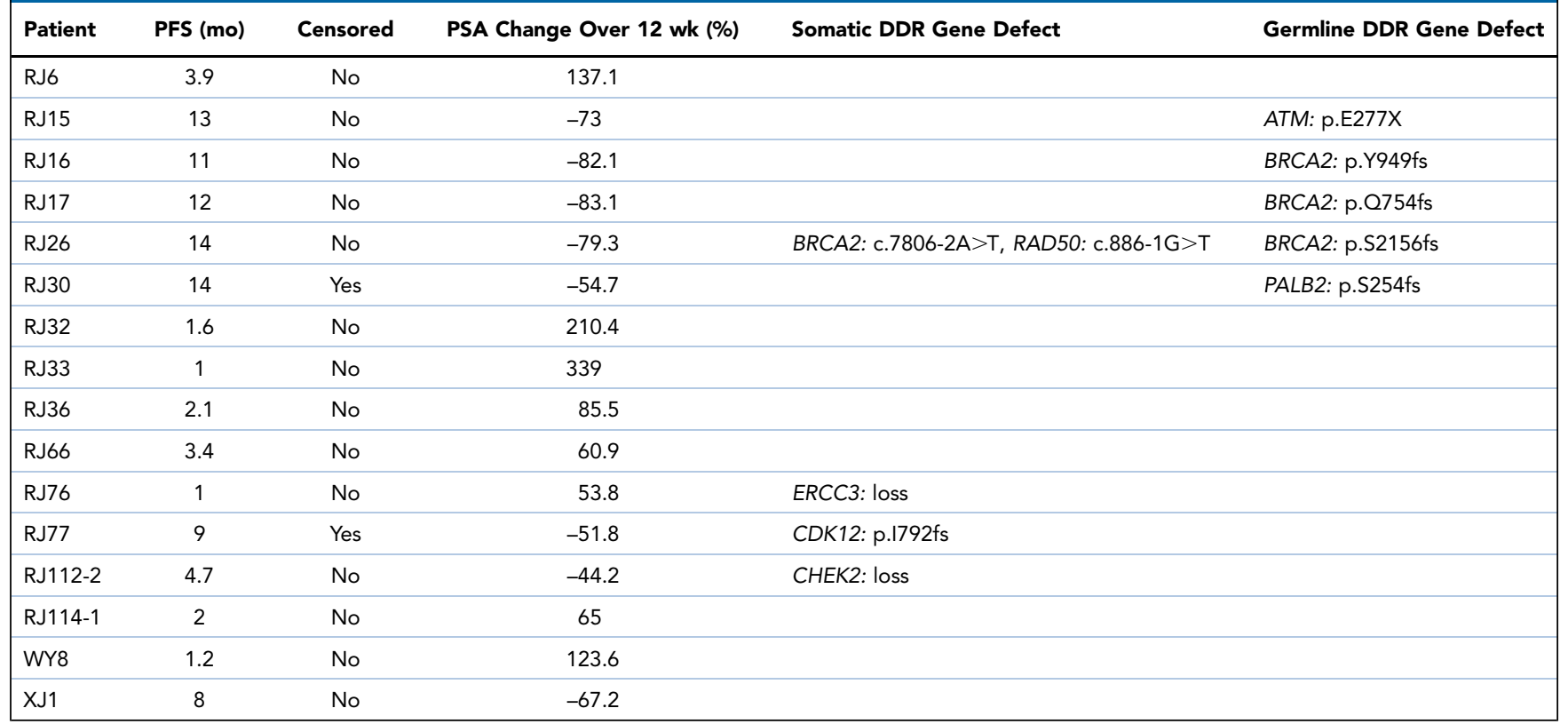

Blank cells indicate no defect.

Abbreviations: cfDNA, circulating free DNA; DDR, DNA damage repair; PFS, progression-free survival; PSA, prostate-specific antigen. 


\section{eTable 9. Genomic Alteration Status, PFS, and PSA Change Over 12 Weeks in 16 Patients With cfDNA} Samples Collected Before Olaparib Treatment

\begin{tabular}{|c|c|c|c|c|c|}
\hline Patient & PFS (mo) & Censored & PSA Change Over 12 wk (\%) & Somatic DDR Gene Defect & Germline DDR Gene Defect \\
\hline RJ55 & 1.5 & No & 100 & & \\
\hline RJ57 & 0.5 & No & 228.6 & & \\
\hline RJ62 & 16 & No & -32 & BRCA2: p.N1784fs & \\
\hline RJ64 & 2.4 & No & 80 & & \\
\hline RJ73 & 10 & No & -78.1 & $C D K 12:$ c. $2419+1 \mathrm{G}>\mathrm{A}$ & \\
\hline RJ74 & 2.4 & No & 421 & ATM: c. $6807+1 \mathrm{G}>\mathrm{T}$ & \\
\hline RJ83 & 1.2 & No & 67.9 & CDK12: p.Q602X, CDK12: p.Y362X & \\
\hline RJ84 & 2 & No & 143.8 & & \\
\hline RJ96 & 1.5 & No & 51.7 & & \\
\hline RJ102 & 9 & No & -18.8 & & \\
\hline RJ103 & 13 & No & -62.2 & & \\
\hline RJ104-1 & 9 & No & 89.4 & CDK12: p.V513fs & \\
\hline RJ110-2 & 8 & No & -83.5 & & \\
\hline RJ113-2 & 3 & No & 57.5 & ATM: p.E38X & \\
\hline RJ114-2 & 1 & No & 27.4 & CDK12: p.Y295fs, CDK12: p.Q612X & \\
\hline WY10 & 3.73 & No & -37.2 & $\begin{array}{l}\text { ATM: p.E2744X, CDH1: p.G49fs, CDK12: } \\
\text { p.P673fs, CDK12: p.V896fs }\end{array}$ & \\
\hline WY13 & 4.3 & No & -98.9 & & BRCA2: p.Y1894X \\
\hline WY16 & 1.27 & No & -61.2 & & \\
\hline WY19 & 0.8 & No & -23.5 & & \\
\hline WY4 & 2.8 & No & -62.4 & & RAD51C: p.R319X \\
\hline WY7 & 5.3 & No & -54.6 & & BRCA2: p.I1859fs \\
\hline FY5 & 11 & Yes & -77.9 & ATM: c. $185+1 \mathrm{G}>\mathrm{C}$, FANCA: loss, BRCA2: loss & MLH3: p.D206fs \\
\hline
\end{tabular}

Blank cells indicate no defect.

Abbreviations: cfDNA, circulating free DNA; DDR, DNA damage repair; PFS, progression-free survival; PSA, prostate-specific antigen. 